University of Louisville

ThinkIR: The University of Louisville's Institutional Repository

Electronic Theses and Dissertations

$5-2013$

\title{
The impact of skin and soft tissue infections on college athletic programs and prevention policies.
}

Alice Kimble 1964-

University of Louisville

Follow this and additional works at: https://ir.library.louisville.edu/etd

\section{Recommended Citation}

Kimble, Alice 1964-, "The impact of skin and soft tissue infections on college athletic programs and prevention policies." (2013). Electronic Theses and Dissertations. Paper 751.

https://doi.org/10.18297/etd/751

This Doctoral Dissertation is brought to you for free and open access by ThinkIR: The University of Louisville's Institutional Repository. It has been accepted for inclusion in Electronic Theses and Dissertations by an authorized administrator of ThinkIR: The University of Louisville's Institutional Repository. This title appears here courtesy of the author, who has retained all other copyrights. For more information, please contact thinkir@louisville.edu. 


\title{
THE IMPACT OF SKIN AND SOFT TISSUE INFECTIONS ON COLLEGE ATHLETIC PROGRAMS AND PREVENTION POLICIES
}

\author{
By \\ Alice Kimble \\ B.S., University of Louisville, 1989 \\ M.S., University of Louisville, 1996 \\ A Dissertation \\ Submitted to the Faculty of the \\ College of Education and Human Development of the University of Louisville \\ In Partial Fulfillment of the Requirements \\ For the Degree of \\ Doctor of Philosophy \\ Department of Leadership, Foundations and Human Resource Education \\ University of Louisville \\ Louisville, Kentucky
}

May 2013 
THE IMPACT OF SKIN AND SOFT TISSUE INFECTIONS ON COLLEGE ATHLETIC PROGRAMS AND PREVENTION POLICIES

By

\author{
Alice Kimble \\ B.S., University of Louisville, 1989 \\ M.S., University of Louisville, 1996
}

A Dissertation Approved on

April 8, 2013

By the following Dissertation Committee:

\begin{tabular}{c}
\hline Ruth Carrico, Dissertation Co-Chair \\
\hline Bridgette Pregliasco, Dissertation Co-Chair \\
\hline Fred Rhodes \\
Joseph Petrosko
\end{tabular}




\section{DEDICATION}

This is dedicated to my family:

Stephen Thomas McMillen

And

Abrayah Faye McMillen 


\section{ACKNOWLEDGEMENTS}

I am fortunate to have several people that have helped me throughout this process that I owe very humble and heartfelt thanks.

I must begin with my outstanding dissertation committee. I would never have considered taking this on without the encouragement of Dr. Fred Rhodes. I will always appreciate his continuous moral support and constant communication with me to ensure I was staying on track. Dr. Joseph Petrosko went out of his way to make clear the statistical process, and remained on my committee after his retirement, for which I am particularly

grateful. Dr. Ruth Carrico was willing to take me on despite the challenges of being outside of her department. Her expertise on the subject matter was invaluable. Dr. Pregliasco was the critical piece in pushing this project to conclusion. Her critical feedback gave me the insight necessary to bring it to completion.

And I also want to thank my village of family and friends that have supported me throughout my entire life, that through all of my successes and failures have provided clarity and focus, made me laugh, and indulged me while continuously reminding me what is most important. 


\title{
ABSTRACT \\ THE IMPACT OF SKIN AND SOFT TISSUE INFECTIONS ON COLLEGE ATHLETIC PROGRAMS AND PREVENTION POLICIES
}

\author{
Alice Kimble
}

April 8, 2013

The majority of skin and soft tissue infections (SSTIs) are caused by Methicillinresistant Staphylococcus aureus (MRSA), and antibiotic resistant strains pose a greater challenge for effective prevention and treatment. Although recommendations outlining procedures for prevention have been provided by the Centers for Disease Control and Prevention (CDC) and the National Athletic Trainers Association (NATA), the actual adherence by the athletic training staff is unclear (Centers for Disease Control and Prevention, 2010; National Athletic trainers' Association, 2010). MRSA can result in devastating illness and staggering healthcare costs, and deaths of athletes have been reported (Ellis, 2007).

The current study used the Health Belief Model to examine the impact of SSTIs on college athletic programs prevention policies. A survey was developed and sent to department heads of colleges and universities that were NATA members. Data were collected on the prevalence of SSTIs, their impact on policy, and variation in standards of treatment.

Responses from 78 trainers indicated that although respondents were aware of guidelines for prevention and treatment and most had policies in place, they varied as to 
which elements were included as standard treatments and which are believed to be most effective. While there does appear to be wide variation, the standards of practice, changes made since the emergence of MRSA, and strategies believed to be most effective all reflect CDC and NATA guidelines, indicating that overall the majority of athletic trainers are being proactive. The study found MRSA to be more prevalent in male athletes and in football players. These populations should be targeted with prevention efforts. The results of this study also suggest that the effect of SSTIs on team performance is a stronger predictor of change in policy to prevent infection that hospitalization.

Future research examining the barriers that prevent health care providers from implementing guidelines, and investigating why athletic trainers choose to implement particular guidelines and not others, could be illuminating for future prevention planning. Research should also focus on obtaining the perceptions of other populations involved. These include parents, recreation and intramural sports staff, and residence life personnel. 
TABLE OF CONTENTS

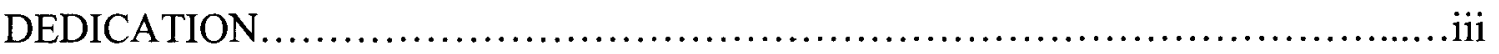

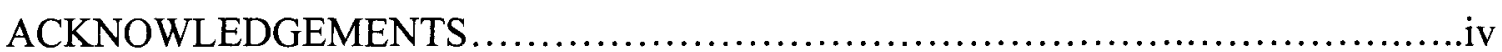

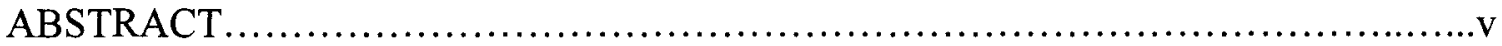

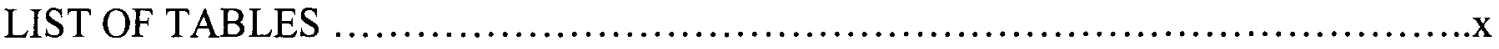

CHAPTER ONE Introduction.....................................................

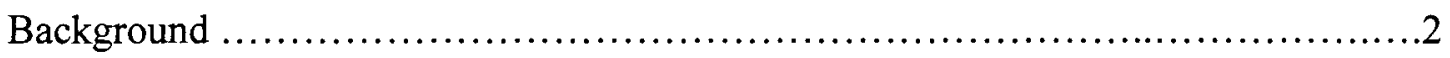

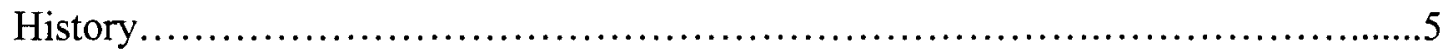

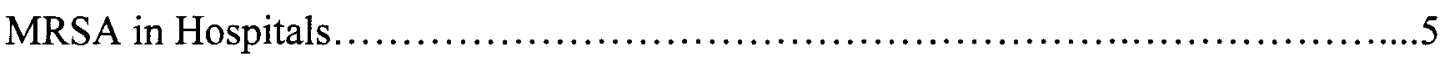

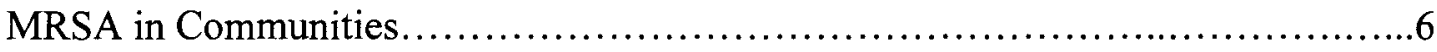

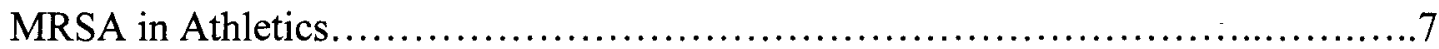

Policy Recommendations.........................................................

Implications of MRSA in Collegiate Athletic Programs..............................12

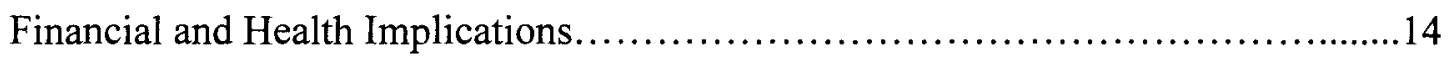

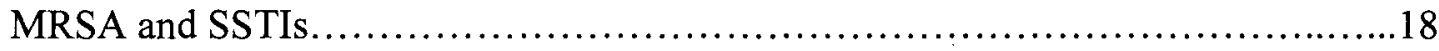

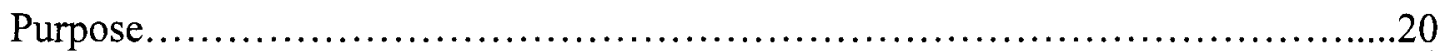

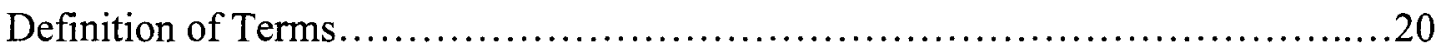

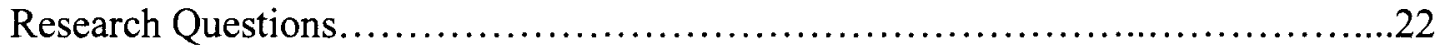

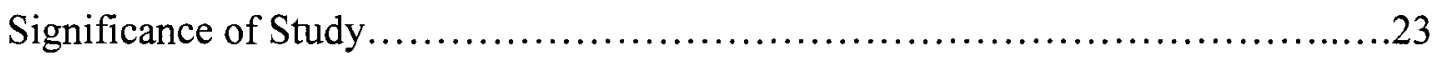

CHAPTER 2 Literature Review

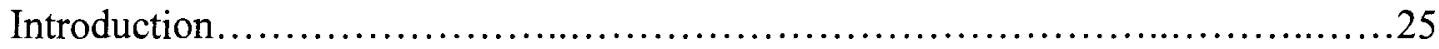

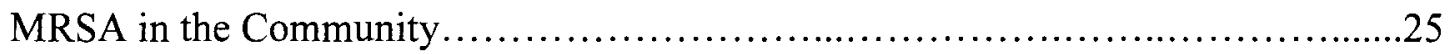

vii 
MRSA in Athletic Settings................................................... 34

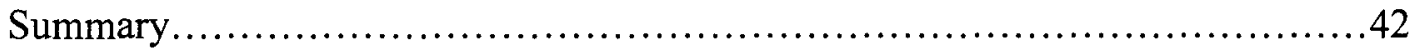

\section{CHAPTER 3 Methodology}

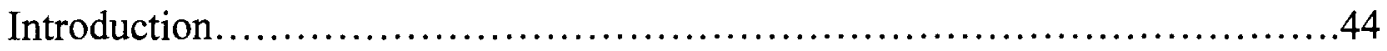

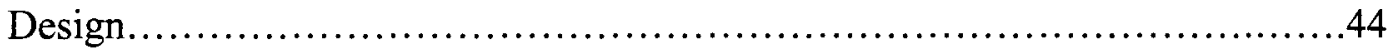

Research Questions..................................................45

Population...............................................................46

Survey Tool.........................................................46

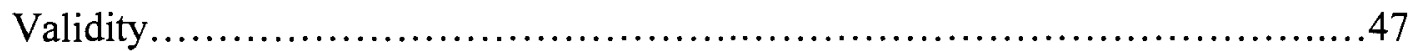

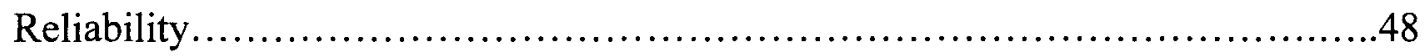

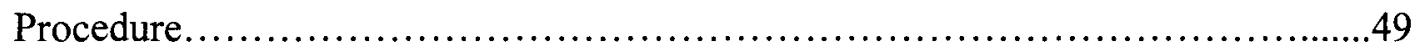

Data Analysis....................................................... 50

Theoretical Framework................................................. 53

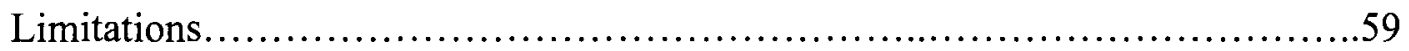

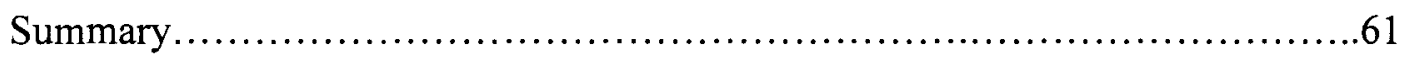

CHAPTER 4 Data Analysis

Background of Sample...............................................63

Examination of Demographic Data.......................................65

Results for Research Question 1............................................ 70

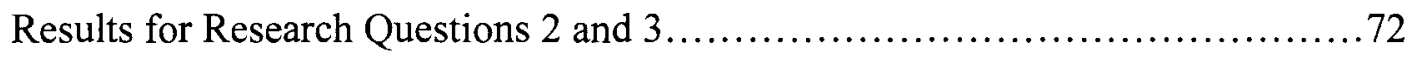

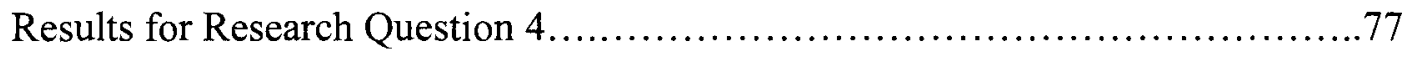

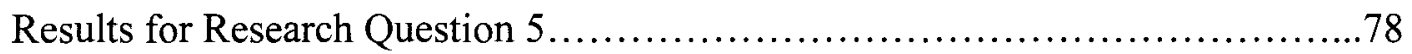

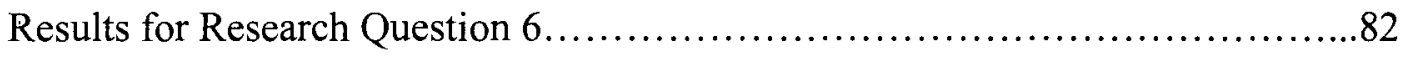




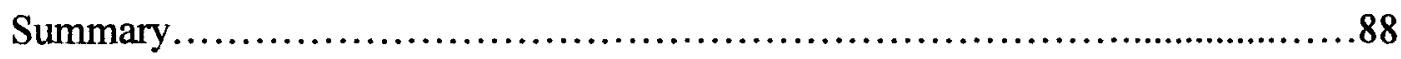

\section{CHAPTER 5 Discussion}

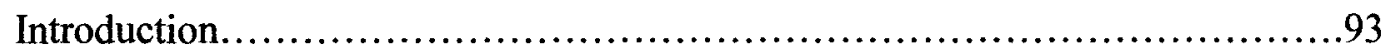

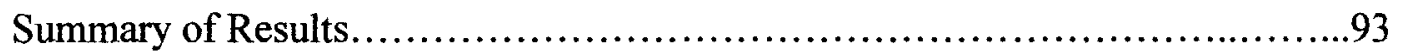

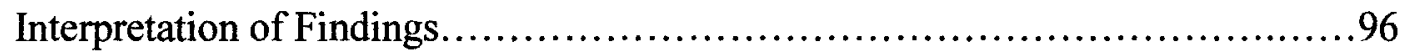

Discussion and Implications............................................. 103

Health Belief Model.................................................... 106

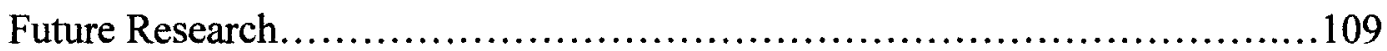

Limitations........................................................... 110

Conclusion.....................................................................

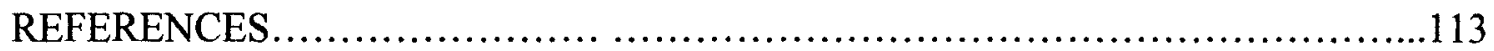

APPENDIXES

Appendix A: Internal Results for Research Question Review Board...............124

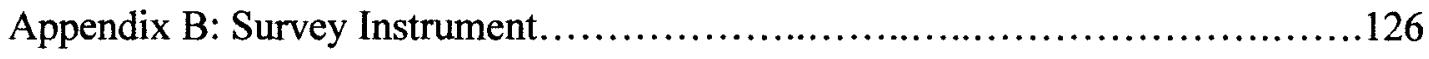

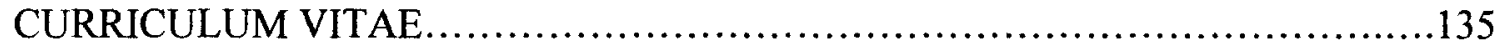




\section{LIST OF TABLES}

TABLE

PAGE

Table 1 Consistency of Responses Over Time in Pilot Sample of Four Cases..........49

Table 2 NATA District of Respondents.....................................66

Table 3 NCAA Divisions of Respondents......................................66

Table 4 Descriptive Statistics on Age and Years as an Athletic Trainer...............67

Table 5 Education Level of Respondents...................................67

Table 6 Job Titles of Respondents..........................................68

Table 7 Institution Type Where Respondents Were Employed......................69

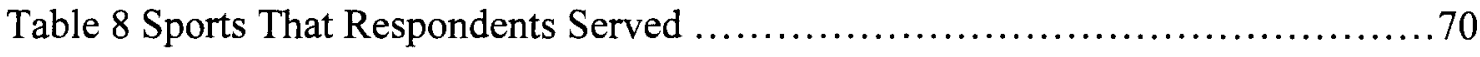

Table 9 Degree of Concern About MRSA ........................................ 71

Table 10 Proportion of Respondents Dealing With MRSA..$\ldots \ldots \ldots \ldots \ldots \ldots \ldots \ldots \ldots \ldots \ldots$

Table 11 Management of SSTIs in Setting of Respondent............................72

Table12 Number of Cases of Hospitalizations Due to MRSA $\ldots \ldots \ldots \ldots \ldots \ldots \ldots \ldots \ldots . \ldots 73$

Table 13 Proportion of Cases of SSTIs Diagnosed in Different Ways.................74

Table 14 Existence of Treatment/Prevention Policy............................. 75

Table 15 Elements Included in Standard of Practice Regarding SSTIs................76

Table 16 Top Five Changes Implemented to Address SSTIs...................... 77

Table 17 Impact of SSTIs Severe Enough to Effect Team Performance?......................78

Table 18 Opinions About Changes in Number of SSTI Since Last Year.......................78

Table 19 Sports That Had SSTIs in the Last Five Years ............................. 79 
Table 20 Proportion of Respondents Reporting SSTIs in Male Athletes................80

Table 21 Cross-Tabulation of NATA Region by Confirmed Cases of MRSA............81

Table 22 Cross-Tabulation of NATA Region by Confirmed Incidence of SSTI............82

Table 23 Awareness of CDC Recommendations for MRSA Prevention .................83

Table 24 Awareness of NATA Recommendations for MRSA Prevention ...............83

Table 25 Quantification of Increase in Operating Costs Due to SSTI Control ...........84

Table 26 Financial Indicators of Costs Due to SSTI Control ..........................84

Table 27 Adequate Financial and Human Resources for SSTI Prevention ...............85

Table 28 Have There Been Changes Implicated Since Emergence of MRSA ...........86

Table 29 Changes Made in Prevention/Treatment Since Emergence of MRSA …......87

Table 30 Five Most Effective Prevention Strategies...................................8 


\section{CHAPTER I}

\section{INTRODUCTION}

This dissertation addresses the impact of skin and soft tissue infections (SSTI) on prevention programs in college athletics. In recent years it has been established that the majority of SSTIs are caused by methicillin-resistant Staphylococcus aureus (MRSA). Furthermore, the emergence of antibiotic-resistant strains poses a greater challenge for effective prevention and treatment of SSTIs. Although the Centers for Disease Control and Prevention (CDC) and the National Athletic Trainers Association (NATA) have provided recommendations outlining procedures for prevention of SSTIs, the actual adherence by the athletic training staff, who are often the athlete's first line of defense for prevention strategies, environmental control and patient education, is unclear (Centers for Disease Control and Prevention, 2010; National Athletic Trainers' Association, 2010).

Ellis (2007) reported that serious SSTIs such as MRSA can result in staggering healthcare costs, devastating illness and deaths (Ellis, 2007). In clinical settings, some estimates attribute approximately 90,000 deaths annually to MRSA (Stanforth, Krause, Starkey, \& Ryan, 2010) with health care costs of six billion (Tonn \& Ryan, 2012). Kahanov et al. (2011) attributed the deaths of student athletes, including four high school students to their sports participation. Therefore, in order to control risk factors effectively researchers require further evidence-based information that would guide consistent prevention efforts. This chapter includes history of Staphylococcus aureus, as well as its development of antibiotic-resistance to methicillin specifically. Furthermore, this section 
discusses the impact of SSTIs such as MRSA on healthcare in hospitals, communities and college campuses.

\section{Background}

The healthcare needs of the students must be met for colleges and universities to operate efficiently. Because of this fact, college settings provide healthcare services in some capacity, from ambulatory clinics or referral services to fully-staffed hospitals. Institutions with athletic programs often tend to feature athletic training facilities that offer medical services for the institution's athletic population. Athletic training staff is often an athlete's primary source of medical care and coaches, athletes, and parents of athletes rely on them to prevent and treat their injuries and illnesses. MRSA infections and occasional serious SSTI outbreaks have emerged as a major issue in the health of athletes. A report of disease outbreaks in competitive sports between 2005 and 2010 identified MRSA as the pathogen most responsible for infectious disease outbreaks (Collins \& O'Connell, 2012). The CDC and the NATA have published recommendations for athletic trainers based on available data for the prevention and treatment of MRSA (Centers for Disease Control and Prevention, 2010; National Athletic Trainers' Association, 2010).

However it is unclear whether these strategies are effective and if health care professionals implement them. Gathering information about MRSA cases is difficult; institutions that have experienced MRSA cannot be identified individually because they are protective of their ability to recruit quality athletes. Furthermore, public health organizations do not deem MRSA a notifiable disease. Lastly, due to an inability to maintain or assure confidentiality, the available literature includes very little data from 
individual colleges. In order to make appropriate program changes and lead preventive efforts, it is necessary to know what interventions exist and which of them elicit the desired effects. The discussion section of this paper addresses the implications of this information for administrators in higher education and other college health professionals.

Staphylococcus aureus is a bacterium and part of the common flora residing on human skin. Although biologists consider the organism a part of the normal human ecology, physicians acknowledge widely as a cause of disease. Staphylococcus aureus was susceptible to penicillin initially; however in the 1950s it was first recognized as resistance to that antibiotic. Since that time, physicians have become more aware of antibiotic resistant Staphylococcus aureus (MRSA) as a major pathogen capable of causing serious disease in adults and children. In recent years MRSA, which was limited historically to hospitals and long term care facilities, has developed an undeniable presence in the community setting (Charlebois, Perdreau-Remington, Kreiswirth, Bangsberg, Ciccarone, Diep, et al., 2004; Cohen, 2005; Cosgrove, Youlin, Kaye, Harbarth, Karchmer, \& Carmeli, 2005; Fridkin, Hageman, Morrison, Sanza, ComoSabetti, Jernigan, et al. 2005; Kazakova, Hageman, Matava, Srinivasan, Phelan, Garfinkel, et al., 2005; Rihn, Posfay-Barbe, Harner, Macurak, Farley, Greenawaly, et al. 2005). Increasingly, MRSA is becoming a serious threat as it moves into healthier populations, including college athletes. Several outbreaks in athletic populations have been studied and documented (Begier, Frenette, Barrett, Mshar, Petit, Boxrud, et al., 2004; Cohen, 2005; Kazakova et al., 2005; Rihn et al., 2005). MRSA in the college setting not only cause problems to the health of students but it can also become a burden to the athletic program. MRSA can be difficult to eradicate once established (Nguyen, 
Mascola, \& Bancroft, 2005), and can result in lost days of practice (Romano \& Holtom, 2006) and competition (Lindenmayer, Schoenfeld, O'Grady \& Carney, 1998).

Additionally, infections can be associated with significant morbidity with many cases requiring hospitalization (Rihn et al., 2005). Thus, logic dictates that college athletes would also lose class time that could affect their academic performance in addition to their health.

The National Collegiate Athletic Association (NCAA) stated In 1992 that over 5.2 million high school and college students participated in some type of organized athletic activity (Goodman, Thacker, Solomon, Osterholm, \& Hughes, 1994). The numbers of student athletes in colleges continues to increase. In a 2012 study the NCAA reported more than twice the number of players than in the previous 10 years and claimed that 450,000 student athletes played from 2011 to 2012. Currently the true extent of MRSA outbreaks in college athletic teams is unclear, as is the current state of their prevention efforts. Research in athletic settings has focused on morbidity-eradication efforts. Institutional leaders hold a stake in researching the evolution of MRSA since it was identified in athletic programs because infections affect daily procedures and policies. Institutions with an astute awareness of MRSA will be better prepared to handle an MRSA outbreak in their environment effectively. Staff trained to look for cases and begin infection management early will have a clear advantage over those who lack preparation. Furthermore, staff must know how to prevent spreading the bacterium, and how to manage the students and their parents adeptly.

In this chapter, MRSA infections in the hospital setting will first be reviewed. Then an overview of the problem of MRSA in communities outside of hospitals and in athletic 
settings will be outlined.

\section{History}

One of the most significant contributions to medicine was the introduction of antibiotics, a discovery that decreased morbidity and mortality rates caused by bacterial infections greatly. Among others, Cosgrove et al. (2003) documented that the overuse of antibiotics has created strains of bacteria that are now much more difficult to combat with traditional methods. Penicillin was discovered in 1929 by Alexander Fleming and was first used in humans in 1940. Just one year later the first case of penicillin resistant Staphylococcus aureus emerged. Similarly, methicillin, a semi-synthetic form of penicillin, was first used in 1960, and methicillin resistant Staphylococcus aureus was discovered in 1961 (Kurkowski, 2007). In the 1970's MRSA began causing serious illnesses in hospitals across the world (Hiramatsu, Cui, Kurado, \& Ito, 2001).

\section{MRSA in Hospitals}

In comparison to methicillin-susceptible Staphylococcus aureus (MSSA), MRSA infection results in significant costs in the hospital setting, with estimates of significantly increased hospital stays and charges (Cosgrove et al., 2005). Using the National Hospital Discharge Survey, a study investigating the costs and deaths attributed to MRSA in the United States between 1999 and 2005 using the found that MRSA hospitalizations more than doubled during that time. In 2005 MRSA infections cost the healthcare system in excess of $\$ 9.7$ billion excluding additional indirect costs resulting from pain, missed work, and other factors (Klein, Smith \& Laxminarayan, 2007). Other estimates are even higher, attributing approximately 90,000 deaths annually to MRSA (Stanforth, et al., 2010 ) with health care costs of $\$ 4.5$ billion (Tonn \& Ryan, 2012). 


\section{MRSA in Communities}

The MRSA outbreaks that plague hospitals and long term care facilities affect persons with common risk factors including recent hospitalization or surgery, dialysis, permanent indwelling catheters, and residence in long term care facilities (Naimi et al., 2003). With greater frequency over the past ten years, healthcare providers have reported outbreaks in younger populations without risk factors of acquiring MRSA (Drews, Temte $\&$ Fox, 2006). These outbreaks have been associated with healthy populations residing in communities or in congregate settings that include persons in prisons, children in child care facilities, and members of sports teams (Klevens, Morrison, Nadles, Petit, Gershman, Ray, 2007). Studies have concluded that populations that three characteristics put an individual at greater-than-average risk for contracting MRSA and other SSTIs. These three risk factors are: 1) a lack of stringent personal hygiene, 2) failure to adhere to basic infection-control principles, and 3) living in crowded conditions and having contact with others who have SSTIs (Kowalski, Berbari \& Osmon, 2005). In one study, the percentage of SSTIs caused by community-acquired MRSA (CA-MRSA) increased from $29 \%$ to $64 \%$ between January of 2003 and March of 2004 . Additionally, CA-MRSA was identified as the most common cause of SSTIs in a hospital in Los Angeles, California.

Of the 131 CA-MRSA cases studied, $24 \%$ of patients were hospitalized, and $5 \%$ required intensive care (Moran, Amii, Abrahamian, \& Talan (2005).

There is empirical evidence by King (2006) and Kurkowski (2007) states that CAMRSA is the primary cause of SSTI's, and that more research is needed in order to provide adequate prevention in the athletic population. King's study (2006) concluded that CA-MRSA is the predominant cause of SSTIs. Although the study did not focus on 
the athletic population, the researcher stressed that, in order to apply appropriate therapies and prevention techniques, one must recognize MRSA as the major cause of SSTI. King stated that continued population-based surveillance is required to understand the magnitude and evolution of CA-MRSA fully. Unlike King, Kurkowski (2007) focused on the emergence of MRSA in athletic populations. The author concluded that clinicians must learn to identify MRSA as this pathogen continues to rise in the athletic population. They must learn the risk factors so that MRSA can be diagnosed and treated correctly. The Kurkowski study stressed that more data are needed to produce optimal prevention and treatment strategies.

CA-MRSA has emerged to possess its own characteristics that separate it from health care associated MRSA (HA-MRSA). CA-MRSA produces a toxin which causes tissue necrosis. The toxin causes an intense inflammatory response likely responsible for the aggressive nature and high morbidity of CA-MRSA. Also, unlike HA-MRSA, CAMRSA is also susceptible to most antimicrobial agents (Drews et al., 2006). The majority (75\%) of CA-MRSA infections tend to result in SSTIs whereas HA-MRSA usually causes pneumonias. In contrast to HA-MRSA, those infected with CA-MRSA are children or people in day care centers, prisons, and athletic facilities (Weiner, 2008). Athletes are particularly susceptible to SSTIs caused by CA-MRSA because athletic activity puts them at an increased risk for alterations in skin integrity (Kowalski at al., 2005). Broken or scratched skin provides the organism with an opportunity to invade surrounding tissue. Having provided background of who acquires CA- and HA-MRSA generally, it is necessary to address MRSA in athletes specifically.

\section{MRSA in Athletics}


The first description of a Staphylococcus outbreak afflicting an athletic team was recorded in 1964 in the Dartmouth College football team, where 24 of 74 players were infected with the bacterium (Patel, Fischer, Calfree, Plante \& Fadale, 2007). Subsequent reports of infections in other athletic settings, primarily in high school football teams, followed soon after the Dartmouth case. In 1993 a Vermont high school wrestling team reported six of 32 wrestlers with MRSA, making the incident one of the first CA-MRSA outbreaks (Patel, et al., 2007). In 1998 Stacey, Endersby, Chan and Marples published a study describing a 1996 outbreak of MRSA that occurred in a rugby team; five members of the rugby team were affected. Researchers found this strain of MRSA clinically different from the MRSA specimens being documented in the hospitals, which indicate that a different strain had evolved.

Several case studies of outbreaks occurring in football, basketball, soccer, and rugby teams have since been studied in an effort to understand how CA-MRSA has spread into the athletic community (Cohen, 2005; Huijsdens, 2006; Nguyen et al., 2005; Stacey, et al., 1998). Professional football teams including the St. Louis Rams, San Francisco 49ers, Pittsburg Steelers, Miami Dolphins and Washington Redskins have all experienced MRSA infections (Newell, 2006). In 2005 Nguyen et al. reported an outbreak in a college football team that spanned parts of 2002 and 2003. Over the course of the time period studied, 21 out of 107 players acquired MRSA infections, with six requiring hospitalization. Beiger et al. (2004) and Romano et al. (2006) also reported other outbreaks in college football teams. Romano's study stated that an outbreak in 2002 resulted in two hospitalizations and 14 confirmed cases of MRSA. Another eleven more cases occurred in 2003, six of which resulted in e hospitalization. In another study by 
Rihn, et al., the researchers described an outbreak in a high school football team in 2003; of the players, 13 had infections. Of those afflicted, some displayed infection of multiple body areas, which made for a total of 20 infection sites.

Similarly Lindenmayer, et al. (1998) conducted a case study of an outbreak in a high school wrestling team from November of 1993 to February of 1994 . Out of 32 wrestlers, five had MRSA infections; the researchers identified 11 additional cases in the surrounding community. Most infected community members had some connection to the wrestling team. All of the previous studies regarding MRSA in athletic teams are discussed in greater detail in Chapter 2.

A report presented at the $17^{\text {th }}$ Annual Scientific Sessions of the Society for Healthcare Epidemiology in America introduced startling information regarding the prevalence and seriousness of MRSA infections (Ellis, 2007). The report stated that more than half of athletic trainers surveyed in 2006 treated MRSA infections and that there had been reported deaths of athletes from MRSA. The report also stated that $86 \%$ of those treated were males (Ellis, 2007). Kahanov, et al. (2011) supported this finding when their research found that males were more than twice as likely as females to contract MRSA. The Healthcare Cost and Utilization project (Elixhauser \& Steiner, 2007) studied trends of MRSA infections from 1993 to 2005 and found that infections had increased significantly over the course of the study, tripling in number since 2000 . They too found that the rates of MRSA infection were higher for males than females. Although the researchers did not speculate as to why males appear more affected more than females, male athlete's participation in contact sports such as football and rugby could be a factor. Accordingly, much of the research found contact to be a component (Beiger et al., 2004; 
Lindenmayer et al, 1998; Sanders, 2009; Stacey et al., 1998). The NCAA reported that from 2011 to 2012 most female student athletes participate in outdoor field and track, a non-contact sport, while most males participated in football (NCAA, 2013). Hospital stay costs were startling, averaging $\$ 14,000$ in comparison with $\$ 7,600$ for all other stays; furthermore, the duration of hospitalization doubled for MRSA patients compared to all other causes of illness (Elixhauser \& Steiner, 2007).

Another article that surveyed athletic trainers concluded that although the trainers were aware of MRSA and considered it a problem, less than $50 \%$ of them employed CDC-recommended techniques for prevention (Kahanov et al., 2011). The authors suggested that budget issues, time, and lack of personnel weighed into this finding. The authors stated "As athletic training focuses on evidence-based medicine in order to provide the best medical care, ATs need to constantly recheck the current research to ensure they are using the most effective techniques to prevent MRSA infection" (Kahanov et al., 2011, p.421). The CDC and NATA have recognized the need to establish policies for the prevention of MRSA infection.

\section{Policy Recommendations}

The CDC (2010) and the NATA (2010) have both issued recommendations designed specifically for the prevention of MRSA infection in athletic facilities.

The CDCs recommendations to improve hygiene among athletes include the following:

1. Keep wounds covered and contained.

2. Shower immediately after activity.

3. Shower before using whirlpools. 
4. Uniforms are to be washed and dried after each use.

5. Report possible infections to coaches, athletic trainers, healthcare provider, or parents (Centers for Disease Control and Prevention, 2010).

The CDC's recommendations for cleaning and disinfecting of athletic facilities include:

1. Athletes should be excluded if wounds cannot be properly covered during activity.

2. Athletes may be excluded if the activity poses a risk to the health of the infected athlete (such as injury to the infected area), even though the infection can be covered.

3. Athletes with infections or open wounds should not any common-use water facilities use that is not cleaned between athletes until infection and wounds are healed.

4. Shared equipment that comes into direct skin contact is to be cleaned and disinfected after each use (Centers for Disease Control and Prevention, 2010).

Recommendations on the prevention of skin diseases in athletics from the NATA include:

1. Institutions must provide adequate financial and human resources to implement a comprehensive infectious disease control policy.

2. Clean facilities are important to limit the spread of infectious diseases.

3. Adequate hand hygiene including frequent hand washing and showering after every sport activity may be one of the most effective factors in 
reducing the spread of infectious diseases.

4. Athletes and coaches must be educated about, and encouraged to follow, good hygiene practices.

5. Athletes must be discouraged from sharing towels, athletic gear, and all personal items.

6. All clothing and equipment should be laundered and/or disinfected on a daily basis.

7. Athletes should be encouraged to complete daily skin surveillance and report anything suspicious (National Athletic Trainers' Association, 2010).

While both sources encourage prudent hygiene and disinfectant recommendations, NATA clearly stresses the need for education and resources, while including information specific to athletes (Centers for Disease Control and Prevention, 2010; National Athletic Trainers' Association, 2010). Similarly, in their 2011 to2012 Sports Medicine Handbook, the NCAA stresses hygiene measures and training athletes and coaches recognize MRSA referenced by CDC publications. The NCAA also stresses athlete specific guidelines (National Collegiate Athletic Association, 2011).

\section{Implications of MRSA on Collegiate Athletic Programs}

Athletic programs in universities are highly visible and are often regarded as important components for institutional success. Research presented in this study will provide empirical evidence of the ways MRSA impacts athletic settings, particularly prevention efforts. Further, this study will evaluate whether the fear of MRSA, or actual experience with infection, drives policy changes in the athletic setting. Lastly, this paper 
will help to validate some perceptions about MRSA. Specifically it assesses if the problem is limited to contact sports, if it has a sporadic attack rate, and if it occurs more often in males than females.

It is imperative that clinicians such as sports medicine doctors, athletic trainers, and administrators know accurate rates of prevalence and understand their impact on financial and less tangible costs to a university. Appropriate data help clinicians make decisions that ensure the most efficient use of sometimes inadequate resources. Because this organism has infiltrated healthy individuals in athletic settings successfully, it is reasonable to predict that it may move to other university populations, such as residents living together on campus, and become a widespread university problem. Although paucity of literature examining MRSA in non-athletic college populations exists, Tonn \& Ryan (2012) examined the common use areas, including showers, toilets and shelves of 15 residence halls at a large campus. Tonn and Ryan found CA-MRSA bathroom surfaces of all 15 sites. No clear screening recommendations exist because CA-MRSA risk factors are understudied and the organism may colonize for days or even years if left alone (Drews et al., 2006). An acute picture of the extent of the problem may spark clinicians to establish concrete guidelines for schools to prevent an incident among their own athletes.

In addition to risk factors and prevention strategies, this study explores how MRSA impacts key groups such as contact- versus non-contact athletes, and males versus females, differently. This research from this study provides data to add to the body of currently available evidence and will establish a framework for practitioners and administrators to use in developing, implementing and evaluating programs aimed toward 
preventing, diagnosing, and treating SSTIs, like MRSA.

Because MRSA adapts, regardless of natural and artificial pressures, it is difficult to achieve an adequate understanding of how widespread CA-MRSA infections are in athletics. Also, the mutative capacity makes it difficult to ascertain the impact of MRSA on policies and procedures for prevention in athletic programs. In order to stress how devastating MRSA can be and the importance of prevention, one must understand the health and financial implications of MRSA infections in non-athletics settings. The next section addresses non-athletic studies to describe how both HA- and CA-MRSA infections are detrimental to finances and health.

\section{Financial and Health Implications}

A study over a seven-year period (1999-2005) investigated MRSA-related hospitalizations and deaths using the National Hospital Discharge Survey. The research indicated a dramatic increase in hospitalizations nationally; over the course of the study, the number of admitted patients climbed from 294,570 to 477,927 , an increase of $62 \%$ increase. Cellulitis and abscesses, which characterize CA-MRSA rather than HA-MRSA, were the most common diagnosis in the study. These findings suggest that CA-MRSA is spreading rapidly, and entering the hospitals (Klein et al., 2007).

From 1971 to 1980 , another study investigated how antimicrobial resistance impacted economics and health by selecting 43 nosocomial, also known as hospitalacquired, outbreaks of Staphylococcus aureus. The research team found that patients with resistant strains endured significantly longer (two-to-two-and-a-half times) total hospital stays than those with non-resistant strains (Holmberg, Solomon \& Blake, 1987), which resulted in greater financial burdens for the patient and the community in general. One 
article estimated the increased stay $\$ 5,000$ to $\$ 40,000$ more per hospitalization; the figure did not account for indirect costs such as lost work time and long-term health consequences (Keminkj, 2009). Another report by Anderson, et al. (2009) determined that MRSA-related surgical site infections caused by MRSA can add up to $\$ 60,000$ in additional healthcare costs.

Yet another study followed the cost of a high school wrestlers' journey through MRSA infection including treatment and rehabilitation care that amounted up to $\$ 208,079.00$. The authors compared this figure to the $\$ 41.45$ needed to improve locker room hygiene and preventative education. Such a striking comparison indicates the wisdom of teaching prevention and treating infections early (O'Laughlin \& Cook, 2009) and it implies that implementing lower-cost procedures could prevent high expenditures in the future.

From 2001 to 2004, a research team in the United Kingdom using the United Kingdom's General Practice Research Database and a frequency matched cohort study examined the mortality of patients with MRSA in the community. The cohort combined 1,439 community patients diagnosed between 2001 and 2004 with 14,090 matching nonMRSA patients from the same age group, geographical area, and time period. The team concluded that $21 \%$ of MRSA patients died in comparison to $5 \%$ of non-MRSA patients. The researchers adjusted results to account for underlying conditions, and the increase persisted across several sensitivity analyses (Delaney, Schneider-Lindner, Brassard \& Suissa, 2008).

From July of 2004 to December of 2005 medical scientists studied was performed of nine sites in the United States as part of Active Bacterial Core surveillance (ABCs) of 
8,987 MRSA cases. Analysts identified $58.4 \%$ of the cases as CA-MRSA. Of the patients sampled 1,598 died which led the authors to extrapolate a possible 94,360 infections in the United States and approximately 18,650 deaths during the same time period. These staggering numbers clearly indicate the need for public awareness, education and research (Klevens et al., 2007).

MRSA is a major public health problem no longer confined to intensive care units, acute care, or other health care institutions. CA-MRSA has been identified as the most frequent cause of SSTIs in United States emergency departments and is associated with significant mortality (Klevens et al., 2007). It appears now that CA-MRSA infections are invading hospitals which counter the previously accepted view that MRSA entered the community from hospitals (Klein et al., 2007).

These aforementioned studies provide overwhelming evidence that SSTIs, particularly forms of MRSA, are a problem everywhere; SSTIs are not confined to athletics, and the cost of an outbreak can be staggering. Athletic programs plagued by outbreaks are certain to suffer similar financial hardships similar to those endured by healthcare institutions. Currently there are not sufficient empirical data on the actual extent of MRSA infections in athletic populations or the cost to schools for medical bills, law suits and punitive damages, reputation, and preventative measures. Although difficult to substantiate, there is additional cost to athletes in the form of lost practice and playing time and lost class time which could impact academic performance. The economic impact can affect institutions in a variety of ways.

In some institutions, athletic programs can produce significant financial gain. In addition, they can provide indirect economic benefits such as increased university 
exposure. More attention to the school could potentially result in larger financial contributions and a greater number of students applying and enrolling. A study that examined the financial impact of athletic programs at 109 NCAA Division I universities concluded that $79 \%$ of the schools exceeded one-million dollars in annual profits, with $72 \%$ exceeding two million dollars (Goff, 2000). Furthermore, the NCAA generated $\$ 104$ million from their 2003 football "Bowl Championship Series", a sum which was distributed amongst 64 universities. In 1999, the NCAA negotiated a six-billion-dollar deal with CBS Broadcasting, Inc. for coverage of the post-season college basketball tournament for the subsequent 11 years. The same study noted that athletic success can also increase exposure substantially resulting in general giving, interest from perspective students, as well as an improved pool of entering students (Goff, 2000). More recently, the NCAA made a deal with the media to be paid 10.8 billion dollars over a 14 year period in 2010. Seven-hundred-and-forty million dollars of this money each year is allocated to NCAA conferences and schools (NCAA, 2013). Other financial benefits attributed to successful athletic programs at universities include: (a) a percentage of the $\$ 370$ million paid to televise the Division I men's basketball tournament in 2002-2003 making its way directly to universities for grants and other projects (Suggs, 2004), (b) $\$ 8$ million dollars were obtained in private contributions from alumni and corporate sponsors for one successful program (Dexheimer, 2003), and (c) national television exposure and increase in enrollment and fundraising (Toy, 2009).

It is evident that schools depend heavily on the success of their athletic programs for future recruitment and continued income. Successful athletic programs not only generate revenue but attract more competitive athletes; therefore athletes and coaches are driven 
by pressure to succeed. Universities have a financial incentive to develop successful athletic programs in order to gain alumni contributions and attract more applicants. Because in a small number of universities athletes provide revenue for the institution, they must practice and play and these factors could create pressure to return a medically compromised player onto the field.

The health ramifications to athletes can be very serious. A high school football player in Texas obtained MRSA from a shoulder burn. He suffered temporary blindness and paralysis, lost 41 pounds and spent more than three weeks hospitalized. He then was confined to his home for two months, and had to refrain from sports for seven months (Hart, 2006). In 2003 an athlete named Ricky Lannetti that played football for Lycoming College in Pennsylvania died due to an MRSA infection (Hart, 2006).

In light of the financial and health repercussions, incidents such as infection outbreaks must be recognized, prevented and stopped before they result in program interruptions such as lost practice and playing time as well as negatively impact the general well-being of the athlete. As outlined above, the economic cost of MRSA infections can be staggering to an individual in hospital costs alone but in athletic settings even a mild outbreak can disrupt an entire playing season and prevent recruitment of future players. The student athlete must be healthy to perform physically. Therefore the college has an interest in their remaining healthy, as well as the responsibility to provide a healthy environment for its students. An infection can be of great cost to the individual athlete, the team as a whole and the institution (Patel et al., 2007).

\section{MRSA and SSTIs}

Raghavan and Linden (2004) explored newer treatment options for SSTIs. Their 
review of several studies resulted in the conclusion that most community-acquired SSTIs are now caused by staphylococcus and that these are becoming increasingly resistant to previously effective antibiotic treatments. The trend inspired their article outlining newer pharmaceutical treatment options for MRSA infection.

In a prospective observational study published by Frazee et al. (2005), MRSA was present in $51 \%$ of 137 patients' site cultures in a hospital emergency department over a five month period. Of these, $76 \%$ fit the clinical definition of community associated MRSA. The authors concluded that these finding were consistent with the worldwide emergence of CA-MRSA.

King et al., (2006) conducted prospective laboratory surveillance from August to November 2003 to identify Staphylococcus aureus isolates of patients with SSTIs. The study took place in a large Atlanta hospital and its affiliated outpatient clinics. The authors found that out of 389 episodes of SSTI, $72 \%$ were caused by MRSA, and $64 \%$ of these were CA-MRSA. Due to this overwhelming evidence that SSTIs are most commonly caused by CA-MRSA, the researchers modified their guidelines for the treatment SSTIs and all SSTIs are treated as if they are laboratory confirmed MRSA (King et al., 2006). It is believed that the true prevalence of CA-MRSA in the general population is likely underreported, because abscess collection for culture is costly and not routine practice. Many clinical settings lack the laboratory resources to determine exact cause of SSTIs and therefore rely on patient history and patient report of etiology to guide treatment (Drews et al., 2006).

The results of these studies clearly establish that the majority of SSTIs are caused by MRSA. Laboratory cultures can be expensive, are time consuming, and waiting for 
results before treating an SSTI that will likely be MRSA can increase recovery time and allow the infection to become more invasive. SSTIs will often be treated as if they are MRSA based upon presentation and patient report in many settings for these reasons. Therefore, for the purpose of this study SSTIs were assumed to be MRSA infections.

\section{Purpose}

Effective prevention policy cannot be made without careful consideration of current procedures and their impact. Information regarding prevention techniques and prevalence will make it possible for administrators and healthcare providers to make evidence-based decisions on how to allocate resources and adjust policy to address this important issue (Klein et al., 2007). The primary purpose of this study was to provide an indication of the impact of SSTIs on college athletic programs prevention policies. With a better understanding of the actual prevalence of these infections in athletic settings and an understanding of the impact an infection can have, healthcare providers can partner with administrators to make more informed decisions and implement effective policy toward the overall goal of enhancing their programs and improving or protecting the status of the institution. Information gathered in this study will help to develop standardized guidelines in an effort to decrease risk with prevention standards instead of relying on treatment after an infection has already been established. While the presence of SSTIs in athletic settings has always been an issue, the seriousness and potential devastating costs of MRSA have caused athletic training facilities to reconsider their policies. To date, the research examining MRSA in athletic settings has not explored the resulting changes to prevention policy and the result of those changes.

\section{Definition of Terms}


The following definitions apply to this study:

1. Staphylococcus aureus - a common, adaptable bacteria that is a common inhabitant on human skin and is capable of causing a variety of illnesses (Centers for Disease Control, 2010)

2. MSSA -- Methicillin susceptible Staphylococcus aureus, or Staphylococcus aureus infections that can be treated and eradicated with conventional antibiotics (Centers for Disease Control, 2010)

3. MRSA - Methicillin resistant Staphylococcus aureus; Staphylococcus aureus that have developed resistance to antibiotics in the penicillin family (e.g., methicillin) and are very difficult to treat and cure with conventional antibiotics (Centers for Disease Control, 2010)

4. HA-MRSA - hospital acquired MRSA, or MRSA infections that were acquired in in-patient settings or associated with care provided in those settings, usually to those at higher risk for infection such as people of older age, with chronic disease, with a history of frequent admissions into inpatient settings, invasive procedures and indwelling lines. As the incidence of MRSA increases and its association with healthcare is more recognized, the more commonly used term has become healthcareassociated MRSA (Mayo Clinic 2012). Therefore, the term HA-MRSA will be used throughout to address MRSA associated or acquired as part of healthcare

5. CA-MRSA - community acquired MRSA, or MRSA infections that were acquired in a community setting (outside of a hospital or clinic) and 
usually occur in younger, healthier populations such as children in daycare centers and students that participate in athletics. Risk factors differ from those of HA-MRSA and include frequent abrasions and lacerations, skin to skin contact, and sharing of personal items. CAMRSA is caused primarily by the USA 300 strain. The term is also used interchangeably with community-associated MRSA (Mayo Clinic 2012)

6. SSTI - skin and soft tissue infections, or infections present in the skin or fascia, which have been found in most cases to be caused by MRSA

7. Certified Athletic Trainer - health care providers specializing in prevention, assessment, sand treatment of injuries and illness (NATA, 2007)

8. Athletic Training - practiced by athletic trainers and includes prevention, diagnosis and intervention of emergency, acute and chronic medical conditions (NATA, 2007)

9. Universal Precautions - Infection control recommendations developed to prevent the transmission of diseases through body fluids (CDC, 1988).

\section{Research Questions}

The literature review in chapter two provides data that explains the basis for the research questions. They are as follows:

1. To what extent are SSTIs recognized as being present in college athletics?

2. What policies exist in college athletics to recognize, prevent and manage SSTIs?

3. Are there significant variations in standards of practice for SSTIs? 
4. Are there significant variations in extent of incidence of SSTIs?

5. Are there epidemiological differences such as gender of athletes or individual sports that may be important in prevention program development?

6. What has been the impact on prevention policies and procedures related to SSTIs?

\section{Significance of Study}

While the benefits and importance of case studies is significant, a clearer picture of the true impact on prevention is needed. It is easy to believe that the possibility of an outbreak will not affect most programs when all that exists in the literature are small case studies that cover only isolated incidences. The focus of this study was on the programmatic elements that are important for administrators as they aim to identify potential problems and develop interventions that serve to protect the athlete and the athletic program, as institutions have a duty to provide the highest level of healthcare and safety possible to their athletes.

The information obtained from this study could help athletic programs in colleges on several levels. A clear understanding of the prevalence of SSTIs could make funding available for equipment and items necessary to prevent infection. Administrators responsible for program and budget development will have the information they need to modify and improve their approach to policy making, and administrators can share what they have learned so that university officials are supportive of actions taken.

The information attained by this study is valuable to athletic teams in their efforts to remain healthy and their ability to practice and compete. The differences and similarities clarified with this research will promote connections between college 
athletics programs, fostering stronger working relationships. Unique relationships between colleges can provide the opportunity to enhance the success of efforts to curtail infections and outbreaks. Information from this study could justify allocation of resources to combat and prevent SSTIs in athletic environments as well as encourage future research on the subject. Institutions struggling from decreased enrollment, grants, and loss of other forms of income are sometimes required to strategically focus resources to areas of most need.

The results of this study contributed to the body of research on SSTIs in the community, particularly in college athletics, and built on previous research. Because this study builds on prior research that is primarily case studies, it provided a broader picture of the overall prevalence of SSTIs in athletics. In addition and of critical importance, information gained from this study assists university administration in developing policy and procedures, developing a deeper appreciation and understanding of the importance of disease transmission and its prevention, and lead to change that ensures athletic programs have healthy student athletes. Lastly, it can help institutions to reduce MRSA cases and the legal implications that can be incurred from outbreaks. 


\section{CHAPTER II}

\section{LITERATURE REVIEW}

\section{Introduction}

An MRSA outbreak in any setting, including college athletics has the potential to become problematic for an institution if not handled appropriately. Because it has been established that most SSTIs are caused by MRSA, the purpose of this chapter is to review available literature of MRSA outbreaks in the community and in athletic settings, and to provide a clearer picture of the impact that MRSA infections have had in these settings. The first section will cover studies on the emergence of the presence of MRSA in the community. The second section will narrow the focus of MRSA to athletic environments.

\section{MRSA in the Community}

The studies presented in this section will illustrate the scope of the problem of MRSA in the community, as opposed to hospital and long term care settings, where it has been historically recognized. A large number of studies that examined MRSA outside of healthcare settings focused on the seriousness of MRSA infections. Cosgrove et al. (2003) performed a retrospective meta-analysis on the mortality rates of methicillin Susceptible Staphylococcus aureus (MSSA), defined as Staphylococcus infections that are still susceptible to traditional antibiotics, compared to MRSA. The authors concluded from the results that MRSA is associated with increased mortality compared with MSSA. The results also support that MRSA is a significant problem and there is a need for efficient infection control to prevent spread. Because this study examined a large pool of 
data over a long period of time it clearly shows the increasing problem of MRSA in the general public.

Noting few studies that reported CA-MRSA infections in healthy people without known risk factors, Gorak, Yamada, and Brown (1999) studied the demographic and clinical features of patients with CA-MRSA infections in their facility, the Tripler Army Medical Center in Honolulu. Medical records of all patients with CA-MRSA isolates between the years of 1992 and 1996 were reviewed. During the study period, 38 patients were admitted to the hospital with CA-MRSA. Fourteen of the twenty-four were clinically infected while the remaining ten were considered colonized (carrying the bacteria, but not actively infected) without clinical infection. Ten of the CA-MRSA infected patients had no risk factors or underlying health problems that are typical of MRSA infection. Six of the infections required surgical intervention and six were hospitalized for longer than five days; there were no deaths or long term complications (Gorak et al., 1999). The results strengthened the recognition that CA-MRSA infections occur in previously healthy young people. The majority of the patients in this study required surgery indicating the seriousness of the disease. The population was unique; most of the patients in this military facility tend to be young and healthy, which may mean that other populations would see even longer hospital stays and increased morbidity.

Fridkin et al. (2005) monitored all MRSA cultures from three populations in an effort to evaluate the incidence of CA-MRSA and the clinical outcomes in several areas of the United States. During the study period 12,553 patients were identified as having MRSA. Of these 2,107 were classified as having CA-MRSA. Of the CA-MRSA 
classified patients 506 were hospitalized (31\%); $371(23 \%)$ specifically for MRSA disease, for a median of four days. Ten percent (37 patients) required hospitalization in the intensive care unit. For one of these 37 patients that subsequently died, it was documented that CA-MRSA either caused or contributed to the death. The authors concluded that eight to twenty percent of the identified CA-MRSA cases were not associated with traditional risk factors. Twenty-three percent of these patients required hospitalization for the infections, further demonstrating the seriousness of the problem (Fridkin et al., 2005). Because MRSA is often treated without diagnostic testing, so this study may not reflect the true prevalence in these populations.

In addition to the serious nature of MRSA infections other authors documented the tendency to find that CA-MRSA infection affects primarily healthier populations, instead of people compromised by illness or surgery. Bratu, et al. (2006) examined the prevalence of CA-MRSA in Brooklyn, New York. The study also looked at the factors of neighborhoods that were identified as having a higher prevalence of the pathogen. They obtained all isolates of Staphylococcus aureus from 15 of the 16 hospitals that served 72 neighborhoods in Brooklyn from December 2005 through February 2006. The authors concluded that risk factors previously associated with MRSA such as hospitalization or hemodialysis had changed and the disease was affecting healthier people. In this study the highest prevalence appeared in a largely minority and indigent population, which is more likely to be living in crowded conditions (Bratu, et al., 2006).

Because MRSA has begun to emerge in patients without the traditionally recognized health care associated risk factors, Naimi et al. (2003) conducted a prospective cohort study to compare CA-MRSA with health care associated cases of 
MRSA. The authors concluded that in this first prospective study comparing HA- MRSA with CA-MRSA in multiple sites, the patients with CA-MRSA were considerably younger (Naimi et al., 2003). Because this was the first study to compare HA-MRSA with CA-MRSA, the finding that a younger population is effected by CA-MRSA is valuable information, particularly in conjunction with other research that indicated that CA-MRSA is more prevalent in crowded conditions. College housing and athletic camps are conducive to both of these conditions.

Before the late 1990's, CA-MRSA had rarely been reported in children without predisposing risk factors. Herold et al. (1998) performed a retrospective review of medical records at one hospital to determine if CA-MRSA infections in children are increasing in the absence of predisposing factors. Records of MSSA and MRSA infections for a two year time period, between 1993 and 1995 were examined and compared to available records between 1988 and 1990 in a 156 bed pediatric facility. There were 32 identified cases of MRSA in 1988-1990 and 56 cases in 1993-1995. In the available charts during the period 1988-1990, eight were determined to be CA-MRSA and 35 of the charts reviewed in the 1993-1995 time period were determined to be CAMRSA. Like Bratu et al. (2006), the authors determined from these findings that there has been a change in the epidemiology of MRSA and were no longer limited to patients with predisposing risk factors (Herold et al., 1998).

Another healthy population found to be at risk for MRSA infections is military personnel. Zinderman, et al. (2004) studied an outbreak at a large military training facility in the southeastern United States. Records showed that from October 2000 to July 2002, there were 47 confirmed MRSA infections. However between August and December of 
2002, 235 cases of MRSA were recorded; increasing the incidence from 4.9 to 11 cases per 1,000 recruits. To investigate which aspects of training may be associated with transmission, cases were sorted by week of training when diagnosed. Most cases $(86 \%)$ occurred during week's six to twelve, during which time period includes a 54 hour strenuous field exercise. Interviews with healthcare providers, laboratory personnel and recruits indicated that most patients did not have risk factors for MRSA infection such as chronic medical conditions, hospitalization within the previous year, or recent use of microbial agents. The outbreak ended in December 2002 soon after interventions were implemented such as forbidding sharing of personal items and increased attention to hygiene (Zinderman, et al., 2004).

The authors determined that this outbreak demonstrates the threat of MRSA in a close contact environment. Activities used by recruits such as hand to hand combat training, lifesaving and team building exercises are much like sports activities in that they involve prolonged physical contact between participants (Zinderman, et al., 2004). The population studied is much like university sports teams because they have crowded living conditions, potential for injury, and close physical contact. It is likely that groups in similar conditions where sharing and close contact are frequent may experience the same kinds of problems such as the MRSA outbreak described here. In accordance to these findings, there is a significant amount of research documenting strong evidence that CAMRSA is more prevalent in populations that are in close contact. The study mentioned earlier by Bratu, et al. (2006) suggested the high prevalence in the region they studied was likely due to lower socioeconomic status and overcrowding of a largely minority and indigent population, putting this population in close contact with one another. 
Another issue that arises when considering that crowded conditions is an element for the spread of MRSA is its' ability to survive on surfaces. In 2006, Kramer, Schwebke and Kampf collected and assessed the data that had been published in previous decades on persistence of all type of pathogens on surfaces. They found that transmission to hands from a single contact was found to be most successful with Staphylococcus aureus among other bacteria (Kramer, Schwebke \& Kampf, 2006). These results are important because compliance rates of healthcare workers for hand hygiene are known to be approximately $50 \%$ (CDC, 2002); it is likely to be much less in high school and college students. The authors pointed out that the risk for contaminated surfaces cannot be overlooked.

These studies contain valuable data that clearly support that MRSA in community settings has become a problem in many environments and continue to affect greater numbers over time. In many of these studies such as those in day care and military settings, MRSA was found to be more prevalent possibly due to crowded conditions, increased contact and also in younger people, populations similar to those factors present in high school and college athletes. Children in day care centers, due to a high level of close contact, could act as reservoirs for bacteria and facilitate spreading of infections. Adcock, Pastor, Medley, Patterson, and Murphy (1998) finding no description of MRSA in day care facilities, conducted a study with the purpose of determining the prevalence of MRSA and evidence of transmission in two day care facilities.

Eleven children were colonized (carrying the bacteria, but not infected) with MRSA; nine (24\%) at facility Y and two (3\%) at facility X. None of the child care providers tested was positive for MRSA. All colonized children at both facilities were 
healthy (Adcock, et al., 1998). The study was the first to examine MRSA in day care centers, a population that is in some ways much like college residential students. The spread of MRSA in this population was believed by the authors to be due to direct person to person contact, much like college contact sports. These types of settings are likely to be conducive to the spread of MRSA with colonization that can persist for months. The authors failed to reveal a contact with MRSA through a person in the household with a history of hospitalization or contact with a long term care facility (Adcock, et al., 1998). The study provides additional evidence of the establishment of MRSA in community settings, particularly those in which people have close contact.

Groom, et al. (2001) researched the occurrence of CA-MRSA and evaluated risk factors compared with MSSA in a rural American Indian community. The retrospective cohort study was conducted at a small hospital. All laboratory confirmed Staphylococcus aureus infections at the facility between January 1 and December 31 of 1997 were evaluated, comparing MSSA with MRSA infection. Results showed that MRSA increased dramatically in this community. In 1997, 112 patients presented with Staphylococcus aureus infections; 50 of them (45\%) were MSSA and $62(55 \%)$ were MRSA. Six MRSA patients (13\%) were hospitalized due to their infection, compared to one patient hospitalized due to infection with MSSA (3\%).

The authors' inferred that low socioeconomic status and crowded living conditions may have enhanced their detection of the emergence of CA-MRSA. They pointed out that these conditions are not unique to the rural American Indian population and that over time, CA-MRSA may be found in increasing numbers in other communities with similarities to this one (Groom, et al., 2001). These finding suggest that health care 
practitioners should be aware of the possibility of MRSA infection among young healthy patients, particularly in crowded living conditions.

Further evidence of MRSA infections in settings where close contact and sharing of equipment is common is supported by Como-Sabetti (2006). After two previously healthy 15 year old patients were hospitilized for MRSA septic arthritis, one of which requiring intensive care, it was discovered that they participated in the same twenty-one day canoe camp trip in northern Minnesota. An additional case of a 17 year old patient with a skin infection was also identified in an earlier canoe trip (Como-Sabetti, 2006). Campers and household members were interviewed regarding health history, hygiene, and contact with other campers, skin infections and injuries. The two case patients occasionally shared the same canoe. The case patients and colonized persons did not report a history of MRSA infection or colonization (Como-Sabetti, 2006).

Several studies offered compelling evidence that MRSA is increasing in the community. Moran, et al. (2005), examined several clinical trials to determine the prevalence of CA-MRSA among emergency department patients with SSTIs, in a county hospital in Los Angeles. MRSA was isolated from 44 (46\%) of 96 patients. MRSA infections increased from $29 \%$ during 2001 to 2002 , to $64 \%$ from January 2003 through March 2004 (Moran, et al., 2005).

The authors concluded that the proportion of patients with SSTIs caused by CAMRSA is increasing and found to be the most common cause of SSTIs at the medical center studied. The researchers did not culture every possible SSTI seen in the emergency department, so the sample may have been under representative of the true prevalence of CA-MRSA in this population (Moran, et al., 2005). These results provide further support 
that MRSA is indeed increasing in prevalence in the community setting.

Also because of the problem of a reported increase in MRSA in the community, Price and McBride (1998) reviewed culture result patterns in an outpatient dermatology population for the period of 1988 through 1996, to determine whether the number of MRSA infections had increased. All records of outpatient cultures in six dermatology clinics from the time period of 1988 to 1996 were studied. The percentage rose from $1.5 \%$ in 1988 to $11.9 \%$ in 1996 . The number in 1996 had significantly increased compared to the number in 1988 . The absolute numbers of MRSA in this study were low, but there did appear to be a trend of increased prevalence in this particular community. The population of outpatients does not represent recognized high risk activity, such as persons on dialysis, although the authors did not have information as to possible exposure in a healthcare facility. They found decreased susceptibility to several antimicrobial agents which is also of importance, as it exemplifies the continued decreasing susceptibility of Staphylococcus aureus to standard treatment (Price and McBride, 1998).

Charlebois et al. (2004) analyzed a large data base of MRSA cases in San Francisco, California in an effort to identify those at risk for MRSA infection. The authors had noticed anecdotal reports, case series, and studies suggesting that MRSA was being acquired in community settings, but feared these may not adequately represent the MRSA problem in the community. Their purpose was to conduct a serial, cross-sectional analysis of electronic databases to identify predictors of CA-MRSA (Charlebois et al., 2004).

The clinical lab that served the Community Health Network (CHN) of San Francisco provided all records of MRSA positive cultures obtained between the years of 
1988-1999. Results showed that the prevalence of MRSA had increased significantly, from $3.1 \%$ in 1988 to $26.9 \%$ in 1999 . CA-MRSA increased from $7 \%$ in 1993 to $29 \%$ in 1999 (Charlebois et al., 2004). The next section will focus on cases studied in athletic settings.

\section{MRSA in Athletic Settings}

Goodman et al., (1994) performed a comprehensive literature search to determine which infectious diseases commonly affect athletes. Their article stated that the NCAA declared that in 1992, over 5.2 million high school and college students participated in athletic activities. Although there was evidence that athletic teams are indeed affected by infectious disease outbreaks, health risks studied were typically injuries and musculoskeletal problems. The authors concluded that health care providers for athletes must be aware of the potential of these diseases to affect their players, and are obligated to use prevention strategies and know how to identify them (Goodman et al., 1994). Standard precautions and screenings should be taught to athletes. Most importantly, a base of solid research is needed to establish effective decision making for preventing it in the sports setting. A firm foundation that infectious diseases, including MRSA are in fact an issue for athletic groups was identified by this research. Because many athletes engage in frequent physical contact they are at a higher risk than some other populations. Following are some research studies specific to athletics that also support physical contact as a risk factor.

Stacey, et al. (1998) published a study that described an outbreak of MRSA that occurred in a rugby football team in 1996. Although cutaneous infections in physical sport participants are common, this was the first known MRSA outbreak outside of 
hospitals and nursing homes. Five members of a rugby football team presented to the club doctor in December of 1996. They all had consulted their own doctors initially; no cultures were obtained, and the infections did not respond to the antibiotics prescribed. The club doctor recognized an outbreak, and proceeded to collect cultures from the wound sites as well as swabs from several carriage sites of the affected players. The strain was found to be different from the epidemic strains seen in many hospitals in the United Kingdom. The authors determined that close physical contact was probably the cause of the outbreak. They stated that despite a recent comment by the Chief Medical Officer that MRSA posed no risk to the community, this case was evidence that some strains have the potential to spread to healthy young adults with favorable conditions. This was the first outbreak outside of the heath care setting identified (Stacey, et al., 1998).

Lindenmayer, et al. (1998) performed a case study of a MRSA outbreak in a high school wrestling team and the surrounding community to investigate the risk factors that may have contributed to the infections. All thirty-two wrestlers on the 1993-1994 affected team were administered a questionnaire that provided demographics, wrestling history, possible risk factors, percentage of time skin was uncovered during practice, sharing of towels or clothing, use of the wrestling room Jacuzzi, contact with hospital or nursing home patients, underlying illness, and mat burns. Seven team members (21.9\%) had MRSA. None of the risk factors studied was associated with an increased risk of infection. In the community, eleven people had MRSA infections. Six had some contact with the high school; they were non-wrestling students, immediate family of wrestlers, or siblings (Lindenmayer, et al., 1998). 
This report was one of the first of an outbreak in a young healthy population. The small sample size may account for the fact that none of the risk factors studied were found to be associated with infection. Despite the results of the study, the authors still believed that the frequency and duration of skin contact may have been an important risk factor. Team members reported practicing for two hours a day, six days a week with other team members. The extended contact because of practice in conjunction with mat burns probably increased spread of the infection. However matches with opposing teams were only three minutes in duration, which may explain why members of the opposing teams did not contract infections (Lindenmayer, et al., 1998). The widespread transmission in healthy members of this sports team further supports implications that coaches and athletic trainers need to be aware of the prevalence and be educated in preventing the transmission of MRSA. No data is available to prove containment measures used here were successful, implying the need for further studies to determine which methods are optimal for preventing the spread once an outbreak has been established (Lindenmayer, et al., 1998).

Begier et al. (2004) described an MRSA outbreak in a college football team by conducting a retrospective cohort study on all 100 players of a college football team for a specific time period, in an effort to guide related policy. Players with turf burns had a seven times higher risk of infection than those without turf burns. Players of the more high risk positions that also had turf burns experienced an additive effect. Players that reported body shaving ( $28 \%$ ) were over six times more likely to develop infection. Shared whirlpool usage of greater than twice a week increased risk by twelve times over those that never shared a whirlpool (Begier et al., 2004). The authors concluded from the 
results that MRSA was spread by frequent skin to skin contact during practice, and that staff who work with athletic teams should note the special risk of this population. Whirlpool use may also have been an additional mechanism to spread the infection (Begier et al., 2004).

Kazakova et al., (2005) conducted a retrospective cohort study on an outbreak of MRSA in a professional football team to identify risk factors that may have led to the transmission of MRSA through an observational study of both on and off field activities and hygiene practices at the team's facility. The epidemiologic investigation revealed eight MRSA infections in five of the 58 players ( $9 \%)$. All quickly became large abscesses that required surgical intervention. Although most infections resolved within ten days, three of the five players developed recurrent infections. None of the players required hospitalization but all missed at least one and up to twelve days of games or practice (Kazakova et al., 2005).

Evidence indicated that those players with more body surface area, and therefore more likely to have exposed skin are at a higher risk. After infection control measures were implemented in the training facility to target MRSA only one other case occurred. Control measures included wall mounted soap dispensers with antimicrobial soap installed for routine hand washing, local wound care, and surveillance for skin infections (Kazakova et al., 2005). The introduction of infection control measures may have eliminated environmental contaminants, also. The authors concluded that personnel involved in care of sports participants need to be aware of MRSA emergence, and provide guidance regarding hygiene procedures to prevent transmission (Kazakova et al., 2005). The results provide further evidence that close contact is a significant risk factor 
for transmission of MRSA.

Romano, Lu, and Holtom (2006) published a three year retrospective study of an outbreak of CA-MRSA in a college football team. The purpose of this study was to examine the MRSA outbreak in a collegiate football team and the effect of infection control measures instituted over a period of three years. The investigators examined the factors used for infection control during the outbreak and the results of these interventions in infection rate among players.

Two players were hospitalized in 2002 due to complications of MRSA infections. Fourteen cases of MRSA were confirmed between the seasons of 2002 and 2004. These ranged from small abscesses to one case of necrotizing fasciitis requiring hospitalization and multiple surgeries; eight of the players were hospitalized. Aggressive hygiene measures were implemented after two cases were identified in week five of the 2002 season. No other infections occurred during the 2002 season (Romano et al., 2006). In the 2003 season, 11 players had confirmed cases of CA-MRSA. Six of the players with severe wounds were hospitalized for intravenous antimicrobial therapy and surgical debridement (Romano et al., 2006).

The authors determined that outbreaks in teams are very serious, and players in team sports are more susceptible due to skin trauma such as turf burns, abrasions, and chafing. This is problematic because the condition can cause a significant loss of practice days. All sports medicine programs should review procedures, because early recognition is important for effective treatment. Staff should be educated that lesions positive for MRSA often look like boils or spider bites with pain out of proportion to the physical exam. Infection control measures for the prevention of CA-MRSA spread are vital to the 
effort to contain the disease. The authors indicated that the implementation of these measures contributed greatly to the significant decrease in further incidence of the infection (Romano et al., 2006).

Similar to some of the research in the previous section many of the studies in athletic setting also found that sharing of items and poor hygiene were prominent factors. Nguyen et al. (2005) reported an outbreak of MRSA in a college football team from August 2002 to September 2003. In August of 2002, the Los Angeles County Department of Health Services (LACDHS) reported that two players on a college football team were hospitalized for what was later identified as CA-MRSA. On August 25, 2003, LACDHS was notified that four players different from the players of the previous year had MRSA infections. The recurrence prompted an investigation in an effort to identify players that were possible carriers, and to implement control measures. The authors concluded that eradicating these infections is difficult once established. Consistent with other reports, sharing of personal items appears to be a risk factor (Nguyen et al., 2005).

Because CA-MRSA infections are more frequently being identified in participants of athletic activities, Cohen (2005) studied MRSA in seven student athletes positive for MRSA, including mechanisms of transmission and measures to prevent spread, at the University of Houston. The purpose of his study was to describe the clinical features of the outbreak at this university, and evaluate the potential mechanisms of transmission. A retrospective chart review was completed between August of 2002 to February of 2004 to evaluate mechanisms of transmission and review measures taken to prevent spread. The students, although all athletes, were in varied athletic programs; three were weight lifters, two women were on the volleyball team, one woman was on the basketball team, and one 
man was on the football team: MRSA infection was confirmed on specimens at the Laboratory Corporation of America in Houston Texas, where all specimens were sent. The author concluded that the results of this study support the concept that coaches and athletes should be trained in detection of MRSA and the measures that can be taken to stop it from spreading (Cohen, 2005).

Huijsdens, et al., (2005) studied an MRSA outbreak in a Dutch soccer club. Screening began after several players noted soft tissue infection and one member was hospitalized for an abscess caused by MRSA. MRSA infection was identified in eleven persons. To prevent further transmission the club was instructed to increase hand hygiene, cease sharing personal items, use disposable towels, place a towel on benches before sitting, and increase cleaning of facilities. Seven patients remained MRSA positive or experienced recurring MRSA infection. Patients were declared free of infection after three negative cultures at one week intervals. One patient with eczema remained MRSA positive (Huijsdens, et al., 2005).

In addition to the similar findings between research on MRSA in the community and in athletic settings concerning physical contact, sharing of personal items and lack in hygiene as risk factors, there was also consistent literature supporting the education of coaches, trainers and the athletes themselves to prevent outbreaks. The research by Cohen, 2005, Kazakova et al., 2006 and Romano et al., (2006) all reinforce the need for education.

A community acquired MRSA outbreak in a high school football team was studied by Rihn et al., (2005). Although outbreaks on athletic teams have been infrequently reported, the authors also recognized that MRSA is an emerging community 
problem and participants of sports with repeated close contact puts them at risk. They noted that the knowledge of risk factors and prevention is inadequate. The study provides a useful description of the outbreak and results of interventions to treat and prevent spread of the infection in athletes (Rihn et al., 2005).

A retrospective review of the outbreak was conducted. Proven and suspected cases were reviewed by survey for possible exposures, hygiene activities, treatment and response to treatment. Characteristics of infected versus uninfected players were compared to identify risk factors. Thirteen players had 20 cases of MRSA infection. Eighteen required incision and drainage. Three of the 102 nares cultured were positive for MRSA. Of the players that had developed MRSA, two also had positive nasal cultures. Higher risk was associated with the lineman position suggesting that repetitive close contact common in playing that position predisposes the player to infection. The study implies the importance of performing cultures for suspicious wounds in athletic teams, and taking measures to prevent recurrent infections (Rihn et al., 2005).

These findings make clear how an established MRSA infection can be difficult to control, even with proven infection control techniques. The high morbidity in this healthy population caused by this organism indicates that future outbreaks are very likely and planning to prevent and control them is essential. The previous small case studies taken together collectively set a solid basis of the problem that MRSA infections present to athletic teams. Research of MRSA in the community setting as well as research specific to athletics both offer strong support that frequent contact, lack in hygiene, and sharing personal items such as razors, soap, and towels are high risk factors for MRSA.

Strong evidence in the research from both athletics and the community at large 
verifies the seriousness of the disease (Bratu, et al., 2006; Cohen, 2005; Gorak et al., 1999; Groom et al., 2001; Herold et al., 1998; Kazakova et al., 2005; Moran et al., 2005; Rihn et al., 2005; and Stacey et al., 1998). Community and athletic research on MRSA also yielded a large amount of research that agreed to the seriousness of the problem of MRSA (Cosgrove et al., 2003; Goodman et al., 1994; Kazakova et al., 2005; Lindenmayer et al., 1998; Moran et al., 2005; Price \& McBride, 1998; Reboussin \& Sheretz, 2004).

\section{Summary}

The scope of the MRSA problem is well illustrated by the research on MRSA in the community and in athletics. The studies in this section provide compelling evidence that MRSA can have devastating effects once it has established itself in members of athletic teams. MRSA infection has the potential for high morbidity as well as high cost to individuals, parents and to the school in terms of potential loss in playing time. Among factors that indicate increased likelihood of infection in athletes include; close contact, including skin to skin contact; crowded living conditions, potential for injury, poor hygiene habits typical of the college population, and perhaps increased antibiotic use. The impact of a serious outbreak could be a huge cost to the institution, affecting the health of the students and potentially the staff, institutional liability, as well as possibly causing irreparable harm to the entire athletic programs.

It is less clear what prevention strategies have been changed or policies implemented as a result of the emergence of these infections, as the research has yet to address this aspect of the issue. The proper management of an MRSA infection once it has been identified is vital so staffs dealing with athletic populations must be educated on 
the identification and management of MRSA infections. If there is a true causal relationship between the infection control measures implemented by institutions and control of spread of the infection then it follows that the measures implemented after an outbreak begins will impede the spread and may prevent it altogether. Many schools place high importance on athletic programs. Because it is a fairly recent phenomenon, an outbreak could spread quickly causing high morbidity, costs to the school, even death. Sensationalizing media coverage could further accelerate a serious situation for the institution.

Institutions of higher education could learn from the MRSA outbreaks experienced by other institutions and become leaders in the effort to prevent it from effecting their programs and institutions. The studies discussed here raise several questions: What is the actual extent of these outbreaks in college athletics? Now that these outbreaks are becoming more frequent, are athletes, athletic trainers and other athletic staff receiving education about these outbreaks, such as how to prevent and recognize them? Which strategies implemented best prevent infections? Are institutions seeking out and implementing recommendations by NATA, the CDC, or the NCAA?

Answers to these kinds of questions through empirical research can assure that future policies addressing the SSTI issue will be more efficient (Frazee et al., 2005). The combination of increased awareness of the potential damage that could be caused by an MRSA outbreak together with proactive well defined policies and plans could make the difference between an MRSA outbreak remaining a manageable problem or becoming a serious problem for sports programs. 


\section{CHAPTER III}

\section{METHODIOLOGY}

\section{Introduction}

CA- MRSA infections are an increasing problem in athletic programs. However the impact their presence has had on prevention policies in athletic programs is unclear. The purpose of this research is to determine the utilization of prevention strategies among athletic trainers, and to measure the occurrence and impact that SSTIs has on college athletics. The literature reviewed in Chapter Two revealed a startling amount of MRSA in hospitals historically, and more recently in community settings. Studies indicate that most SSTIs are indeed usually caused by MRSA infection. The methodology chosen to address the research questions will be detailed, including research design, population, survey tool, reliability and validity, procedures, and analysis.

\section{Design}

A descriptive design with a survey instrument was used for this study. The type of design used is appropriate for exploratory studies investigating baseline data describing frequency of gathered data with percentages or proportions. "Descriptive design is desired when the investigator seeks to organize and summarize a data collection (Shavelson, 1996, p. 8)". The focus of this study was to establish baseline data on the perceptions of clinicians of the impact of SSTIs on the college athletic population and to determine their prevention strategies.

Percentages and proportions were used to report the data in this study. 
Percentages and proportions are used when the concern is on the extent to which a population has a specific characteristic. Proportions show the portion of the total that has the specific characteristic; percentages are the same measurement expressed in a different form (Stat Trek, 2013). Confidence intervals were calculated in this study to provide a margin of error for the reader. Confidence intervals provide a specific space in which there is a probability that the true mean of a given sample of a population will fall (Shavelson, 1996). Chi-square was also used in this study. Chi-square is a common test used to test the significance of a relationship between categorical variables (StatSoft, 2013).

\section{Research Questions}

The six research questions evolved from the literature review in chapter two, and are designed to explore the impact MRSA has had on athletic programs and their prevention policies.

Research Question 1: To what extent are SSTIs recognized as being present in college athletics?

Research Question 2: What policies exist in college athletics to recognize, prevent and manage SSTIs?

Research Question 3: Are there significant variations in standards of practice in SSTI prevention?

Research Question 4: Are there significant variations in extent of incidence of SSTIs?

Research Question 5: Are there epidemiological differences in gender of athletes or individual sports that may be important in prevention program development? 
Research Question 6: What has been the impact on prevention policies and procedures secondary to SSTIs?

\section{Population}

The population examined consisted of athletic training clinicians. Athletic trainers are responsible for preventing and treating illnesses and injuries of athletes. Because they are often the primary health care provider for athletes, they have a great potential to influence policy and are therefore the appropriate population to examine.

The investigator obtained a mailing list of athletic training centers in colleges and universities from the NATA database. Only one athletic trainer per institution was surveyed, head trainers' or their equivalent. A total of 497 names were collected during this process.

\section{Survey Tool}

Because no previous research existed that addressed this particular focus or population, the investigator developed an original survey for the purposes of the current study to answer the research questions. The instrument was a questionnaire entitled "Evaluation of Skin and Soft Tissue Infection Policies and Prevention Practices Among College Athletic Programs" that was distributed electronically through the RedCap ${ }^{\mathrm{TM}}$ (Research Electronic Data Capture) software program to gather data (Appendix B). The purpose of survey tools is for gathering descriptive data that cannot be readily observed from a large population to measure the present condition of variables (Thomas, 2003, p. 44). Study data were collected and managed using RedCap ${ }^{\mathrm{TM}}$ electronic data capture tool hosted at the University of Louisville. RedCap ${ }^{\mathrm{TM}}$ (Research Electronic Data Capture) is a secure, web-based application designed to support data capture for research studies 
(Harris, Taylor, Thielke, Payne, Gonzalez, \& Conde, 2009).

The survey included 30 questions. The first nine addressed demographic data about the clinicians and their institution. Respondents were asked to state their title and number of years employed, if the institution was public or private, NATA district, and what sports they serve.

The remaining questions addressed their perceptions of the extent of SSTIs presence in athletics and their impact on prevention policy, policies employed in their setting to prevent SSTIs, impact of any prevention strategies and differences in types of athletes affected by SSTIs. A final open-ended question was included in an effort to gather information regarding SSTI impact and prevention not addressed in the survey questions. Because this was an original survey developed by the investigator, content validity was established through feedback from a panel of four experienced athletic trainers and a $\mathrm{PhD}$ prepared registered nurse, and for reliability through a test-retest procedure.

\section{Validity}

"Validity refers to how well an instrument measures what it purports to measure and if the results may be generalized (Shavelson, 1996, p.20)". The investigator solicited a panel of four athletic training professionals to establish content validity of the survey items through professional contacts. Feedback was requested from these volunteers to determine comprehension, clarity and to address any ambiguity of wording. A panel of individuals known to have experience in the content area is recommended to establish content validity. The members used for this purpose had a range of five to 27 years of athletic training experience, with an average of 18 years of experience. After reviewing 
the survey, members of the panel offered suggestions to improve clarity. In addition, per Dillman's (2007) recommendations to maximize participation, the members were asked to comment as to if the survey instructions were simple, and the survey concise and brief. Minor changes were made based upon their recommendations. In addition, the survey was developed with the aid of a $\mathrm{PhD}$ prepared registered nurse with more than 35 years nursing experience and more than 20 years of experience in infection prevention and control.

\section{Reliability}

A measurement is said to have reliability if two different measurements at different points of time result in identical or near identical results and speaks to the reproducibility of the data. Reliability indicates the stability of the instrument (Huck, 2004). Because stability is likely to decrease over time, it is recommended that the time interval between the two measurements be reported by the investigator (Huck, 2004). The same group of four athletic director professionals that served as the panel for validity volunteered for the pre and post test to determine reliability. The survey was sent to each volunteer one week apart on November $3^{\text {rd }}, 2011$ and again on November $10^{\text {th }}, 2011$. Responses from the four athletic trainers were analyzed for consistency and appear in the table below. Only items pertaining to the SSTI research were considered for this analysis, demographic data were not included: 
Table 1

Consistency of Responses Over Time in Pilot Sample of Four Cases

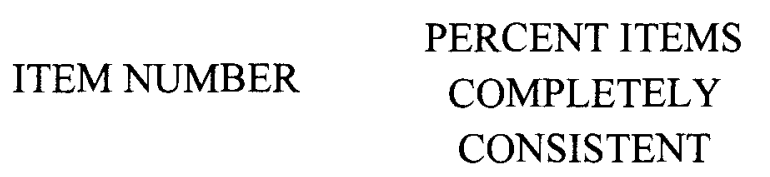

\begin{tabular}{ll}
\hline Item 10 & 100 \\
\hline Item 11 & 100 \\
\hline Item 12 & 75 \\
\hline Item 13 & 100 \\
\hline Item 14 & 50 \\
\hline Item 15 & 100 \\
\hline Item 16 & 100 \\
\hline Item 17 & 100 \\
\hline Item 18 & 100 \\
\hline Item 19 & 100 \\
\hline Item 20 & 100 \\
\hline Item 21 & 100 \\
\hline Item 22 & 75 \\
\hline Item 23 & 100 \\
\hline Item 24 & 100 \\
\hline Item 25 & 75 \\
\hline Item 26 & 100 \\
\hline Item 27 & 75 \\
\hline Item 28 & 100 \\
\hline Item 29 & 75
\end{tabular}

The closer the consistency is to $100 \%$, the more stable the instrument (Huck, 2004). Table 1 demonstrates that findings for the two measurements denotes that $75 \%$ of the items were $100 \%$ consistent with $92 \%$ consistency overall.

\section{Procedure}

The researcher utilized Dillman's survey methods (2007) to administer this survey. In accordance with Dillman's guide to administration of internet surveys, all 
participants received the purpose of the survey, the survey preamble, and informed consent attached to the survey. The project and the survey instrument were reviewed by the University of Louisville Institutional Review Board and was deemed as exempt from further review (see Appendix A).

Participants were sent an email invitation to participate in the electronic survey. They had the option of continuing on to the survey by clicking onto a link or exiting/deleting the email. The survey software $\left(\right.$ REDCap $\left.^{\mathrm{TM}}\right)$ includes a feature preventing the entry or completion of duplicate surveys from the same web address. An email link makes it easier for responders to navigate from the consent to the survey. Anonymity is protected by the electronic survey software design (Harris et al., 2009). The researcher designed the survey to maximize participation and ensure that it is concise, requiring approximately 10 minutes to answer the questions. The survey had evidence of reliability and validity as reported above.

The first email with the survey was sent July 23, 2012 to head athletic trainers in all states via the NATA website. The number of trainers in the population to be surveyed was 497 . The investigator strove to achieve the highest possible response rate to maximize the validity of the study and to reduce sampling error. One, two and three weeks after the original email was sent, the email was sent again to non-respondents. Because of a poor response rate, a last attempt was made in early October 2012 to obtain additional responses. Total time of data collection was approximately 10 weeks with a final sample of $N=78$ or a $15.67 \%$ response rate. After the data were collected, the researcher began data analysis.

\section{Data Analysis}


The following section is an explanation of the data analysis procedures that were used to address each research question. Demographic data obtained with the first nine survey items, including institutional and respondent information were summarized with descriptive statistics and reported as percentages. Most of the remaining data were also reported as percentages, which is appropriate to summarize categorical data (Huck, 1996) and confidence intervals were calculated to further interpret the results. Confidence intervals provide a range around the percentage that is likely to contain the population mean (Shavelson, 1996).

Research Question 1: To what extent are SSTIs recognized as being present in college athletics?

Items 9, 17, and 24 of the survey (see Appendix B) address Research Question 1. Question 9 asks respondents to indicate if MRSA is of concern to athletes in colleges nationally, locally, or in their own setting, or not a concern. The number of responses for each choice of answer was calculated and presented as a percentage for item number 9 . In addition the $95 \%$ confidence interval was calculated for each response. For example, if $20 \%$ of respondents report that MRSA is a concern locally, the percentage value was converted to a proportion: .20 . Then the procedure for calculating the $95 \%$ confidence interval was applied (Harnett, 1982).

Question 17 asks respondents if they have experienced lab confirmed cases of MRSA, and question 24 for number of hospitalizations due to MRSA infection. The number was calculated for each response, and a $95 \%$ confidence interval created to estimate the number of cases in the population of institutions from which the survey had been sampled. Then the procedure for calculating the $95 \%$ confidence interval for a 
population mean was applied (Harnett, 1982).

Research Question 2: What policies exist in college athletics to recognize, prevent and manage SSTIs?

Items 11, 12, 13, 14 and 28 of the survey (see Appendix B) address Research Question 2. Question number 11 asked respondents to indicate if they require a definitive diagnosis, assume all lesions are MRSA, or to provide an alternative answer. The number of responses for each answer is presented as a percentage with $95 \%$ confidence intervals calculated for each response. Question 12 asks type of diagnosis when diagnosis is required and is presented the same way, also with $95 \%$ confidence intervals calculated for each response. Question 13 asks if policies for treatment and prevention are in place in their setting, and question 14 asks respondents to identify elements included in their policies. Question 28 asks for their opinion of which the strategies for prevention are most effective. All questions are reported as percentages with $95 \%$ confidence intervals reported for each response option.

Research Question 3: Are there significant variations in standards of practice for SSTIs

Survey questions numbers 13 and 14 address Research Question 3. Question 13 asks if there is a policy in place and 14 asks which elements are included in their policies and they were analyzed the same way as outlined for Research Question numbers 1 and 2. This approach included calculating $95 \%$ confidence intervals for the percentages of persons selecting response options.

Research Question 4: Are there significant variations in extent of incidence of SSTIs?

Question numbers 17, 24, 25 and 29 address Research Question 4. They were analyzed the same way as outlined for the previous research questions. This included 
calculating $95 \%$ confidence intervals for the percentages of persons selecting response options.

Research Question 5: Are there epidemiological differences in geographical location, gender of athletes, or individual sports that may be important in prevention program development?

Question numbers 21, 22, and 23 address Research Question 5. In addition, survey question number 1 was compared to responses from questions 17 and 29 in an effort to determine if there were districts that indicate more laboratory confirmed cases or increases in incidence. Data were summarized with percentages and confidence intervals as in the previous research questions. This included calculating $95 \%$ confidence intervals for the percentages of persons selecting response options. In addition, chi-square statistics were calculated to test: (a) the associations between geographic location and confirmed cases of MRSA and (b) changes in incidence of MRSA in the past year.

Research Question 6: What has been the impact on prevention policies and procedures related to SSTIs?

Question numbers 12, 15, 16, 18, 19, 20, and 26 all address Research Question 6 and are presented in the same manner as the previous research questions, including calculating $95 \%$ confidence intervals for the percentages of persons selecting response options. In addition, chi-square tests were performed to ascertain if there was an association between variables of region and incidence of SSTI, as well as the variables of region and confirmed cases of MRSA.

\section{Theoretical Framework}

The researcher sought to determine if professionals are using a set of procedural 
standards outlined to prevent SSTIs. The current study draws upon the need for more information regarding the interventions that are being used, and more importantly, which ones have a positive impact on the prevention and treatment of these infections. The review of the literature in Chapter 2 led to the research questions that explored the incidence of these infections in college athletics and which strategies yield results. The review of literature further revealed the need to consider variation in practice in athletic sub-populations, such as special attention to contact sports and male dominated sports.

A theory provides a systematic basis to present a research question. The Health Belief Model (HBM) focuses on compliance and preventative health care practices and was chosen as the best fit to describe the impact of MRSA on the actions of healthcare providers and athletes. The HBM examines the relationship between health beliefs and behaviors in an effort to understand and predict compliance. If the factors that cause people to engage in health promotion can be identified, they can be applied to programming efforts (Von Ah, D., Ebert, S., Ngamvitroj, A., Park, N, \& Kang, D. 2004). Because this study is examining the impact of these infections on college athletic programs, this model helps to provide structure for determining the factors that motivate athletic programs to implement prevention policies. These could be as simple as increased awareness or an infection of a player, to something as serious as a costly outbreak or a death.

The Health Belief Model is a behavioral theory that was formulated in the 1950s. It was developed by United States Public Health Service social psychologists in an effort to explain why so few people were willing to participate in programs, (U.S. Department of Health and Human Services, National Institutes of Health, 2005) and has been used to 
examine issues such as prevention in (a) use of tobacco, (b) abuse of alcohol, and (c) spread of sexually transmitted diseases among college students (Sharma, 2011).

The HBM examines a person's health related behavior using six components. Following is an explanation of the components and how they pertain to this study. Perceived Susceptibility

The first component is perceived susceptibility (U.S. Department of Health and Human Services, National Institutes of Health, 2005). People vary in their perception as to whether they are at risk to a particular illness or injury. While some will completely deny they could ever be affected by SSTIs, others could be extremely fearful they will experience them. It is often difficult for any of the constituents involved to see the benefit in preventing an illness they have not experienced or dealt with themselves. Athletic programs that have experienced SSTIs are more likely to view these infections as a threat.

\section{Perceived Severity}

The second component is perceived severity of the potential illness (U.S. Department of Health and Human Services, National Institutes of Health, 2005). Perceived severity also varies, and may differ among the populations involved. Athletic trainers, coaches, college administrators, athletes and parents may differ greatly in their perception of the seriousness of an SSTI infection. These differences can be attributed to personal experience, differences in their knowledge about SSTIs, and also to the lens through which the situation is viewed. Athletic trainers could see SSTIs from a purely medical perspective and consider cost and use of resources in relation to severity of the potential problem. Athletes and coaches may consider the potential loss in practice and 
playing time, and administrators may consider the threat of litigation and possible media attention. Parents may fear their child could experience illness or even death. A heightened sense of severity may result from the publicity surrounding an experience of infection or outbreak. Parents of athletes and administrators may demand action to ensure the decrease in likelihood of future infection.

\section{Perceived Benefits}

The third component is perceived benefits (U.S. Department of Health and Human Services, National Institutes of Health, 2005). Higher perceived susceptibility must exist for there to be perceived benefit to prevention. The benefits of policies and practices to prevent MRSA infection in a given sports program may be difficult to appreciate without having already experienced an infection or outbreak. Those that have not experienced the cost from loss of practice or playing time, potential lawsuits, and health issues may not feel the pressure to allocate time and resources toward its prevention. A program that has experienced SSTIs and negative outcomes such as cost of treatment, loss in playing time, and the physical pain of illness is more likely to see the value of implementing prevention procedures.

\section{Barriers}

A fourth component is barriers to preventative action and relates to perceived costs (U.S. Department of Health and Human Services, National Institutes of Health, 2005). The more perceived barriers to a health behavior, the less likely people are to adopt the health behavior (Van Oh et al., 2004). Barriers for SSTI prevention in athletic programs would include expenses to the university such as disposable towels, antibacterial hand wash, infection control cleaning solutions and educational materials such as pamphlets 
and posters. Athletic trainers, coaches and athletes may consider educational programs and having any alteration in skin integrity to be examined an inconvenience. The increase in cleaning of equipment and surfaces is time consuming and all of these actions could be considered a waste of resources. Additional barriers could be the lack of additional resources provided to some programs. If administration does not perceive SSTIs as threatening they may be unwilling to increase budgets to meet the demand of increased infection control procedures. Athletes that know little about SSTIs and have not experienced them may ignore the policies. This may be particularly true of male athletes that feel pressure from peers and society to be independent and self-reliant (Davies, 2000).

\section{Cues to Action}

Cues to action are the factors that drive the parties involved such as coaches, athletes, athletic trainers and administration to enforce and to practice prevention policies (U.S. Department of Health and Human Services, National Institutes of Health, 2005). A program that has experienced SSTIs will be driven by the desire to prevent the negative impact of additional infections or outbreaks. In addition to the athletes, coaches and athletic trainers directly involved in the event of an outbreak, there may be pressure from parents, administration and the media demanding to know what the university is doing to ensure it will not happen again. Also, even when a program has not had experience with SSTIs, an increase of awareness in the literature and the encouragement of trusted organizations can produce action. Many programs may have been compelled to implement prevention strategies upon reading about them in professional journals, and from the encouragement of NATA through their conferences and publications. 


\section{Self-efficacy}

The last component is self-efficacy. The component was added to the HBM in the 1980 's and refers to the confidence needed to pursue a behavior (U.S. Department of Health and Human Services, National Institutes of Health, 2005). Self-efficacy was found to be the most significant predictor of health behaviors for college students in a study by Van Oh et al. (2004). In the case of SSTIs in college athletics, these enabling factors can come from various sources and depends upon the particular party involved. Athletic trainers and coaches may feel more confidence if they have the support of their administration. Publications from organizations such as NATA and the CDC that reiterate the importance of MRSA prevention will also boost the confidence of athletic trainers and coaches to implement these policies. Similarly, athletes themselves will be more likely to feel confident that they can change their behavior related to MRSA prevention with the support and continuous encouragement from coaches and athletic trainers. This may be particularly important for male athletes. Making infection control procedures and inspection of skin trauma normal, mandated procedure removes the fear of appearing weak or dependent (Davies, 2000).

Together these components are used to predict health behavior. They are all interrelated and often, the strength or weakness of one component directly influences another. Health behavior is often based on the perception of a threat, such as MRSA infection. When prevention guidelines for the threat are introduced they must be perceived as positive rather than restrictive (Brinsley, 2005). Past research has demonstrated that effective prevention efforts require behavioral change, yet there are barriers to implementation of these changes and adoption of prevention policies. This study 
examines the changes that have been implemented because of the emergence of MRSA which illustrates the extent as to it is seen as a threat, and further examines the factors that may have led to that perception.

One limitation to the HBM is that the model does not include many other important factors that influence compliance to health behavior change. Some of these factors are cultural, socioeconomic, political, environmental and previous experiences (Sharma, 2011; Thomas 1995). However it provides a strong basis for the relationship between the problem of MRSA infections in college athletic programs and its impact on the adoption of guidelines and prevention policies. The next section will summarize limitations to this study.

\section{Limitations}

The limitations of all self-reported data apply because this is a survey. Convenience sampling which was used in this study likely resulted in self-selection bias. Because participants chose for themselves whether or not to become a participant, there may be an overrepresentation of participants with strong opinions about MRSA or prevention. Similarly, those with little knowledge of the topics may have chosen not to participate perhaps leading to a biased representation of the topic population (Lavrakas, 2012). Because a survey collects responses at a particular point in time, the results are limited to the responses only for that time period. Recall bias can occur, meaning that questions may not be answerable because respondents failed to remember the answer accurately or completely. Because of this they may elaborate, or over or under-estimate their answers (mediLexicon, 2013). The investigator in unable to control the degree of honesty and clarity respondents provide when answering survey questions. In addition, 
when using descriptive statistics, the results are limited to the clinicians that responded to the survey.

A comprehensive evaluation of SSTI poses a number of challenges as the motivation for individual colleges or universities participation may be limited. Accurate reporting of SSTI rates may be viewed as threatening to the athletic program and therefore negatively influence a clinician's willingness to complete the survey or to be completely honest. Another limitation concerns information loss due to computer software problems. In the study, respondents were asked to report their gender. For an unknown reason, responses to this demographic item were not recorded for subjects; therefore the variable was not included.

A final limitation is the low response rate. Low response rates can result in selection bias and threaten the likelihood of an accurate representation of the population being studied, weakening the validity of the study (Sivo, Saunders, Chang, \& Jiang, 2006). A review on email survey response rates (Sheehan, 2001) looked at response rates as well as influences on response rates since 1986 . The author concluded that response rates to email surveys have declined for several reasons including a decline in the novelty from the time when email surveys first began, threat of computer viruses and increasing number of requests to complete surveys. The author identified multiple reminders as an important variable to increase rates. The population in this study was sent four reminders and still yielded a low rate. The investigator chose to begin in summer months to avoid the sports seasons when athletic trainers are busiest. However it is plausible that many did not check email over the summer or were not keeping regular office hours. One attempt was made after the beginning of most institutions' fall semesters, however the 
athletic trainers may have busy with the start of the new school year and fall sports. In addition, athletic trainers with little knowledge of their policies and prevention practices may have avoided the survey,

Sivo, Saunders, Chang and Jiang (2006) examined response rates and prudent reporting suggestions when rates are low. They found reports of surveys with response

rates as low as $7 \%$. They suggested providing comparison of demographic information of the reporting population and the calculation of confidence intervals when response rates are lower than anticipated. These suggestions were implemented and are described in the following chapter.

\section{Summary}

Surveys provide quantitative description of the trends in a given population by assessing a sample of that population. The current study sought to determine the utilization of prevention strategies, measure the occurrence, and to examine the impact of SSTIs on the prevention strategies in college athletics. Because this study sought to collect baseline data survey methodology was appropriate for this study. The instrument employed information collected from the literature review on prevention and management strategies, including the recommendations published by NATA and the CDC to prevent MRSA outbreaks.

Validity and reliability were tested using a panel of athletic training professionals and pre-posttest of the instrument, and modifications were made on the instrument based on their feedback. The population surveyed was athletic trainers obtained from the NATA database. One athletic trainer per institution was surveyed, those that identified themselves as department heads, to prevent duplication. The population was surveyed 
electronically using Dillman's (2007) internet survey guidelines and produced a sample of 78 respondents. The survey consisted of 30 questions, including demographic information and questions that addressed each of the research questions. Data collected were analyzed with SPSS software using descriptive statistics. Percentages and proportions were the statistical techniques used for the majority of the data, with confidence intervals to provide a margin of error.

The focus of the Health Belief Model is upon what factors can predict compliance with preventative health care practices. The model was therefore chosen as the framework to describe the impact of MRSA on the actions of healthcare providers and athletes. The six components the HBM uses to examine compliance are perceived susceptibility, perceives severity, perceived benefits, barriers to preventative action, cues to action and self-efficacy.

Limitations of this study include the use of a convenience sample, that the data were self-reported, the possibility of recall bias, and the low response rate. The next chapter details the results of the research collected in Chapter 3. 


\section{CHAPTER IV}

\section{RESULTS}

The focus of this study was to establish baseline data on the perceptions of clinicians of the impact of SSTIs on the college athletic population and to determine their prevention strategies. The study examined self-reported professional practices and attitudes of athletic trainers in managing skin and soft tissue infection which have been determined to be caused primarily by MRSA. The participants in this study were members of the National Athletic Trainers' Association (NATA) employed at colleges and universities in the NCAA. Data were obtained from an online survey conducted in the summer and fall of 2012. Data were collected between July $23^{\text {rd }}, 2012$ and October $3^{\text {rd }}, 2012$.

The results will be presented in seven sections. First, descriptive statistics will be presented on several variables collected in the study. The information will include description of the sampling procedures and the response rate. The remaining six will present the results of analyses that addressed the research questions posed by the author of the study.

\section{Background of Sample}

Following the procedure outlined in Chapter 3, online questionnaires were sent to a total of 497 athletic trainers reported by NATA to be department heads. The anticipated 
population for this study was to consist of athletic trainers who were members of the National Athletic Trainers' Association (NATA) and were employed by colleges and universities. Because the information gathered was to reflect policies and procedures of individual clinics, department heads were surveyed to avoid duplication of responses.

The athletic trainers in this study completed the survey entitled The Impact of Skin and Soft Tissue Infections on College Athletic Programs and Prevention Policies Survey. The survey was a Web-based instrument comprised of demographic items and questions measuring the experiences, practices, and attitudes of athletic trainers in dealing with SSTI. The instrument used in this study was developed by the author specifically for this study and had 30 items.

The researcher obtained a list of the e-mail addresses of members of the National Athletic Trainers' Association (NATA) that described themselves as department heads. The list had 497 addresses. The survey was sent to all 497 addresses provided with a request to complete the survey and detailed instructions on July $23^{\text {rd }}, 2012$. Twelve addresses came back as undeliverable. The survey was sent again on July $30^{\text {th }}$, August $6^{\text {th }}$ and August $13^{\text {th }}$. In a final attempt to get responses, the survey was sent one last time on October $3^{\text {rd }}, 2012$. For the majority of analyses, the number of respondents was 78 ; this constitutes a total response rate of $15.68 \%$.

The survey took subjects approximately 10 minutes to complete. Prior to reading the questionnaire items, participants read a preamble explaining the voluntary nature of the study and the right of the participants to choose not to answer every question. Those persons who read the preamble and continued to participate in the study by answering questions were assumed to have given informed consent to participate. The preamble to 
the survey was approved the Institutional Review Board (IRB) of the University of Louisville (Appendix A).

\section{Examination of Demographic Data}

Members of the National Athletic Trainers' Association (NATA) were classified by 10 geographic areas. The first question in the survey asked responders to identify the NATA district in which they were currently employed. Table 2 indicates that all districts were represented, with the most respondents (about $62 \%$ ) coming from districts $3,4,5$ or

9. States in these regions were in the Midwest and eastern parts of the United States. The districts with the least respondents $(7,8,9$ and 10$)$ were the far west $(6.4 \%)$, southwest (5.1\%), Rocky Mountain (5.1\%) and the northwest (1.3\%), representing states located in the western part of the country. The column on the far right reflects the percentage of NATA members in the districts. Three of the same districts (3,4 and 9) that have the greatest percentage of NATA members are also where the greatest number of participants for this study reported that they are employed. Similarly, the NATA districts with the least percentage of members $(7,8$, and 10$)$ also produced the least percentage of respondents. 


\section{Table 2}

NATA District of Respondents

\begin{tabular}{lcccc} 
District & States & $n$ & $\%$ & $\%$ NATA members \\
\hline 1 Eastern, D1 & CT, ME, MA, NH, RI, VT & 9 & 11.5 & 7 \\
\hline 2 Eastern, D2 & DE, NJ, NY, PA & 7 & 9.0 & 15 \\
\hline 3 Mid-Atlantic & DC, MD, NC, SC, VA, WV & 14 & 17.9 & 12 \\
\hline 4 Great Lakes & IL, IN, MI, MN, OH, WI & 10 & 12.8 & 21 \\
\hline 5 Mid-America & IA, KS, MO, NE, ND, OK, SD & 11 & 14.1 & 8 \\
\hline 6 Southwest & AR, TX & 4 & 5.1 & 6 \\
\hline 7 Rocky Mountain & AZ, CO, NM, UT, WY & 4 & 5.1 & 5 \\
\hline 8 Far West & CA, HI, NV & 5 & 6.4 & 8 \\
\hline 9 Southeast & AL, FL, GA, KY, LA, MS, TN & 13 & 16.7 & 14 \\
\hline 10 Northwest & AK, ID, MT, OR, WA & 1 & 1.3 & 4 \\
\hline Total & & 78 & 100.0 & 100.0
\end{tabular}

Table 3 denotes the number of respondents by National Collegiate Athletic Association (NCAA) division. About half of the respondents were represented in Division I, with the remainder split between Divisions II and III.

\section{Table 3}

NCAA Divisions of Respondents

\begin{tabular}{|c|c|c|}
\hline Division & $n$ & $\%$ \\
\hline Division I & 41 & 52.6 \\
\hline Division II & 20 & 25.6 \\
\hline Division III & 16 & 20.5 \\
\hline Valid cases & 77 & 98.7 \\
\hline
\end{tabular}




\begin{tabular}{|c|c|c|}
\hline Missing & 1 & 1.3 \\
\hline Total & 78 & \\
\hline
\end{tabular}

Table 4 provides the years of experience of the respondents and their age. Ages ranged from 25 to 67 , while years of experience range from 3 to 40 years with an average of 21.3 years.

Table 4

Descriptive Statistics on Age and Years as an Athletic Trainer

\begin{tabular}{lccccc} 
Variable & Minimum & Maximum & $M$ & Interval & $S D$ \\
\hline Age & 25.0 & 67.0 & 46.7 & $44.3--49.1$ & 10.8 \\
\hline $\begin{array}{l}\text { Years of } \\
\text { experience }\end{array}$ & 3.0 & 40.0 & 21.3 & $19.1-23.7$ & 10.2 \\
\hline
\end{tabular}

Table 5 shows that the majority $(84.6 \%)$ of respondents reported a minimum education level of a Master's degree. Doctorates were held by $29.5 \%$ of respondents, and $12.8 \%$ held bachelor's degrees.

\section{Table 5}

Education Level of Respondents

\begin{tabular}{ccc} 
Education Level & $n$ & $\%$ \\
\hline Bachelor's & 10 & 12.8 \\
\hline Master's & 43 & 55.1 \\
\hline Doctorate & 23 & 29.5 \\
\hline Other & 2 & 2.6 \\
\hline Total & 78 & 100.0
\end{tabular}


NATA was asked to provide addresses of all members that identified themselves as department chair, director, or other titles that indicated they were the head of their department. The purpose of surveying this sub-population of members was to avoid duplication of policy and procedure information for each institution. The majority of responders reported titles that included director or department head (see Table 6). The remaining responders reported their titles as faculty, clinical or rehab coordinators, assistant directors, athletic trainers, and two did not respond. Some directors contacted the investigator and explained that they had forwarded the survey to other athletic trainers in the department that did not have a director or department head title because they have more knowledge of the information requested in the survey.

\section{Table 6}

Job Titles of Respondents

\begin{tabular}{lcc} 
Job Title & $n$ & $\%$ \\
\hline Director/Department Head & 55 & 70.5 \\
\hline Clinic/Rehab Coordinator & 8 & 10.3 \\
\hline Faculty & 5 & 6.4 \\
\hline Assistant Director & 2 & 2.6 \\
\hline Athletic trainers & 6 & 7.7 \\
\hline No Response & 2 & 2.6 \\
\hline Total & & \\
\cline { 2 - 3 } & 78 & 100.00
\end{tabular}

Table 7 is respondents by institutional type. There was almost an even split between public and private institutions. 


\section{Table 7}

Institution Type Where Respondents Were Employed

\begin{tabular}{ccc} 
Institution Type & $n$ & $\%$ \\
\hline Private & 40 & 51.3 \\
\hline Public & 38 & 48.7 \\
\hline Total & 78 & 100.0
\end{tabular}

Table 8 lists the sports served by the respondents. The most reported sport was basketball (51.28\%), but a large number also reported serving men's football (38.46\%), volleyball (37.18\%), soccer (41.03\%), cross country (38.46\%), softball (38.46\%), and baseball (38.46\%). Sports least served included women's field hockey $(12.82 \%)$, lacrosse $(12.82 \%)$, wrestling $(10.26 \%)$, and gymnastics $(3.85 \%)$. 
Table 8

Sports That Respondents Served

\begin{tabular}{lccc}
$\quad \begin{array}{c}\text { Sports receiving } \\
\text { medical services }\end{array}$ & $\begin{array}{c}\text { Percentage of } \\
\text { cases } \\
(n=78\end{array}$ & $\begin{array}{c}\text { Proportion } \\
\text { of cases } \\
(n=78)\end{array}$ & $95 \%$ confidence interval \\
\hline Men's Football & 38.46 & .3846 & $0.277-0.493$ \\
\hline Gymnastics & 3.85 & .0385 & $0.000-0.081$ \\
\hline Volleyball & 37.18 & .3718 & $0.265-0.479$ \\
\hline Soccer & 41.03 & .4103 & $0.301-0.519$ \\
\hline Tennis & 39.74 & .3974 & $0.289-0.506$ \\
\hline Lacrosse & & & \\
\hline Basketball & 12.82 & .1282 & $0.054-0.202$ \\
\hline Track \& Field & 51.28 & .5128 & $0.402-0.624$ \\
\hline Cross Country & 34.62 & .3462 & $0.241-0.452$ \\
\hline Softball & 38.46 & .3846 & $0.277-0.493$ \\
\hline Baseball & 38.46 & .3846 & $0.277-0.493$ \\
\hline Hockey \& Rowing/Crew & & & \\
\hline Swimming \& Diving & 38.46 & .3846 & $0.277-0.493$ \\
\hline Wrestling & 15.38 & .1538 & $0.074-0.234$ \\
\hline Women Field Hockey & 20.51 & .2051 & $0.116--0.295$ \\
\hline Other & 10.26 & .1026 & $0.035--0.170$ \\
\hline & 12.82 & .1282 & $0.054-0.479$ \\
\hline 37.18 & .3718 & $0.265-0.479$ \\
\hline
\end{tabular}

\section{Results for Research Question 1}

Research Question 1 dealt with the extent that SSTIs were recognized as being present in college athletics. Table 9 shows that almost all of the respondents believed MRSA to be of national concern. Almost half thought MRSA is a concern both locally and in their own setting, and very few saw MRSA as not being a concern. 
Table 9

Degree of Concern About MRSA

\begin{tabular}{lcccc} 
& $\begin{array}{l}\text { Percentage of } \\
\text { cases }(n=78)\end{array}$ & \multicolumn{2}{c}{$\begin{array}{l}\text { Proportion of } \\
\text { cases }(n=78)\end{array}$} \\
\cline { 2 - 6 } & Yes & Yes & $\begin{array}{r}\text { No } \\
\begin{array}{l}95 \% \text { confidence interval } \\
\text { for a selection of Yes }\end{array}\end{array}$ \\
\hline $\begin{array}{l}\text { MRSA is a concern } \\
\text { nationally }\end{array}$ & 96.15 & .9615 & .0385 & $0.890-0.992$ \\
\hline $\begin{array}{l}\text { MRSA is a concern } \\
\text { locally }\end{array}$ & 44.87 & .4487 & .5513 & $0.338-0.559$ \\
\hline $\begin{array}{l}\text { MRSA is a concern } \\
\text { in my own setting }\end{array}$ & 47.44 & .4744 & .5256 & $0.364-0.585$ \\
\hline $\begin{array}{l}\text { MRSA is not a } \\
\text { concern }\end{array}$ & 2.56 & .0256 & .9744 & $0.000--0.061$ \\
\hline
\end{tabular}

Most respondents, almost $80 \%$, reported that they had dealt with confirmed cases of MRSA in their settings, as shown in Table 10 below.

\section{Table 10}

Proportion of Respondents' Dealing with MRSA

\begin{tabular}{|c|c|c|}
\hline $\begin{array}{l}\text { Percentage } \\
\text { of cases ( } n \\
\quad=78) \\
\end{array}$ & $\begin{array}{l}\text { Proportion of cases } \\
\qquad(n=78)\end{array}$ & \\
\hline Yes & $\begin{array}{cc}\text { Yes } & \text { No } \\
& \text { Or do not } \\
\text { know }\end{array}$ & $\begin{array}{c}95 \% \text { confidence interval for } \\
\text { a selection of } Y e s\end{array}$ \\
\hline
\end{tabular}

\begin{tabular}{lllll}
\hline $\begin{array}{l}\text { Dealt with confirmed } \\
\text { case(s) of MRSA }\end{array}$ & 79.50 & .7950 & 20.50 & $0.705--0.884$ \\
\hline
\end{tabular}




\section{Results for Research Questions 2 and 3}

Research Questions 2 and 3 dealt with: (a) policies in college athletics to recognize prevent and manage SSTIs; and (b) variations in standards of practice in SSTI prevention.

Table 11 indicates that most athletic trainers' settings require a definitive diagnosis for management of MRSA (51.3\%). A large percentage also reported assuming all lesions are MRSA (38.5\%).

\section{Table 11}

Management of SSTIs In Setting of Respondent

\begin{tabular}{lrr} 
& $n$ & $\%$ \\
\hline Assume all lesions are MRSA & 30 & 38.5 \\
\hline Do not know & 1 & 1.3 \\
\hline Other & 7 & 9.0 \\
\hline Require definitive diagnosis & 40 & 51.3 \\
\hline Total & 78 & 100.0
\end{tabular}

Of the respondents, $50.1 \%$ reported at least one hospitalization of an athlete during the last five years due to MRSA. One respondent reported 15 cases in the last 5 years and $15.4 \%$ of respondents reported 3 or more. In the last 5 years the respondents report a total of 91 total hospitalizations due to MRSA (see Table 12). A large number of respondents (44.9\%) also reported that they had not experienced any hospitalizations due to MRSA in the last five years. 


\section{Table 12}

Number of Cases of Hospitalization Due To MRSA

Number of

$n$

$\%$

Hospitalizations

\begin{tabular}{cccc} 
& 15.00 & 1 & 1.3 \\
\cline { 2 - 4 } & 5.00 & 7 & 9.0 \\
\hline 4.00 & 1 & 1.3 \\
\hline 3.00 & 3 & 3.8 \\
\hline 2.00 & 8 & 10.3 \\
\cline { 2 - 4 } & 1.00 & 19 & 24.4 \\
\cline { 2 - 4 } & .00 & 35 & 44.9 \\
\hline & Valid cases & 74 & 94.9 \\
\hline & Missing & 4 & 5.1 \\
\hline Total & & 78 & 100.0
\end{tabular}

Note. For number of hospitalizations: $M=1.32, S D=2.23$.

95\% confidence interval: $0.81-1.84$

The majority of respondents $(65.4 \%)$ diagnose SSTIs with an outside health provider and $43.6 \%$ diagnose in their own setting. A smaller percentage $(12.8 \%)$ reported that SSTIs were diagnosed by the patients' own healthcare provider. Of the respondents that replied 'other', six stated how they managed SSTIs. Two stated they used team physicians, which could also be interpreted as managing in your own setting. Two others stated they treated all wounds as MRSA until the culture came back, and then treated them accordingly afterwards. Of the last two, one stated they had them cultured at the student health center, and the other stated they treat SSTIs, and if they begin to look infected they are sent to a physician. 
Table 13

Proportion of Cases of SSTI Diagnosed in Different Ways

\begin{tabular}{lccc} 
& $\begin{array}{c}\text { Percentage of } \\
\text { cases }(n=78)\end{array}$ & $\begin{array}{c}\text { Proportion of } \\
\text { cases }(n=78)\end{array}$ & $\begin{array}{c}95 \% \text { confidence } \\
\text { interval }\end{array}$ \\
\hline $\begin{array}{l}\text { Diagnosed in your own } \\
\text { setting }\end{array}$ & 43.60 & .4360 & $.326--.546$ \\
\hline $\begin{array}{l}\text { Diagnosed by outside } \\
\text { healthcare provider }\end{array}$ & 65.40 & .6540 & $.548--.759$ \\
\hline $\begin{array}{l}\text { Diagnosed by patients' own } \\
\text { healthcare provider }\end{array}$ & 12.80 & .1280 & $.054--.202$ \\
\hline Do not know & 00.00 & .0000 & ----- \\
\hline Other & 8.97 & .0897 & $.037--.177$ \\
\hline
\end{tabular}

Table 14 shows that most respondents reported that they did have a treatment and prevention policy in their settings ( $82 \%)$. The elements included for prevention in their standards of practice are listed below in Table 15. Those that were included most are listed in Table 16. The most common elements of practice reported were to clean and cover any open wounds ( $82 \%$ ), daily cleansing of all equipment $(77 \%)$, all wounds much be evaluated by a trainer/doctor (70\%), and encouraging frequent hand washing (74\%). Least reported were culture staff on a regular basis (4\%), reminder letters (4\%), culture athletes on a regular basis $(8 \%)$ and reminder email messages (12\%). The top five changes in Table 16 reflect the most common elements of practice in Table 15; all wounds evaluated by a trainer/doctor (56\%), clean and cover any open wounds (54\%), daily cleansing of equipment (50\%) and encourage frequent hand washing (49\%) were all included in the top five changes implemented in policy/ practice since the emergence of MRSA. 


\section{Table 14}

Proportion of Respondents Reporting Treatment/Prevention Policy for SSTIs

\begin{tabular}{lcccc} 
& $\begin{array}{c}\text { Percentage of } \\
\text { cases }(n=78)\end{array}$ & $\begin{array}{r}\text { Proportion of } \\
\text { cases } \\
(n=78)\end{array}$ \\
\cline { 2 - 5 } & Yes & Yes & $\begin{array}{c}\text { No } \\
\text { Or do } \\
\text { not know }\end{array}$ & $\begin{array}{c}95 \% \text { confidence } \\
\text { interval for a selection } \\
\text { of Yes }\end{array}$ \\
\hline $\begin{array}{l}\text { Have a } \\
\text { Treatment/Prevention } \\
\text { Policy }\end{array}$ & 82.10 & .8210 & .1790 & $0.735-0.906$ \\
\hline
\end{tabular}




\section{Table 15}

Elements Included in Standard of Practice Regarding SSTIS

\begin{tabular}{|c|c|c|c|}
\hline & $\begin{array}{c}\text { Percentage of } \\
\text { cases } \\
(n=78)\end{array}$ & $\begin{array}{c}\text { Proportion of } \\
\text { cases } \\
(n=78) \\
\end{array}$ & $\begin{array}{l}95 \% \text { confidence } \\
\text { interval }\end{array}$ \\
\hline Clean \& cover open wounds & 82.05 & .8205 & $0.735--0.906$ \\
\hline $\begin{array}{c}\text { Not allow participation if wound } \\
\text { cannot be adequately covered }\end{array}$ & 64.10 & .6410 & $0.535-0.747$ \\
\hline $\begin{array}{l}\text { Culture athletes on a regular basis } \\
\text { for carriage }\end{array}$ & 7.69 & .0769 & $0.676--0.863$ \\
\hline $\begin{array}{l}\text { Culture staff on a regular basis } \\
\text { for carriage }\end{array}$ & 3.85 & .0385 & $0.000-0.081$ \\
\hline $\begin{array}{l}\text { Treat anyone with positive } \\
\text { carriage }\end{array}$ & 39.74 & .3974 & $0.289--0.506$ \\
\hline Use of disposable towels & 26.92 & .2692 & $0.171--0.368$ \\
\hline Daily cleansing of all equipment & 76.92 & .7692 & $0.676--0.863$ \\
\hline $\begin{array}{l}\text { Daily cleansing of all athletic } \\
\text { surfaces }\end{array}$ & 53.85 & .5385 & $0.428--0.649$ \\
\hline Reminder email messages & 11.54 & .1154 & $0.044--0.186$ \\
\hline Reminder letters & 3.85 & .0385 & $0.000--0.081$ \\
\hline $\begin{array}{l}\text { Annual or regular athlete/staff } \\
\text { education sessions on risks and } \\
\text { prevention }\end{array}$ & 53.85 & .5385 & $0.428--0.649$ \\
\hline $\begin{array}{l}\text { All wounds must be evaluated by } \\
\text { trainer/doctor }\end{array}$ & 70.51 & .7051 & $0.604--0.806$ \\
\hline $\begin{array}{l}\text { Policy prohibiting sharing of } \\
\text { personal items such as soap } \\
\text { and razors }\end{array}$ & 55.13 & .5513 & $0.441--0.663$ \\
\hline $\begin{array}{l}\text { Culture all soft skin and tissue } \\
\text { infections }\end{array}$ & 26.92 & .2692 & $0.171--0.368$ \\
\hline $\begin{array}{l}\text { Posters and signs on high traffic } \\
\text { areas/ } \\
\text { shower and restroom areas }\end{array}$ & 58.97 & .5897 & $0.481 \quad--0.699$ \\
\hline Brochures & 21.79 & .2179 & $0.126--0.310$ \\
\hline $\begin{array}{l}\text { Encourage frequent hand } \\
\text { washing }\end{array}$ & 74.36 & .7436 & $0.647-0.840$ \\
\hline Other & 8.97 & .0897 & $0.026-0.153$ \\
\hline
\end{tabular}




\section{Table 16}

Top Five Changes Implemented to Address SSTIS

\begin{tabular}{lccc} 
& $\begin{array}{c}\text { Percentage of } \\
\text { cases } \\
(n=78)\end{array}$ & $\begin{array}{c}\text { Proportion of } \\
\text { cases } \\
(n=78)\end{array}$ & $\begin{array}{c}95 \% \text { confidence } \\
\text { interval }\end{array}$ \\
\hline $\begin{array}{l}\text { All wounds must be } \\
\text { evaluated by trainer/doctor }\end{array}$ & 56.41 & .5641 & $0.454-0.674$ \\
\hline $\begin{array}{l}\text { Clean and cover any open } \\
\text { wounds }\end{array}$ & 53.85 & .5385 & $0.428-0.949$ \\
\hline $\begin{array}{l}\text { Do not allow participation } \\
\text { if wound cannot be adequately } \\
\text { covered }\end{array}$ & 52.56 & .5256 & $0.415-0.636$ \\
\hline $\begin{array}{l}\text { Daily cleansing of all } \\
\text { equipment }\end{array}$ & 50.00 & & \\
\hline $\begin{array}{l}\text { Encourage frequent hand } \\
\text { washing }\end{array}$ & 48.72 & .5000 & $0.389-0.611$ \\
\hline
\end{tabular}

\section{Results for Research Question 4}

Research Question 4 dealt with significant variations in extent of incidence of SSTIs.

Tables 17 shows that $58.44 \%$ of respondents observed cases of SSTI that were severe enough to affect team performance, while $41.56 \%$ stated it did not, or they did not know. Table 18 indicates that $42 \%$ report a decrease in SSTIs since last year, while only $6.5 \%$ report an increase, and $26.32 \%$ reported there was no change in number of SSTIs. Team performance was defined for this question in the survey as "athletes unable to play or practice". 


\section{Table 17}

Proportion of Respondents Claiming SSTI Effects on Team Performance

\begin{tabular}{lcccc}
$\begin{array}{l}\text { SSTIs have a severe } \\
\text { effect on team }\end{array}$ & $\begin{array}{c}\text { Percentage of } \\
\text { cases }(n=77)\end{array}$ & \multicolumn{2}{c}{$\begin{array}{l}\text { Proportion of } \\
\text { cases }(n=77)\end{array}$} \\
\cline { 2 - 5 } $\begin{array}{l}\text { performance? } \\
\text { Yes }\end{array}$ & Yes & $\begin{array}{c}\text { No } \\
\text { Or do not } \\
\text { know }\end{array}$ & $\begin{array}{c}\text { 95\% confidence } \\
\text { interval for a selection } \\
\text { of Yes }\end{array}$ \\
\hline & 58.44 & .5844 & .4156 & $0.474--0.694$ \\
\hline
\end{tabular}

Table 18

Proportion of Respondents Opinions About Changes In Numbers of SSTIs

\begin{tabular}{lccc}
$\begin{array}{l}\text { Changes in numbers of } \\
\text { SSTIs }\end{array}$ & $\begin{array}{c}\text { Percentage of cases } \\
(n=78)\end{array}$ & $\begin{array}{c}\text { Proportion of cases } \\
(n=78)\end{array}$ & $\begin{array}{c}95 \% \text { confidence } \\
\text { interval }\end{array}$ \\
\hline $\begin{array}{l}\text { Decrease in SSTI } \\
\text { compared to last year }\end{array}$ & 42.11 & .4211 & $0.310-0.532$ \\
\hline SSTI same as last year & 26.32 & .2632 & $0.164-0.362$ \\
\hline $\begin{array}{l}\text { Increase in SSTI } \\
\text { compared to last year }\end{array}$ & 6.58 & .0658 & $0.010-0.122$ \\
\hline Do not know & 25.00 & .2500 & $0.153-0.347$ \\
\hline
\end{tabular}

\section{Results for Research Question 5}

Research Question 5 pertained to epidemiological differences in geographical location, gender of athletes, or individual sports that may be important in prevention program development. Sports that had incidence of SSTI are reported in Table 19. Most 
were in football (55.13\%) and soccer (50\%). Basketball and baseball (24.36\%) also had reported higher percentages of SSTIs, $30.77 \%$ and $24.36 \%$, respectively. Lower incidence was reported in lacrosse $(8.97 \%)$, cross country $(8.97 \%)$, tennis $(2.56 \%)$, and gymnastics $(3.85 \%)$.

\section{Table 19}

Sports That Had SSTIs in the Last Five Years

\begin{tabular}{lccc} 
Sports with SSTIs & $\begin{array}{c}\text { Percentage of Proportion of } \\
\text { cases } \\
(n=78)\end{array}$ & $\begin{array}{c}\text { cases } \\
(n=78)\end{array}$ & $95 \%$ confidence interval \\
\hline Men's football & 55.13 & .5513 & $0.441--0.662$ \\
\hline Gymnastics & 3.85 & .0385 & $0.000-0.081$ \\
\hline Volleyball & 19.23 & .1923 & $0.105-0.280$ \\
\hline Soccer & 50.00 & .5000 & $0.389--0.611$ \\
\hline Tennis & 2.56 & .0256 & $0.000--0.061$ \\
\hline Lacrosse & 8.97 & .0897 & $0.026--0.153$ \\
\hline Basketball & 30.77 & .3077 & $0.205-0.410$ \\
\hline Track \& Field & 12.82 & .1282 & $0.054-0.202$ \\
\hline Cross Country & 8.97 & .0897 & $0.026--0.153$ \\
\hline Softball & 12.82 & .1282 & $0.054--0.202$ \\
\hline Baseball & 24.36 & .2436 & $0.148--0.339$ \\
\hline Hockey & 10.26 & .1026 & $0.035--0.170$ \\
\hline Rowing/Crew & 11.54 & .1154 & $0.044--0.186$ \\
\hline Swimming \& Diving & 11.54 & .1154 & $0.044-0.186$ \\
\hline Do not know & 8.97 & .0897 & $0.026-0.153$ \\
\hline Other & 17.95 & .1795 & $0.094-0.265$ \\
\hline
\end{tabular}

To determine if SSTIs occurred more in males or females, respondents were asked to report what percentage of the SSTIs they treated occurred in male athletes. Table 20 indicates that the majority of respondents (33\%) reported that most of their cases ( 80 to $100 \%)$ occurred in male athletes. It further shows that half of respondents $(50 \%)$ reported that at least $60 \%$ of SSTIs occur in male athletes. Fewer respondents reported that SSTIs occurred in lower percentages of male athletes; only $2.56 \%$ reported that 20 to 
$40 \%$ of their SSTIs occurred in male athletes, and $30.76 \%$ reported their SSTIs occurred in 0 to $20 \%$ male athletes.

\section{Table 20}

Proportion of Respondents Reporting SSTIs in Male Athletes

\begin{tabular}{lccc}
$\begin{array}{l}\text { Percentages of Male } \\
\text { Athletes }\end{array}$ & $\begin{array}{c}\text { Percentage of cases } \\
(n=78)\end{array}$ & $\begin{array}{c}\text { Proportion of cases } \\
(n=78)\end{array}$ & $\begin{array}{c}95 \% \text { confidence } \\
\text { interval }\end{array}$ \\
\hline $0-20 \%$ & 30.76 & .3076 & $0.205--0.410$ \\
\hline $20-40 \%$ & 2.56 & .0256 & $0.000-0.061$ \\
\hline $40-60 \%$ & 16.67 & .1667 & $0.084--0.249$ \\
\hline $60-80 \%$ & 16.67 & .1667 & $0.084--0.249$ \\
\hline $80-100 \%$ & 33.33 & .3333 & $0.229--0.438$
\end{tabular}

Table 21 shows the cross-tabulation between two variables: NATA region and confirmed cases of MRSA. NATA region was based on the 10 NATA districts. Those in the East and Great Lakes areas (Districts I through IV) were grouped together in one group. Those in the Southeast and West areas (Districts V through X) were grouped together in a second group. This grouping roughly divides the states between northeast and southwest to determine if there were any differences in number of confirmed cases of MRSA in either half of the country.

A chi-square test of association revealed there was no relationship between the two variables, $\chi(1)=0.35, p=.557$. The percentages of cases in the regions were not significantly different. 


\section{Table 21}

Cross-Tabulation of NATA Region by Confirmed Cases MRSA

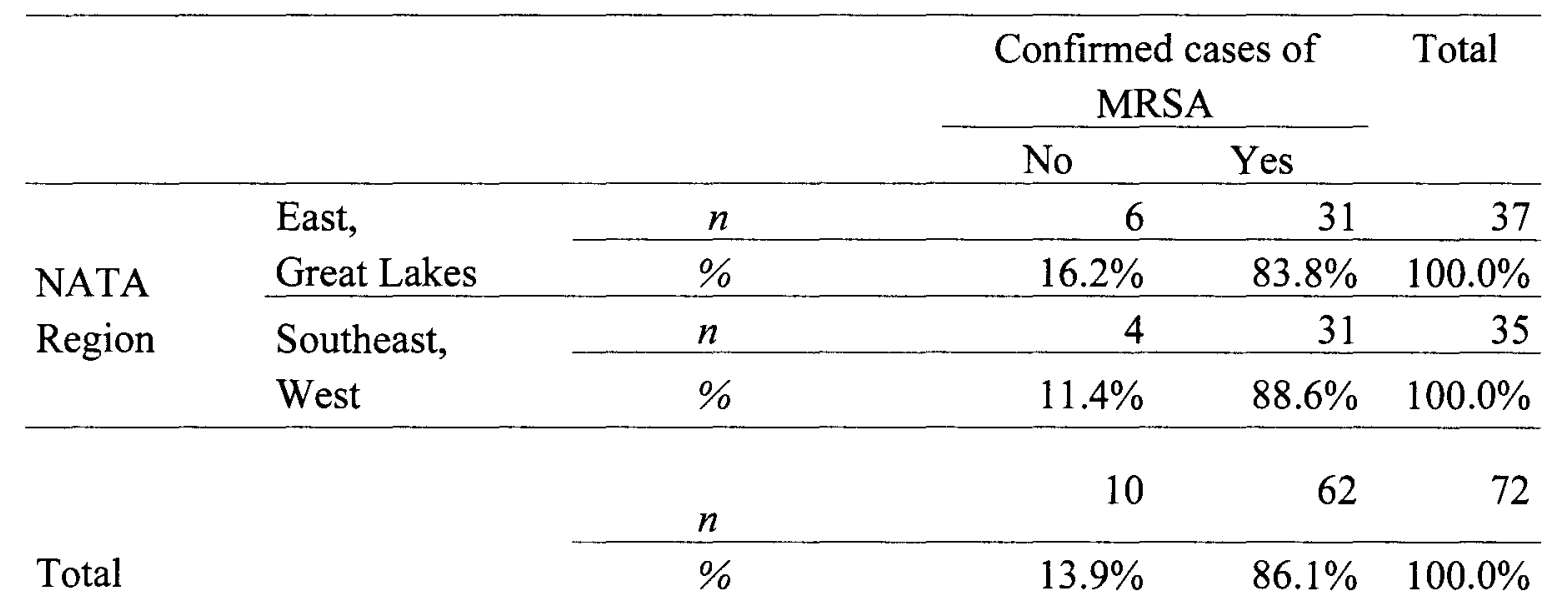

Table 22 shows the cross-tabulation between two variables: NATA region and difference in incidence of SSTI. A chi-square test of association revealed there was no relationship between the two variables, $\chi(2)=5.48, p=.06$. The percentages of cases in the regions were not significantly different. Similar to Table 21 , this was calculated to determine if either half of the country experienced changes in incidence of SSTI differently. This grouping allowed for an almost even split of respondents; 40 total respondents in districts 1 through 4, and 38 total respondents in districts 6 through 10 . 


\section{Table 22}

Cross-Tabulation of NATA Region by Difference in Incidence of SSTI

\begin{tabular}{|c|c|c|c|c|c|c|}
\hline & & & \multicolumn{3}{|c|}{$\begin{array}{c}\text { Difference in incidence of SSTI this year } \\
\text { compared to last year }\end{array}$} & \multirow[b]{2}{*}{ Total } \\
\hline & & & $\begin{array}{c}\text { Decrease in SSTIs } \\
\text { compared to last } \\
\text { year }\end{array}$ & $\begin{array}{l}\text { SSTIs same } \\
\text { as last year }\end{array}$ & $\begin{array}{c}\text { Increase in SSTIs } \\
\text { compared to last } \\
\text { year }\end{array}$ & \\
\hline \multirow{4}{*}{$\begin{array}{l}\text { NATA } \\
\text { Region }\end{array}$} & East, & $n$ & 14 & 10 & 5 & 29 \\
\hline & $\begin{array}{l}\text { Great } \\
\text { Lakes }\end{array}$ & $\%$ & $48.3 \%$ & $34.5 \%$ & $17.2 \%$ & $100.0 \%$ \\
\hline & Southeast, & $n$ & 18 & 10 & 0 & 28 \\
\hline & West & $\%$ & $64.3 \%$ & $35.7 \%$ & $0.0 \%$ & $100.0 \%$ \\
\hline \multirow[t]{2}{*}{ Total } & & $n$ & 32 & 20 & 5 & 57 \\
\hline & & $\%$ & $56.1 \%$ & $35.1 \%$ & $8.8 \%$ & $100.0 \%$ \\
\hline
\end{tabular}

\section{Results for Research Question 6}

Research Question 6 dealt with prevention policies and procedures related to SSTIs.

Table 23 indicates that over $85 \%$ of respondents were aware of the CDC recommendation for MRSA prevention; similarly Table 24 below indicates that almost $90 \%$ of respondents were aware of NATAs recommendations for prevention of MRSA. 


\section{Table 23}

Is Your Practice Aware of CDC Recommendations on MRSA Prevention?

\begin{tabular}{lcc} 
Aware of CDC? & $n$ & $\%$ \\
\hline Yes & 67 & 85.9 \\
\hline Do not know & 11 & 14.1 \\
\hline Total & 78 & 100.0
\end{tabular}

Note. $95 \%$ confidence interval for a selection of Yes: $\quad .782-.936$

\section{Table 24}

Is Your Practice Aware of NATA Recommendations on MRSA Prevention?

\begin{tabular}{ccc} 
Aware of NATA ? & $n$ & $\%$ \\
\hline No & 1 & 1.3 \\
\hline Yes & 70 & 89.7 \\
\hline Do not know & 7 & 9.0 \\
\hline & & \\
Total & 78 & 100.0
\end{tabular}

Note. $95 \%$ confidence interval for a selection of Yes: $\quad .830 \quad--.965$

Over $70 \%$ of respondents reported that their practice had not attempted to quantify increase in operating costs due to SSTI control (see Table 25). Financial indicators identified are below in Table 26 and identify increased attention to environmental disinfection as the most evaluated indicator of costs; only one respondent indicated new/refurbished equipment as a cost indicator. Table 27 shows that the majority of respondents (69.2\%) report that there are adequate financial and human resources in their setting to implement the recommendations to prevent SSTIs, while six respondents $(7.7 \%)$ indicated there were not adequate resources to implement recommendations to 
prevent SSTIs.

\section{Table 25}

Has Your Practice Quantified Increase in Operating Costs Due to SSTI Control?

\begin{tabular}{|c|c|c|}
\hline Quantified SSTI control costs? & $n$ & $\%$ \\
\hline No & 55 & 70.5 \\
\hline Yes & 10 & 12.8 \\
\hline Do not know & 12 & 15.4 \\
\hline Valid cases & 77 & 98.7 \\
\hline Missing & 1 & 1.3 \\
\hline Total & 78 & 100.0 \\
\hline
\end{tabular}

Note. $95 \%$ confidence interval for a selection of Yes: $\quad .054 \quad-\quad .202$

\section{Table 26}

Financial Indicators of Costs Due to SSTI Control

\begin{tabular}{lcc} 
& $n$ & $\%$ \\
\hline No & 67 & 85.9 \\
\hline $\begin{array}{l}\text { Increased attention to } \\
\text { environmental disinfection }\end{array}$ & 10 & 12.8 \\
\hline Additional new/refurbished equipment & 1 & 1.3 \\
\hline Total & 78 & 100.0
\end{tabular}

Note. Item was to be answered only by those who answered Yes to the survey item Has Your Practice Quantified Increase in Operating Costs Due to SSTI control?

$95 \%$ confidence interval for a selection of Increased Attention to

Environmental Disinfection: $\quad .054 \quad--\quad .202$ 


\section{Table 27}

There are adequate financial and human resources to prevent SSTIS.

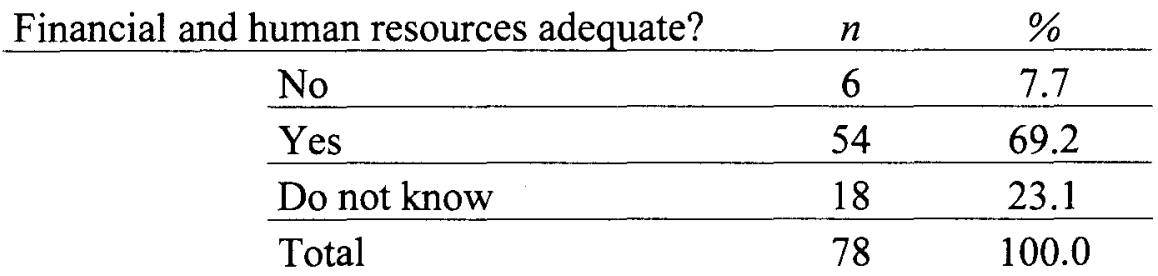

Note. $95 \%$ confidence interval for a selection of Yes: $\quad .590--.795$

In Table 28 most respondents (73.2\%) report that they have implemented changes in their setting since the emergence of MRSA; Table 29 lists the changes implemented. Over half of respondents indicated that they implemented the cleaning and covering of any open wounds $(53.8 \%)$, do not allow athletes to participate if a wounds cannot be adequately covered $(52.56 \%)$, daily cleansing of all equipment $(50 \%)$, and having all wounds evaluated by an athletic trainer or doctor $(56.4 \%)$. The addition of posters and signs in high traffic areas (47.4\%) and encouraging frequent hand washing (48.7\%) were also implemented by almost half of respondents. Approximately one third of respondents also implemented treating anyone with positive carriage (30.8\%) daily cleansing of all athletic surfaces (36\%), annual or regular staff and athlete education (39.7\%), and policy prohibiting sharing of personal items (37\%). Least implemented changes included reminder email messages $(12.8 \%)$, culturing athletes on a regular basis for carriage $(5 \%)$, culturing staff on a regular basis for carriage (3.8\%), and reminder letters $(2.5 \%)$. 


\section{Table 28}

Has Your Setting Implemented Changes In the Way

SSTIs Are Prevented and Treated Since MRSA emerged?

\begin{tabular}{lcc} 
Implemented changes? & $n$ & $\%$ \\
\hline No & 12 & 15.4 \\
\hline Yes & 57 & 73.1 \\
\hline Do not know & 8 & 10.3 \\
\hline Valid cases & 77 & 98.7 \\
\hline Missing & 1 & 1.3 \\
\hline & & \\
Total & 78 & 100.0
\end{tabular}

Note. $95 \%$ confidence interval for a selection of Yes: $.632 \quad--.829$ 
Table 29

Changes In the Way SSTIS Are Prevented and Treated Since MRSA Emerged

\begin{tabular}{|c|c|c|c|}
\hline Changes in dealing with SSTIs & $\begin{array}{c}\text { Percentage of } \\
\text { cases } \\
(n=78)\end{array}$ & $\begin{array}{c}\text { Proportion of } \\
\text { cases } \\
(n=78)\end{array}$ & $\begin{array}{l}95 \% \text { confidence } \\
\text { interval }\end{array}$ \\
\hline Clean $\&$ cover any open wounds & 53.85 & .5385 & $0.428-0.649$ \\
\hline $\begin{array}{l}\text { Do not allow participation if } \\
\text { wound } \\
\text { cannot be adequately covered }\end{array}$ & 52.56 & .5256 & $0.415--0.636$ \\
\hline $\begin{array}{l}\text { Culture athletes on a regular } \\
\text { basis for carriage }\end{array}$ & 5.13 & .0513 & $0.014-0.127$ \\
\hline $\begin{array}{l}\text { Culture staff on a regular basis } \\
\text { for carriage }\end{array}$ & 3.85 & .0385 & $0.000--0.081$ \\
\hline $\begin{array}{l}\text { Treat anyone with positive } \\
\text { carriage }\end{array}$ & 30.77 & .3077 & $0.205--0.410$ \\
\hline Use of disposable towels & 12.38 & .1538 & $0.074--0.234$ \\
\hline Daily cleansing of all equipment & 50.00 & .5000 & $0.389--0.611$ \\
\hline $\begin{array}{l}\text { Daily cleansing of all athletic } \\
\text { surfaces }\end{array}$ & 35.90 & .3590 & $0.253--0.465$ \\
\hline Reminder email messages & 12.82 & .1282 & $0.054-0.202$ \\
\hline Reminder letters & 2.56 & .0256 & $0.000--0.061$ \\
\hline $\begin{array}{l}\text { Annual/Reg athlete/staff } \\
\text { education }\end{array}$ & 39.74 & .3974 & $0.289--0.506$ \\
\hline $\begin{array}{l}\text { All wounds must be } \\
\text { evaluated by athletic } \\
\text { trainer/doctor }\end{array}$ & 56.41 & .5641 & $0.454-0.674$ \\
\hline $\begin{array}{l}\text { Policy prohibiting sharing of } \\
\text { personal items }\end{array}$ & 37.18 & .3718 & $0.265--0.479$ \\
\hline $\begin{array}{l}\text { Culture all soft skin and tissue } \\
\text { infections }\end{array}$ & 23.08 & .2308 & $0.137--0.324$ \\
\hline $\begin{array}{l}\text { Posters and signs on high traffic } \\
\text { areas }\end{array}$ & 47.44 & .4744 & $0.364-0.585$ \\
\hline Brochures & 17.95 & .1795 & $0.094--0.265$ \\
\hline $\begin{array}{l}\text { Encourage frequent hand } \\
\text { washing }\end{array}$ & 48.72 & .4872 & $0.376--0.598$ \\
\hline Other & 7.69 & .0769 & $0.018-0.136$ \\
\hline
\end{tabular}

The respondents were asked to list what they believe to be the top five most effective prevention strategies against SSTIs. The results are summarized in Table 30. The responses were very diverse and offered a wide variety of prevention strategies. 
Requiring that athletes not share personal items was a very close sixth to the five listed below (22\%). Also listed were proper and frequent laundering of clothing $(15 \%)$, aggressive wound management $(8 \%)$, change in policy $(5 \%)$, posters $(7 \%)$, early diagnosis (4\%), and holding out athletes with suspicious wounds (5\%). A few respondents listed random screening for carriage, aggressive antibiotic therapy, new facilities, change of habit and verbal reminders.

\section{Table 30}

Top Five Most Effective Prevention Strategies

\begin{tabular}{lccc} 
& $\begin{array}{c}\text { Percentage of } \\
\text { cases } \\
(n=74)\end{array}$ & $\begin{array}{c}\text { Proportion of } \\
\text { cases } \\
(n=74)\end{array}$ & $\begin{array}{c}95 \% \text { confidence } \\
\text { interval }\end{array}$ \\
\hline $\begin{array}{l}\text { Cleaning of surfaces, area, and/or } \\
\text { equipment }\end{array}$ & 52.70 & .5270 & $0.413-0.641$ \\
\hline $\begin{array}{l}\text { Education of athletes, Athletic } \\
\text { trainers, and/or coaches }\end{array}$ & 48.64 & .4864 & $0.373-0.600$ \\
\hline $\begin{array}{l}\text { Proper hygiene/ hand washing } \\
\text { All wounds evaluated }\end{array}$ & 37.83 & .3783 & $0.268-0.489$ \\
\hline Clean and cover all wounds & 25.67 & .2567 & $0.157-0.356$ \\
\hline
\end{tabular}

\section{Summary}

The results of the statistical analysis of the data collected from athletic trainers that responded to the survey entitled The Impact of Skin and Soft Tissue Infections on College Athletic Programs and Prevention Policies were presented. NATA members that identified themselves as department heads or directors only were surveyed to avoid duplication of data. The survey contained 30 questions and was administered electronically July through October of 2012. The survey yielded 78 total respondents of 497 surveys that were sent.

Demographic data were presented first with descriptive statistics to create a picture 
of the attributes of the population studied. All 10 NATA districts are included, with most respondents coming from the mid-Atlantic and southeast states, and were similar to the NATA membership distribution across districts. About half of the respondents were from NCAA Division I and the remainder are almost evenly split between Divisions II and III. There was an almost even number of public versus private institutions. The average age of respondents was 46.7 years with a range of 25 to 67 years of age, and years of experience averaged 21.3 years with a range of 3 to 40 years. The majority of respondents identified themselves as directors or department heads (over 70\%). The majority had master's degrees (55\%) or doctorates (29\%), consistent with department head's.

Respondents served a variety of sports, but most heavily represented were men's football, volleyball, soccer, tennis, basketball, track and field, cross country, softball, and baseball. Over half of respondents had a minimum of a Master's Degree and the majority was directors or department heads.

The first research question was: To what extent are SSTIs recognized as being present in college athletics? Results revealed that although the overwhelming majority saw MRSA, recognized as the primary cause of SSTIs in athletics, as a national concern, only $44.87 \%$ saw it to be a concern locally, and $47.44 \%$ saw it as a concern in their own settings. However $79.5 \%$ of respondents stated that they had dealt with MRSA and $50.1 \%$ reported cases that required hospitalization. The results indicate that while they do see this as an important concern nationally they appear confident they are managing it well in their clinics.

Research question 2 was: What policies exist in college athletics to recognize, 
prevent, and manage SSTIs? Research question 3 also addressed management of SSTI's. It was: Are there significant variations in standards of practice in SSTI prevention? Respondents were asked how they managed SSTIs in their settings; $38.5 \%$ stated they assumed all lesions to be MRSA, and 51.3\% required a definitive diagnosis. Of those that required a definitive diagnosis $43.6 \%$ said they diagnosed in their own setting, $12.8 \%$ relied on the athletes own healthcare provider, and $65.4 \%$ used outside healthcare providers.

Most respondents ( $82.1 \%$ ) reported they had a treatment and prevention policy in place for SSTIs. The elements most implemented in their standards of practice included cleaning and covering open wounds (82.01\%), daily cleansing of all equipment $(76.92 \%)$, encouraging frequent hand washing $(74.36 \%)$, having all wounds evaluated by a doctor or athletic trainer $(70.51 \%)$, and not allowing participation if a wound cannot be adequately covered $(64.10 \%)$. The results indicated that most trainers require a definitive diagnosis from an outside healthcare provider, and that the majority have a treatment and prevention plan in place that includes the above mentioned elements.

Research question number 4 was: Are there significant variations in the extent of incidence in SSTIs? When asked if there had been any instances of SSTI severe enough to impact team performance, such as athletes unable to practice or play, $57.7 \%$ answered that they had. When asked if there had been any change in instance of SSTI since the previous year, $41 \%$ reported a decrease, $25.6 \%$ stated they were the same, and only $6.4 \%$ reported an increase.

Research question number 5 was: Are there epidemiological differences in gender of athletes or individual sports that may be important in prevention program development? 
Sports identified by respondents as having been affected by SSTI in the last five years most were men's football (55.13\%), soccer (50\%), basketball (30\%), and baseball (24.36\%). The respondents identified males as suffering most SSTIs, with $66.7 \%$ stating at least $40 \%$ of their SSTIs occurred in males; $33.3 \%$ said 80 to $100 \%$ of their SSTIs occurred in males. These results support the literature review of this study that conclude that a large amount of SSTIs occur in participants contact sports (Begier et al., 2004; Kazakova et al., 2005 Rihn et al., 2005) and in male athletes (Elixhauser \& Steiner, 2007; Ellis, 2007; Kahanov, et al., and 2011).

Cross-tabulation examining if there was a relationship between NATA regions (districts I through IV versus district $\mathrm{V}$ through $\mathrm{X}$ ) and confirmed cases reported of MRSA were not significantly different. No significant difference was found between the two NATA regions and difference in incidence in SSTI (if SSTI had increased, decreased or had stayed the same since the previous year). It appears that is this sample epidemiological differences do not exist for incidence of SSTIs.

Research question 6 asked: What has been the impact on prevention policies and procedures secondary to SSTIs? Most respondents reported that their practice had not quantified increase in operating costs due to SSTI control (70.5\%). Of the $12.8 \%$ that stated they did, all stated increased to environmental disinfection as the financial indicators, and $1.3 \%$ also identified additional new or refurbished equipment. Most (69.2\%) stated they had adequate financial and human resources to prevent SSTIs in their settings, and $73.1 \%$ stated that changes were implemented since the emergence of MRSA. The changes identified most were evaluation of all wounds by a doctor or personal trainer (56.41\%), cleaning and covering all open wounds (53.85\%), not allowing 
participation if a wound cannot be adequately covered (52.56\%), daily cleaning of all equipment $(50 \%)$, and encouraging frequent hand washing (48.71\%). While responses were varied, the top five strategies believed to be most effective by the respondents were cleaning surfaces, areas and equipment (52.70\%), education of athletes, athletic trainers and coaches (48.64\%), proper hygiene and hand washing (37.83\%), having all wounds evaluated (25.67\%), and cleaning and covering all wounds (22.97\%). The emergence of MRSA has made an impact on the way SSTIs are handled in this population. It seems that most respondents in this sample feel that resources are appropriate for implemented changes and the changes are in line with CDC and NATA MRSA management guidelines (Centers for Disease Control and Prevention, 2010; National Athletic Trainers;' Association, 2010).

The next and final chapter will further summarize the findings reported in Chapter 4. Additionally there will be discussion about the findings in relation to the six research questions, and limitations and recommendations for future research in this area. 


\section{CHAPTER V}

\section{DISCUSSION}

\section{Introduction}

The primary purpose of this study was to provide an indication of the impact of SSTIs on college athletic programs' prevention policies. A clearer understanding of the prevalence of these infections in athletic settings as well the impact an infection can have can help healthcare providers, such as athletic trainers, to make more informed decisions and implement effective policy toward the prevention of these infections. In the previous chapters the researcher outlined the progression of this research study on the impact of SSTIs on the policies and prevention efforts in college athletics. The first chapter provided the history and impact of SSTIs, particularly MRSA in first clinical, and then community and athletic settings. The first chapter was followed by a literature review of the past research that has focused on outbreaks and their treatment and prevention efforts in clinical, community and finally in athletic programs in the college setting. Chapters 3 and 4 described the survey instrument, data analysis, and results. The final chapter includes a discussion a brief summary of the results and the interpretation of the findings for each research question. The chapter concludes with a discussion of the limitations of the study and suggestions for future research.

\section{Summary of Results}

The respondents included 78 athletic trainers representing each of the 10 NATA districts. Fewer respondents came from the western states; therefore results may not 
accurately represent those areas and it would not be prudent to compare geographical differences between eastern and western areas. Only one respondent was from the far east district; this means most of the states in that group are not represented in this study. Therefore, the researcher decided to compare results by grouping the districts into two divisions that roughly divided the country into northeast and southwest. About half of respondents were from NCAA division I, and there was an almost even split between divisions II and III for the other half of respondents.

The survey was used to evaluate the SSTI policies and prevention practices among college athletic programs. Therefore, only department heads were surveyed to avoid duplication of data. Respondents' ages ranged from 25 to 67 years averaging 46.7 years. The years in their profession ranged from 3 to 40 years with an average of 21.3 years. An older sample with more years of experience was expected because department heads were surveyed. Similarly, department heads were expected to have a higher educational level; most respondents had a minimum of a master's degree while almost one third had doctorates. The majority of respondents stated they were directors or department heads. Approximately half were from private and half from public institutions.

The respondents served a large variation of sports but a higher number served men's football, volleyball, soccer, tennis, basketball, track and field, cross country, softball, and baseball. The least served sports included women's field hockey, lacrosse, wrestling, and gymnastics.

Respondents agreed almost universally that MRSA is of national concern (over 96\%). However less than half of respondents stated it was of concern locally and in their 
own setting. Over $65 \%$ utilized outside healthcare providers to diagnose MRSA. Over $80 \%$ reported having a treatment and prevention policy in place. Almost $86 \%$ were aware of CDC recommendations, and almost $90 \%$ were aware of NATA recommendations for MRSA prevention.

When asked how they managed SSTIs, more than half stated that they required a definitive diagnosis for MRSA. Thirty-nine percent reported they assumed all SSTIs were MRSA and treated them accordingly. Most of their standards of practice included cleaning and covering all wounds, not allowing participation if wounds cannot be adequately covered, daily cleansing of all equipment, requiring that an athletic trainer or physician evaluate wounds, prohibiting sharing of personal items, posters and signs in high traffic areas, and encouraging frequent hand washing. Most also reported that they had made changes to prevention management of SSTI after the emergence of MRSA. The top five changes they reported implemented to address SSTIs were 1) evaluation of all wounds by an athletic trainer or physician, 2) cleaning and covering all wounds, 3) not allowing participation if wounds cannot be adequately covered, 4) daily cleansing of all equipment, and 5) encouraging frequent hand washing. While responses varied, the top five strategies believed to be most effective for prevention by the respondents were 1) cleaning surfaces, areas and equipment; 2) education of athletes, athletic trainers and coaches; 3 ) proper hygiene and hand washing; (4 having all wounds evaluated; and 5) cleaning and covering all wounds.

Sixty-nine percent of respondents stated they had adequate financial resources for SSTI prevention while $18 \%$ reported they did not know. A larger number $(70.5 \%)$ did not quantify the increase in operating costs due to SSTI control, but of those that did, 
almost all identified increased attention to environmental disinfection as a financial indicator. Seventy percent of respondents agreed that the number of SSTIs had either decreased or stayed the same. Sports reported to have had the most cases of SSTIs included football, soccer, and basketball. Half of respondents reported that at least $60 \%$ of their cases occurred in male athletes. The next section will summarize the findings in accordance with the research questions.

\section{Interpretation of Findings}

The following is a review of the findings as they relate to each research question.

\section{Research Question 1}

To what extent are SSTIs recognized as being present in college athletics? The findings indicated that the respondents are familiar with SSTIs and MRSA, and almost all see MRSA as a national concern (96\%). Because most respondents dealt with confirmed cases of MRSA it is interesting that less than half see it as a concern locally or in their own settings. This implies that factors other than the presence of MRSA in their programs evoke concern. The results are consistent with those of Kahanov et al. (2011) who surveyed athletic trainers regarding their knowledge of infection control techniques and had similar results; $92 \%$ of respondents see MRSA as a national problem and only $57 \%$ see it as a problem in their own practice.

Most respondents in the current study reported having experienced cases of MRSA in their settings and about half reported hospitalizations due to SSTIs. More than half stated that they had experienced cases serious enough to affect team performance, defined as missing practice or play. Kahanov et al. (2011) also reported a high number of respondents that had treated MRSA (88\%). The differences in responses may be 
attributed to the difference in the respondents to each study. Kahanov et al. surveyed all athletic trainers whereas the present study surveyed department heads only. Department heads may not be as involved in actual patient care and therefore not as aware of the true incidence. Similarly, in the Kahanov study the majority had also seen hospitalizations and cases severe enough to affect performance due to SSTIs. This finding is significant because the cost of a case with hospitalization is far greater than the already high cost of a non-complicated case. There is significant disparity between the costs of prevention versus the cost of healthcare (Sanders, 2009).

Because of these finding the respondents who reported they saw MRSA as a local problem or a problem in their own setting were examined in accordance with their experiences with MRSA. Almost $83 \%$ of respondents who saw it as a local problem or their own problem had seen cases of MRSA and 55\% reported seeing hospitalizations. However, $77.5 \%$ of this group stated that they had seen MRSA severe enough to impact playing time. Therefore, athletic trainers that experienced MRSA saw it as a problem, but it appears that loss of playing time is more influential than illness resulting in hospitalization. If athletic trainers do not see MRSA as their own problem, which is not only reflected in this study but at least one other (Kahanov et al., 2011), then it follows that there is less perceived susceptibility to MRSA, and athletic trainers may be less compelled to engage in prevention efforts.

\section{Research Question 2}

What policies exist in college athletics to recognize, prevent and manage SSTIs? More than $80 \%$ of respondents reported having a treatment and prevention policy in place. Eighty-six percent were aware of CDC recommendations and $90 \%$ were aware of 
NATA recommendations for MRSA prevention. It is interesting that while a small number, some of the respondents that were familiar with the recommendations by the CDC and NATA, large and respected organizations, still did not report having a policy in place. It is unlikely that department heads were simply unaware of their programs policies; however it could be that they believe the practice of universal precautions, in place for many years, are sufficient to prevent the spread of all diseases, including MRSA. This possibility is concerning in light of the evidence suggesting there may be a lack of compliance of universal precautions with some health care providers (Gammon, 2007). CDC and NATA recommendations may not be sufficient reasons to adhere to a policy without having experienced a serious case. Most also stated that they required a definitive diagnosis for MRSA, but a large number assumed all SSTIs were MRSA and treated them as if they were MRSA. These results are consistent with NATA guidelines.

In the NATA position statement on skin diseases published in the Journal of Athletic Training (Zinder, 2010) the guidelines are to diagnose MRSA based on history and appearance, and perform a culture if the lesion is questionable. Over $65 \%$ used an outside source for diagnosis, but almost $44 \%$ also diagnosed in their own setting. Methods to diagnose will likely always vary because of differences in program size and resource availability. Standards of practice included cleaning and covering all wounds, not allowing participation if wounds cannot be adequately covered, daily cleansing of all equipment, evaluation of all wounds by an athletic trainer or physician, prohibiting sharing of personal items, posters and signs in high traffic areas, and encouraging frequent hand washing for the majority of the respondents. These standards are all consistent with CDC and NATA guidelines. 


\section{Research Question 3}

Are there significant variations in standards of practice for SSTIs? As discussed above the results indicated wide variation in utilization of techniques to prevent and manage SSTIs and their standards of practice included many of the factors recommended by the CDC and NATA. However, universal agreement was not on the use of any one intervention, even the encouragement of frequent hand washing. This finding indicates a disparity between what is documented in the literature as standard procedure and the actual practices of athletic trainers. As discussed earlier, not all respondents reported having policies in place. While research shows a multifaceted policy is recommended to prevent MRSA, it is difficult to ascertain which are considered most beneficial when the practicing health care providers vary in their approach.

\section{Research Question 4}

Are there significant variations in extent of incidence of SSTI? The majority of respondents reported having experienced cases of MRSA in their own settings. Half of respondents also reported hospitalizations due to SSTIs and the majority stated they experienced cases serious enough to effect team performance, which was defined as missing practice or play. When asked if there had been a change in incidence of SSTI in the last year, a majority reported a decrease. A large number also reported there was not a change from the previous year (26\%) and only $6.5 \%$ reported an increase. No relationship was found between number of confirmed cases of MRSA and NATA region, or between incidence of SSTI from the last year and NATA region. However, the small sample in this study could have prevented uncovering a true relationship.

\section{Research Question 5}


Are there epidemiological differences such as gender of athletes or individual sports that may be important in prevention program development? The highest incidence of SSTIs was reported in football, with higher numbers of SSTI also reported in soccer and basketball. This result was expected, because much of the literature studied MRSA cases and outbreaks in football players, with high numbers also in soccer and basketball (Beiger et al., 2004; Cohen, 2005; Huijdens, 2006; Nguyen et al., 2005; Ramano et al., 2006; Rihn et al., 2003; Stacey et al., 1998). Kahanov et al. (2011) also found football to be the sport with the greatest number of SSTIs.

Football, basketball, and soccer were also among the highest number of sports served by the athletic trainers that responded to this survey. Other contact sports reported in the literature to see higher numbers of SSTIs such as wrestling (Lindenmayer et al., 1998; Patel et al., 2007) were underrepresented; this may account for lower numbers of incidence in other groups.

Also comparable with previous research, the majority of cases were reported to have occurred in male athletes (Elixhauser \& Steiner, 2007; Ellis, 2007; Kahanov et al., 2011). In the survey administered to athletic trainers by Kahanov et al. (2011) more than twice as many male athletes reported having MRSA than female athletes. As mentioned earlier, the fact that football is a male dominated sport could be related to the high incidence of SSTIs.

Multiple reasons may explain why SSTIs may be more prominent in males. While males do participate heavily in contact sports, Davies et al. (2000) also found that although college men had an awareness of health needs, barriers existed that prevented them from seeking help. The strongest barrier was the social stigma of appearing weak 
and vulnerable. Gender role stereotypes exist that socialize males to be independent, strong and aggressive and to hide weakness. Men may consider themselves invulnerable to illness and injury and have been proven to engage in less health promoting behavior than women and to use campus health related services less than women. They are less likely to seek health care or report an injury unless they are in extreme pain (Davies et al. 2000). These factors could prevent male athletes from implementing the interventions that would ensure alterations in skin integrity and possible SSTIs are managed earlier and more aggressively.

\section{Research Question 6}

What has been the impact on prevention policies and procedures related to SSTIs? As discussed earlier, most respondents were aware of the recommendations of the CDC and NATA. Most respondents did say they had made changes to prevention management of SSTI after the emergence of MRSA. The top five changes they reported were (a) evaluation of wounds by an athletic trainer or physician, (b) cleaning and covering all wounds, (c) not allowing participation if wounds cannot be adequately covered, (d) daily cleansing of all equipment, and (e) encouraging frequent hand washing. These changes closely resemble the five top standards of practice of the respondents reported earlier. However, each of the top five changes were reported from no more than $53 \%$ of the respondents, indicating there was not universal agreement on the changes implemented. Wide variation to the responses to the top five strategies believed to be most effective for prevention of MRSA were revealed. Twenty different strategies were identified by the respondents as most effective. The five identified most were (a) cleaning of surfaces areas and equipment; (b) education of athletes, athletic trainers, and coaches; (c) proper 
hygiene and hand washing, (d) evaluation of all wounds, and (e) cleaning and covering all wounds. These results indicate that there was some disagreement as to which strategies are most important in preventing MRSA.

These results suggest that the respondents in this study may not have perceived additional measures were necessary to prevent MRSA in addition to universal precautions already in place. It is concerning that clinicians may focus on previous techniques out of habit and ignore newer recommended alternatives based on empirical evidence. While there does appear to be wide variation, the standards of practice, changes made since the emergence of MRSA, and top five strategies to be most effective all reflect CDC and NATA guidelines. Overall, it appears that the majority of athletic trainers are being proactive. They are not only are they aware of the recommended guidelines, but are putting at least some of them into practice. Furthermore, few reported an increase in MRSA occurrence, indicating that the techniques used are effective.

While Kahanov et al. (2011) found respondents felt there were not adequate resources to implement prevention strategies, in the current study the majority of respondents did not quantify increase in operating costs due to SSTI control. However of those that did, the vast majority (more than 90\%) identified increased attention to environmental disinfection as a financial indicator. The cost did not appear to be relevant for either NCAA division or type of institution. Of the respondents that stated they did not have adequate resources $(7.7 \%)$, they were divided equally between public and private institutions, and half were division NCAA II or III, the other half division I. This finding closely reflects the demographic of the sample population. Kahanov surveyed all athletic trainers instead of department heads. It could be that department heads surveyed 
in the current study are less involved in the day to day cleaning and disinfection routines, and therefore may not be aware that resources are inadequate.

\section{Discussion and Implications}

Careful consideration of current procedures and their effectiveness must be examined to ensure adequate prevention policy. The evidence from the current study suggests that while the emergence of MRSA has made an impact on policies, the changes the programs have implemented vary. The results of this study suggest that practitioners may want to evaluate their current prevention practices. Periodic reviews of the elements included in their policies, evidence that efforts are getting the desired in their setting, education that includes the latest research, and a plan for improvements could keep practices abreast of newest research.

The research that demonstrates that healthcare workers including athletic trainers lack consistency with universal precautions may explain some of the variance in prevention efforts. Universal precautions began the emergence of the human immunodeficiency virus (HIV) in the 1980s. The discovery of HIV prompted a universal series of guidelines to be put in place that required precautions for health care providers of all levels. These precautions, which include basic hand hygiene and other factors that aid in the prevention of transmission of disease, are now standard procedure and part of any basic first aid training (Furlin, 2011). It is widely accepted that prevention efforts can substantially decrease MRSA rates (Tacconelli, 2008). Ideally all athletic trainers would implement all CDC and NATA recommendations in support of prevention; it appears that while most are implementing many of them, none of the respondents in this sample was doing them all, and there was disagreement on what works best. 
Prevention efforts in the form of universal precautions are not practiced adequately in many areas of sports medicine (Furlin, 2011). A study of universal precaution compliance was conducted at the World Cup soccer games in 20120. The researcher observed 48 of the 64 matches. Injuries involving blood exposure were witnessed in $43.8 \%$ of the games watched. Despite the fact that all athletic trainers are educated in universal precautions, not once did the researcher observe the health care provider wearing gloves (Furlin, 2011). This revelation is concerning not only because the World Cup is so broadly viewed, but because hand hygiene is considered the most important prevention factor in the NATA statement on skin diseases (Zinder, Basler, Foley, Scarlata, \& Vasily, 2010). The CDC (2002) also released a document specifically emphasizing the importance of hand hygiene.

Standard infection control procedures including universal precautions are essential and should be integral to any healthcare setting for the protection of healthcare providers, patients and the public (Gammon, 2007). Proper procedure should extend to cleaning of all possibly exposed surfaces when providing any form of health care, and include transmission based precautions to reduce the transmission of organisms. This approach includes decontamination of equipment, the environment, and linen and waste management (Gammon, 2007). The presence of infections such as MRSA makes this even more compelling in the athletic setting; however, infection control techniques are often found to be suboptimal. Gammon (2007) performed a review of compliance studies and found that in all studies the health care workers were generally deficient in the use of universal precautions. The reasons stated for noncompliance were that health care workers saw the precautions as unnecessary, they interfered with their work, they were 
cumbersome and inconvenient, materials such as gloves were unavailable, it was time consuming, they did not perceive any risk, and lack of knowledge of appropriate techniques. Furthermore, while education improved compliance in most of these studies, it did not persist for long time periods and health care workers returned to less optimal infection control. Therefore, knowledge of proper infection control factors did not ensure compliance (Gammon, 2007). The evidence of non-compliance by health care workers including athletic trainers evokes the need for institutions to seek out new educational efforts to increase compliance. All college students would benefit from practicing prevention of diseases. This information could be provided in student and athlete orientations and other college health programming.

Another important consideration is the cost of prevention versus the cost of infection. Researchers with the goal to decrease the number of MRSA cases in one college football team by $50 \%$ instigated simple educational and behavioral adjustments to their players, coaches, and athletic trainers. Among the interventions were explanation of CDC guidelines before the season began, instruction of how to recognize MRSA, and education about hygiene and the importance of refraining from sharing personal items. These guidelines were presented in the forms of Power Point presentations, booklets, and posters. In addition, the use of sanitizing hand wipes was encouraged and they were stocked in facility locker rooms, weight rooms, and fields. Players were also instructed to contact a coach or athletic trainer if they suffered and injury or ailment for evaluation. Results from these interventions were that MRSA decreased in the team by more than $75 \%$ (Sanders, 2009). In this study the total cost for the interventions was $\$ 850.00$; the cost of one uncomplicated case of MRSA, based on local urgent care and emergency 
department charges, is $\$ 400$ to $\$ 1000$. Cases that included office visits, advanced treatment such as incision and drainage or debridement, pharmaceutical prescriptions or hospitalization would cost much more. During their previous three seasons, the college averaged 12.6 cases at the cost of $\$ 5,040$ to $\$ 12,600$. Because there were 9.6 fewer cases during the intervention season, the college saved between $\$ 3,840$ and $\$ 9,600$. Not taken into consideration were the non-tangible costs of decrease in lost playing time, physical pain, and less spread to other players (Sanders, 2009).

The evidence from the current study supports previous research concluding that these infections occur more prominently in male athletes. Because of social stereotypes and pressure, males may have more concern about the possibility of infection if they feared their athletic skills could be affected. Also, the results here suggest that the threat of loss of playing time could be more influential than other factors. Education aimed at athletes may want to consider addressing the likelihood that an infection could affect their playing time rather than the threat of illness. Also, instituting a policy that all skin problems must be evaluated by athletic trainer or other health care provider is prudent as it takes the pressure off of the male athlete to appear vulnerable for seeking help. It will be important to repeatedly provide outreach to this population, because they likely will not seek information about SSTI prevention on their own.

\section{Health Belief Model (HBM)}

The HBM provides a useful structure for examining the results of this study. The results support the HBM as a guide in predicting the change of health related behaviors. The following is a discussion of the results as they pertain to each factor of the HBM.

Perceived susceptibility: According to the results, the majority of respondents had 
experienced MRSA in their settings, and also saw it as a national concern. This is one of the major components required to promote change in health behaviors.

Perceived severity: There appeared to be less perceived severity in this population than perceived susceptibility. Compared to the majority that saw MRSA as a national concern, about half saw it as a local concern, or a concern in their own setting. Similarly, about half had experienced hospitalizations of athletes. In addition, most of respondents stated the number of MRSA cases had either decreased or stayed the same. However over $70 \%$ did report that they had experienced cases severe enough to impact team performance.

Perceived benefits: In order to perceive benefits of a health behavior change, there must be perceived susceptibility and perceived severity. Because the majority of respondents reported that they had policies in place for the prevention and treatment of SSTIs and also had made changes after the emergence of SSTIs, they appear to perceive benefits to making health behavior changes related to SSTI prevention. These changes appeared to have been driven by the susceptibility from their experience with MRSA and severity in the form of the effect of SSTIs on team performance.

Perceived barriers: Possible barriers were identified in the current study that could influence implementation of the health behaviors necessary to prevent SSTIs. Lack of resources did not appear to be a barrier for this group of department heads; most did not attempt to quantify increased costs. However, in the study by Kahanov et al. (2011) which surveyed athletic trainers, resources were perceived to be inadequate. This disparity between the perceptions of department heads versus staff may be because staff may engage more in clinical practice. Unfortunately, collecting data on the gender of the 
respondent was not completed because of a technical software problem with the survey. It may have resulted in some interesting observations regarding perceptions of male versus female athletic trainers. The conclusion that more cases are reported in male athletes does present the possibility that male athletes are less likely to adopt the health behaviors necessary to prevent SSTIs due to male stereotypes that make males less likely to seek medical attention (Davies, 2000). Although not examined in this study, the barriers for use of adequate infection control found in the study by Gammon (2007), such as inconvenience, time, and lack of materials such as gloves, may also be barriers for this population. A clear understanding of the barriers to change of prevention behavior is key to promoting change.

Cues to action: The overwhelming majority of respondents were aware of the guidelines recommended by the CDC and NATA. These organizations are prestigious and the recommendations are likely to have merit to the population studied, and encouragement from the CDC and NATA are likely to lead to changes in health behavior. Cues from the public, such as media coverage of cases, can also exert pressure to act. Males may be driven more from social factors such as the risk of appearing weak if unable to play rather than scientific factors (Davies, 2000).

Self-efficacy: Similar to knowledge of the recommendation by the CDC and NATA being cues to action, they also provide confidence for the change in health behavior. Not examined was administrative support. Support from athletic directors and coaches would also add to self-efficacy to implement changes. Because males are pressured by social stigma of appearing weak or dependent they may have less selfefficacy to change health behaviors in general; not just in the athletic setting (Davies et 
al., 2000).

\section{Future Research}

Because of the rapid evolution of MRSA, it is difficult to remain current on the topic. MRSA is likely to become resistant to the antibiotics that are currently being used to successfully treat it. To continue to prevent it from occurring or spreading, effective prevention techniques and prevalence must be evaluated periodically. The current study supports evidence that the recommendations for a multifaceted approach to prevention is being utilized and is keeping serious infections from increasing in prevalence, although to varying degrees. Because of constant medical innovation, theories of best practices must be tested adequately to contribute to the pool of information so health care providers can give the best possible patient care.

Examination of barriers that prevent health care providers from implementing some of the guidelines, and why they choose the ones they do implement, could be illuminating in future prevention planning. Similarly a study that directly examines student athletes, and what factors motivate them to engage in prevention behaviors could help in planning effective educational programs. Because there is evidence that education does not necessarily result in changed behavior (Gammon, 2007), the role of education, as opposed to other interventions amongst the various groups that are affected by MRSA may be of interest.

This study addressed a very small aspect of an issue involving many facets. SSTIs in sports programs ultimately involve many more groups besides athletic trainers and athletes. Higher administration, parents, and even intramural sports and residence life staff should be involved in SSTI prevention. While there appears to be agreement that 
health care staff is responsible for prevention of SSTIs, there may be other groups that could have a significant impact on prevention efforts such as athletic directors, intramural and recreational staff, residence hall staff, and even custodial staff, particularly as they can offer support of efforts. Because this study supported previous research that found that males and athletes involved in contact sports are more likely to contract MRSA, continued research in the areas of gender and specific sports could offer insight as to the true nature of this association.

The opinions and perceptions of administrators such as athletic directors and even vice presidents and presidents may provide a richer perspective of how decisions regarding prevention are reached. The degree of awareness higher administration has of the prevalence and recommendations for prevention could impact the degree to which changes are implemented. Cues to action for administrators may be very different than those of athletes and athletic training staff. They may be more motivated by outside pressures such as views of parents, media coverage, and the threat of litigation.

\section{Limitations}

Limitations to this study include the use of self-reported data collected via survey. Convenience sampling which was used in this study likely resulted in self-selection bias. Self-selection bias, or respondents choosing for themselves whether or not to participate, may result in an overrepresentation of participants with strong opinions about MRSA or prevention, and those with little knowledge of the topics may have chosen not to participate. This may lead to a biased representation of the topic population (Lavrakas, 2012).

The results are limited to the responses only for the time period in which the data 
was collected. Recall bias can occur if respondents failed to remember the answer accurately or completely may also have occurred (mediLexicon, 2013).

The investigator was unable to control the degree of honesty and clarity respondents provided when answering survey questions. The results are limited to the clinicians that responded to the survey. Accurate reporting of SSTI rates could have been viewed as threatening to the athletic program and therefore negatively influence a clinician's willingness to complete the survey or to be completely honest.

Information was lost from one of the demographic questions, gender of respondent, due to computer software problems. Although this did not result in loss of

pertinent data researched, gender of respondent could have been examined in relation to some of the factors. Gender of athletic trainer may have impacted the perception of severity of the MRSA issue. Lastly, the low response rates may have resulted in an inaccurate representation of the population studied.

\section{Conclusion}

Because MRSA has been found to be very adaptable, strategies working now may not continue to prevent infection to take hold. The findings in the current study are consistent with previous research that playing and practice time lost can have significant effect on a program. Therefore it is imperative that this kind of information be gathered at regular intervals so that trends may be recognized and acted upon. Their emergence and potential serious complications for athletes have led to the evolution of guidelines for their prevention. Athletic trainers have a key role in prevention as primary caregivers to the athletic population. Their influence on athletes and coaches puts them in a position to relay the latest information of how to prevent infections. The results of the newest 
research must be distributed to Athletic Trainers through their annual continuing education programs.

While in this study most respondents had policies in place to address the issue of prevention, there was not universal agreement on best practices, leaving questions as to which standards are essential. The results of this study suggest that the effect of SSTIs on team performance is a stronger predictor of change in policy to prevent infection than having dealt with MRSA or hospitalization of an athlete. This study also supports previous research that found that most of these infections occur in male athletes. Future research exploring these factors within the construct of the HBM could illuminate how to best address enforcing change, and how to best reach populations such as male athletes.

History dictated that the epidemiology of SSTIs will continue to change; therefore we cannot assume we are continuing to treat MRA in the most efficient manner without continuous testing of our theories and practices. A solid body of evidence is essential and continuous education is necessary to allow athletic trainers to be proactive and to ensure quality practices. It is likely that this disease will not only persist in athletic environments, but become even more resistant to current treatment. In the community, MRSA spread to healthy populations, particularly athletes; it is likely to spread to other areas of the college community such as recreation, intramural sports, and residence halls. Therefore, it is imperative that research continue to remain current on its progression and guidelines for prevention should also continue to evolve. 


\section{REFERENCES}

Adcock, P. M., Pastor, P., Medley, F., Patterson, J. E., \& Murphy, T. V. (1998).

Methicillin-resistant Staphylococcus aureus in two child care centers. The Journal of Infectious Diseases, $178,577-580$.

American Psychological Association. (2010). Publication Manual of the American psychological association $\left(6^{\text {th }}\right.$ ed.). Washington, DC: Author.

Anderson, D. J., Kaye, K. S., Chen, L. F., Schmader, K. E., Choi, Y., Sloan, R. \& Sexton, D.J. (2009). Clinical and financial outcomes due to methicillin resistant Staphylococcus aureus surgical site infection: A multi-center matched outcomes study. PLoS ONE 4(12), e8305. doi:10.1371/journal.pone

Begier, E. M., Frenette, K., Barrett, N. L., Mshar, P., Petit, S., Boxrud, D. J...Hadler, L.J. (2004). A high-morbidity outbreak of methicillin- resistant staphylococcus aureus among players on a college football team, facilitated by cosmetic body shaving and türf bưrns. Clinical Infectious Diseases, 39, 1446-1453.

Bratu, S., Landman, D., Gupta, J., Trehan, M., Panwar, M., \& Quale, J. (2006). A population-based study examining the emergence of community-associated methicillin-resistant staphylococcus aureus USA300 in New York City. Annals of Clinical Microbiology and Antimicrobials, 5, 29-25.

Brinsley, K. J., Sinkowitz-Cochrane, R. L., Cardo, D. M., \& The CDC. Campaign to Prevent Antimicrobial Resistance Team. (2005). Assessing motivation for 
physicians to prevent antimicrobial resistance in hospitalized children using the health belief model as a framework. American Journal of Infection Control, 33, $175-181$.

Brown, G. (2012). NCAA Student-athlete participation hits 450,000 . September $19^{\text {th }}$, 2012. Retrieved from http://www.ncaa.org

Centers for Disease Control and Prevention. (2002). Guideline for hand hygiene in healthcare settings. $M M W R, 51, \mathrm{RR}-16$.

Centers for Disease Control and Prevention. (2010a). Definition of MRSA. Retrieved from http://www.cdc.gov/mrsa/definiton/index.html

Centers for Disease Control and Prevention. (2010b). MRSA infections: Prevention of MRSA infections in athletic facilities. Retrieved from http://www.cdc.gov/mrsa/ prevent/athletic

Centers for Disease Control and Prevention. (2011). Methicillin-resistant staphylococcus aureus (MRSA) infections. Retrieved from http://www.cdc.gov/nutrition/

Centers for Disease Control and Prevention. (1988) Update: Universal precautions for prevention of transmission of human immunodeficiency virus, hepatitis B virus, and other bloodborne pathogens in health-care settings. Retrieved from http://www.cdc.gov/universal/precautions

Charlebois, E. D., Perdreau-Remington, F., Kreiswirth, B., Bangsberg, D. R., Ciccarone, D., Diep, B. A., et al. (2004). Origins of community strains of methicillin-resistant staphylococcus aureus. Clinical Infectious Diseases, 39, 47-54.

Cohen, P. R. (2005). Cutaneous community-acquired methicillin-resistant staphylococcus aureus infection in participants of athletic activities. Southern Medical Journal, 
$98,596-602$.

Collins, C. J., \& O'Connell, B. (2012). Infectious disease outbreaks in competitive sports, 2005-2010. Journal of Athletic Training, 47, 516-518.

Como-Sabetti, K., Harriman, K., Juni, B., Westbrook, A., Cebelinski, E., Boxrud, D., \& Lynfield, R. (2006). Methicillin-resistant staphylococcus aureus at canoe camp. Emerging Infectious Diseases Journal, 12, 360-363.

Cosgrove, S. E., Sakoulas, G., Perencevich, E. N., Schwabber, M. J., Karchmer, A. W., \& Carmeli, Y. (2003). Comparison of mortality associated with methicillin resistant and methicillin susceptible staphylococcus aureus bacteremia: A meta-analysis. Clinical Infectious Diseases, 36, 53-59.

Cosgrove, S. E., Youlin, Q., Kaye, K. S., Harbarth, S., Karchmer, A. W., \& Carmeli, Y. (2005). The impact of methicillin resistance in staphylococcus aureus bacteremia on patient outcomes: mortality, length of stay, and hospital charges. Infection Control and Hospital Epidemiology, 26, 166-174.

Daney, J. C., Schneider-Lindner, V., Brassard, P., \& Suissa, S. (2008). Mortality after infection with methicillin-resistant staphylococcus aureus diagnosed in the community. BMC Medicine, 6, 134-143.

Davies, J., McRae, B. P., Frank, J., Dochnahl, A., Pickering, T., Harrison, B., Zakrzewski, M., \& Wilson, K. (2000). Identifying male college students' perceived health needs, barriers to seeking help, and recommendations to help men adopt healthier lifestyles. Journal of American College Health, 48, 259-267.

Dexheimer, E. (2003, November 13). Department of higher learning: other schools do the math as metro state calculates the cost of subtracting athletics. Westword. 
Retrieved from http://www.westweord.com

Dillman, D. A. (2007). Mail and internet surveys ( $2^{\text {nd }}$ ed.). Hoboken, NJ: Wiley.

Dixon, A. S. (1990). The evolution of clinical policies. Medical Care, 28, 201-220.

Drews, T. D., Temte, J. L., \& Fox, B. C. (2006). Community-associated methicillinresistant staphylococcus aureus: Review of an emerging public health concern. Wisconsin Medical Journal, 105, 52-57.

Elixhauser, A., \& Steiner, C. (2007). Infections with methicillin-resistant Staphylococcus aureus (MRSA) in U.S. hospitals 1993-2005. Retrieved from Healthcare Cost and Utilization Project website: http://www.hcup-us.ahrg.gov/toolssoftware/ $\operatorname{ccs} / \operatorname{ccs} . j \mathrm{sp}$.

Frazee, B. W., Lynn, J., Charlebois, E. D., Lambert, L., Lowery, D., \& PerdreauRemington, F. (2005). High prevalence of methicillin-resistant staphylococcus aureus in emergency department skin and soft tissue infections. Annals of Emergency Medicine, 45, 311-320.

Fridkin, S. K., Hageman, J. C., Morrison, M., Sanza, L. T., Como-Sabetti, K., Jernigan, J. A., et al. (2005). Methicillin-resistant staphylococcus aureus disease in three communities. The New England Journal of Medicine, 352, 1436-1444.

Furin, J. (2011). Blood exposure at the 2010 international federation of football association world cup: time for universal adaption of universal precautions. Clinical Journal of Sports medicine, 21, 264-265.

Gammon, J, Morgan-Samuel, H., \& Gould, D. (2007). A review of the evidence for suboptimal compliance of healthcare practitioners to standard/universal infection control precautions. Journal of Clinical Nursing, 17, 157-167. 
Goff, B. (2000). Effects of university athletic s on the university: A review of extension of empirical assessment. Journal of Sport Management, 14, 85-104.

Goodman, R. A., Thacker, S. B., Solomon, S. L., Osterholm, M. T., \& Hughes, J. M. (1994). Infectious diseases in competitive sports. The Journal of the American Medical Association, 271, 862-867.

Gorak, E. J., Yamada, S. M., \& Brown, J. D. (1999). Community-acquired methicillinresistant staphylococcus aureus in hospitalized adults and children without known risk factors. Clinical Infectious Diseases, 29, 797-800.

Groom, A. V., Wolsey, D. H., Naimi, T. S., Smith, K., Johnson, S., Boxrud, D., et al. (2001). Community-acquired methicillin-resistant staphylococcus aureus in a rural American Indian community. The Journal of the American Medical Association, 286, 1201-1205.

Harnett, D. L (1982). Statistical methods ( $3^{\text {rd }}$ ed.). Reading, MA: Addison-Wesley.

Harris, P. A., Taylor, R., Thielke, R., Payne, J., Gonzalez, N., \& Conde, J. G. (2009). Research electronic data capture (REDCap) - A metadata-driven methodology and workflow process for providing translational research informatics support. Journal of Biomedical Information, 42, 377-81.

Hart, P. K. (2006). Field of nightmares. Texas Monthly, 34, 74-79

Herold, B. C., Immergluck, L. C., Maranan, M. C., Lauderdale, D. S., Gaskin, R. E., Boyle-Vavra, S., et al. (1998). Community -acquired methicillin-resistant Staphylococcus aureus in children with no identified predisposing risk. The Journal of the American Medical Association, 279, 593-598.

Hiramatsu, K., Cui, L., Kurado, M., \& Ito, T. (2001). The emergence and evolution of 
methicillin-resistant staphylococcus aureus. Trends in Microbiology, 9, 486-493.

Holmberg, S. D., Solomon, S. L., \& Blake, P. A. (1987). Health and economic impact of antimicrobial resistance. Reviews of Infectious Diseases, 9, 1065-1078.

Huck, S. W. (2004). Reading statistics and research ( $4^{\text {th }}$ ed.) Boston, MA: Allyn \& Bacon.

Huijsdens, X. W., vaan Lier, A. M., van Kregten, E., Verhoef, L., van Santen-Verheuvel, M.G., Spalburg, E., \& Wannet, W. J. (2006). Methicillin-resistant Staphylococcus aureus in Dutch soccer team. Emerging Infectious Diseases, 12, 1584-1586.

Kahanov, L., Gilmore, E. J., Eberman, L. E., Roberts, J., Semerjian, T., \& Baldwin, L. (2011). Certified athletic trainers' knowledge of methicillin-resistant staphylococcus aureus and common disinfectants. Journal of Athletic Training, 4, $415-432$

Kazakova, S. V., Hageman, J. C., Matava, M., Srinivasan, A., Phelan, L., Garfinkel, B....Jernigan, D. B. (2005). A clone of methicillin-resistant staphylococcus aureus among professional football players. The New England Journal of Medicine, 352, 468-475.

Keminkj, S. M. (2009). Community-acquired MRSA infections. Drug Topics, 153, 3240.

King, M. D., Humphrey, B. J., Wang, Y. F., Kourbatova, E. V., Ray, S. M., \& Blumberg, H. M. (2006). Emergence of community-acquired methicillin-resistant staphylococcus aureus USA 300 clone as the predominant cause of skin and soft tissue infections. Annals of Internal Medicine, 144, 309-317.

Klein, E., Smith, D. L., \& Laxminarayan, R. (2007). Hospitalizations and deaths caused 
by methicillin-resistant staphylococcus aureus, United States, 1999-2005. Emerging Infectious Diseases, 13, 1840-1846.

Klevens, R. M., Morrison, M. A., Nadles, J., Petit, S., Gershman, K., Ray, S., et al. (2007). Invasive methicillin-resistant staphylococcus aureus infections in the United States. The Journal of the American Medical Association, 298, 1763-1771.

Kowalski, T. J., Berbari, E. F., \& Osmon, D. R. (2005). Epidemiology, treatment, and prevention of community-acquired methicillin-resistant staphylococcus aureus infections. Mayo Clinic Proceedings, 80, 1201-1208.

Kramer, A., Schwebke, I., \& Kampf, G. (2006). How long do nosocomial pathogens persist on inanimate surfaces? A systematic review. Biomed Central Infectious Diseases, 6, 130-151.

Kurkowski, C. (2007). CA-MRSA: the new sports pathogen. Orthopaedic Nursing, 26, $310-317$.

Lavrakas, P. J. (2012). Sage research methods. Retrieved from http://srmo.sagepub.com /view/encyclopedia-of-survey-research-mehtods/n526.xml. doi: $10.4135 / 9781412963947$

Lindenmayer, J. M., Schoenfeld, S., O’Grady, R., \& Carney, J. K. (1998). Methicillinresistant staphylococcus aureus in a high school wrestling team and the surrounding community. Archives of Internal Medicine 158, 895-899.

Mayo Clinic. (2012). MRSA infection. Retrieved from www.mayoclinic.com/health /mrsa/D500735

mediLexicon. (2013). Recall bias - medical definition. Retrieved from http://www. medilexicon.com/medicaldictionary.php/?t=10084 
Moran, G. J., Amii, R. N., Abrahamian, F. M., \& Talan, D. A. (2005). Methicillinresistant staphylococcus aureus in community-acquired skin infections. Emerging Infectious Diseases, $11,928-930$.

Naimi, T. S., LeDell, K., H., Como-Sabetti., K., Borchardt, S. M., Boxrud, D. J., Etienne., et al. (2003). Comparison of community and health care-associated methicillin resistant Staphylococcus aureus infection. The Journal of the American Medical Association, 290, 2976-2984.

NATA releases guidelines on the prevention of skin diseases in adults. (2010). Retrieved from http://www.nata.org/print/NR062310

NATA. (2007). ATC terminology. Retrieved from http://www.nata.org/athletic training/terminology

NCAA. (2013). Where does the money go? Retrieved from http://www.ncaa.org/wps /wcm/connect/public/NCAA/Answers/Nine+points+to+consider_one

National Collegiate Athletic Association. (2011) Sports medicine handbook. Retrieved from NCAA.org/health-safety

Newell, K. (2006). The invisible enemy. Coach and Athletic Director: Jefferson City, 76, $62-73$.

Nguyen, D. M., Mascola, L., \& Bancroft, E. (2005). Recurring methicillin-resistant staphylococcus aureus infections in a football team. Emerging Infectious Diseases, 11, 526-532.

O’ Laughlin, D. M., \& Cook, J. (2009). Financial analysis of methicillin-resistant staphylococcus aureus in a high school wrestler. Pediatric Ethics, Issues, \& Commentary, 35, 130-136. 
Patel, A., Fischer, S., Calfree, R., Plante, M., \& Fadale, P. (2007). Locker room acquired methicillin-resistant staphylococcus aureus. Orthopedics, 30, 532-536.

Prevention of MRSA infections in athletic facilities.(2010). Retrieved from http://www.cdc.gov/mrsa/prevent/athletic.html

Price, M. F., \& McBride, M. E. (1998). Prevalence of methicillin- resistant staphylococcus aureus in a dermatology outpatient population. Southern Medical Journal, 91, 384-388.

Qualtrics Labs, Inc. (2009). Qualtrics university (Version 12.018). Provo, Utah USA. Qualtrics Labs, Inc.

Raghavan, M., \& Linden, P. K. (2004). Newer treatment options for skin and soft tissue infections. Drugs, 15, 1621-1642.

Rihn, J. A., Posfay-Barbe, K., Harner, C. D., Macurak, A., Farley, A., Greenawaly, K., et al. (2005). Community-acquired methicillin-resistant staphylococcus aureus outbreak in a local high school football team unsuccessful interventions. The Pediatric Infectious Disease Journal, 24, 841-843.

Romano, R., Lu, D., \& Holtom, P. (2006). Outbreak of community acquired methicillin resistant staphylococcus aureus skin infections among a collegiate football team. Journal of Athletic Training, 41, 141-145.

Root, B. (2009). Note: How the promises of riches in collegiate athletic s lead to the compromised long-term health of student-athletes: Why and how the NCAA should protect its student-athletes' health. Health Matrix, 19, 279-315.

Sanders, J. C. (2009). Reducing MRSA infections in college student athletes: implementation of a prevention program. Journal of Community Health Nursing, 


$$
26,161-172 \text {. }
$$

Sharma, M. (2011). Health belief model: Need for more utilization in alcohol and drug education. Journal of Alcohol \& Drug Education, 55, 3-6.

Shavelson, R. J. (1995). Statistical reasoning for the behavioral sciences ( $3^{\text {rd }}$ ed.). Boston, MA: Allyn \& Bacon.

Sheehan, K. B. (2001). E-mail survey response rates: a review. Journal of ComputerMediated Communication, 6, 0. doi: 10.1111/j.1083-6101.2001.tb00117

Sivo, S. A., Saunders, C., Chang, Q., \& Jiang, K. (2006). How low should you go? Low response rate and the validity of inference in is questionnaire research. Journal of the Association of Information Systems, 7, 351-414.

Stacey, A.cR., Endersby, K.cE., Chan., P. C., \& Marples, R. R. (1998). An outbreak of methicillin resistant staphylococcus aureus infection in a rugby football team. British Journal of Sports Medicine, 32, 153-154.

StatSoft, Inc. (2012). Electronic statistics textbook. Retrieved from http://www.statsoft.com/textbook/

Stat Trek. (2013). Statistics, probability, and survey sampling. Retrieved from http:www//stattrek.com/

Suggs, W. (2004, October 29). Big money in college sports flows to the few. The Chronicle of Higher Education. Retrieved from http://www.chronicle.com Tacconelli. E.(2008). Methicillin-resistant staphylococcus aureus: Risk assessment and infection control policies. European Society of Clinical Microbiology and Infectious Diseases, 14, 407-410.

Thomas, L. W. (1995). A critical feminist perspective on the health belief model: 
implications for nursing theory, research, practice, and education. Journal of Professional Nursing, 11, 246-252.

Tonn, K., \& Ryan, T.J. (2012). Community-associated methicillin-resistant staphylococcus aureus in college resident halls. Journal of Environmental Health. $75,44-49$.

Toy, C.cE. (2009, September 14). OU athletics trumpet its contribution to local economy. The Athens News. Retrieved from http://wwwtheathensnews.com

U.S. Department of Health and Human Services, National Institutes of Health. (2005). Theory at a glance: Application to health promotion and human behavior.

Von Ah, D., Ebert, S., Ngamvitroj, A., Park, N., \& Kang, D. (2004). Predictors and health behaviors in college students. Journal of Advanced Nursing, 48, 463-474.

Weiner, H. R. (2008). Methicillin-resistant staphylococcus aureus on campus: A new challenge to college health. Journal of American College Health, 56, 347-351.

Zinder, S. M., Basler, S. W., Foley, J., Scarlata, C., \& Vasily, D. B. (2010). National athletic trainers' association statement: Skin diseases. Journal of Athletic Training, 45, 411-428

Zinderman, C. E., Conner, B., Malakooti, M. A., LaMar, J. E., Armstrong, A., \& Bohnkert, B. K. (2004). Community-acquired methicillin-resistant staphylococcus aureus among military recruits. Emerging Infectious Diseases, 10, 941-944. 


\title{
Appendix A
}

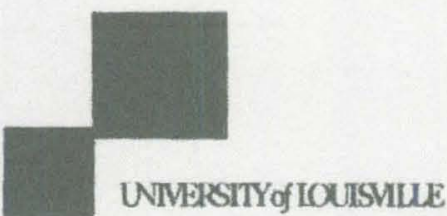

UNVBSITYof IOUISYUE

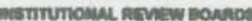

Unverenty of toulavile

Meocenter One, sillie 200

BOt E. Broadway

Lounville, Kentucty 40802-1708

Oalce: 502.832 .5188

Fax: $\quad 502-652-2164$

\author{
To: $\quad$ Carrico, Ruth \\ From: The University of Louisville Institutional Review Boerd (IRB) \\ Date: Thursday, January 05, 2012 \\ subject: IRB Correspondence \\ Tracking : 11.0624 \\ Titls: $\quad$ Evaluation of skin and sof tissue infection policies and practices among \\ college athletic programs
}

This study was reviewed on 12/21/2011 and determined by the chair of the institutional Review Board that the study is exempt according to 45 CFR 46.101 (b) under category (2) Research involving the use of educational tests (cognitive, diagnostic, aptitude, achievement), survey procedures, interview procedures or observation of public behavior, unless: (i) information obtained is recorded in such a manner that human subjects can be identified, directly or through identifiers linked to the subjects; and (ii) any disclosure of the human subjects' responses outside the research could reasonably place the subjects at risk of criminal or clvil liability or be damaging to the subjects' financial standing, employability, or reputation.

The study is exempt onty if information that couid identify subjects is not recorded.

Since this study has been found to be exempt, no additional reporting, such as submission of Progress Reports for continuation reviews, is needed. If your research focus or activities change, please submit a Study Amendment Request Form to the IRB for review to ensure that the study still meets exempt status. Best wishes for a successful study. Please send all inquires and electronic revisedirequested items to our office email address at hsppofc:louisville.edu. 


\section{Pite 11 dusach}

Board Designee: Quesada, Peter

Letter Sent By: Block, Sherry, 1/5/2012 2:13 PM

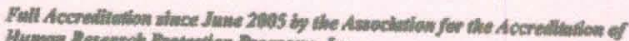

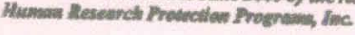


Appendix B

Instructions for Completing Survey

Thank you for taking the time to complete this survey that focuses on gaining knowledge regarding the incidence, programs and prevention policies for skin and soft tissue infections in college athletics.

Please answer each of the following questions. You will be asked to select one or more responses or free text additional information.

The first nine questions request demographical information; the remaining questions address your current practices regarding skin and soft tissue infection management. The survey has been constructed to be completed in approximately 10 minutes.

The following information provides some working definitions for some of the terms used in the survey:

1. MRSA - Methicillin resistant Staphylococcus aureus; Staphylococcus aureus that has developed resistance to antibiotics in the penicillin family (e.g., methicillin).

2. SSTI - skin and soft tissue infections, or infections present in the skin or fascia, which have been found in most cases to be caused by MRSA.

3. Carriage - hosting an organism without symptoms of illness with the potential to pass the organism on to others.

4. Culture - process of collecting body tissue or fluid for laboratory evaluation to detect and identify source of infection. 
1. In which NATA district are you currently employed?
A. District I
B. District II
C. District III
D. District IV
E. District V
F. District VI
G. District VII

H. District VIII

I. District IX

J. District X

K. Other, please specify

2. Your NCAA division:
A. Division I
B. Division II
C. Division III

3. Your gender is:
A. Male
B. Female

4. Please type in your present age:

5. Please type in the number of years you have been a certified trainer:

6. What is your highest level of education?
A. Bachelor's Degree
B. Master's Degree
C. Doctorate/ $\mathrm{PhD}$

7. Is your institution:
A. Public
B. Private 
8. Your current job title:
A. Director of Sports medicine
F. Athletic Trainer (not
B. Head Athletic trainer certified)
C. Assistant Athletic Trainer
G. Student
D. Graduate Assistant
H. Other, please specify

E. Certified Athletic Trainer

9. For which sport(s) do you currently provide medical services? Please check all that apply.
A. Men's Football
B. Gymnastics
C. Volleyball
D. Soccer
E. Tennis
F. Lacrosse
G. Basketball
H. Track \& Field
I. Cross Country
J. Softball
$\mathrm{K}$. Baseball

L. Hockey Rowing/Crew

M. Swimming \& Diving

N. Wrestling

O. Women Field Hockey

P. Others, please specify

10. MRSA is a concern to athletes in colleges (please check all that apply):
A. Nationally
B. Locally
C. In my own setting
D. MRSA is not a concern

11. How do you manage Skin and Soft Tissue Infections (SSTIs) in your setting?
A. Require definitive diagnosis
B. Assume all lesions are MRSA
C. Do not know
D. Other, please specify

12. If a diagnosis is required, how do you diagnose an SSTI in your setting? Please check all that apply. 

A. Diagnosed in your own setting
B. Diagnosed by outside healthcare provider
C. Diagnosed by patients' own healthcare provider
D. Do not know
E. Other, please specify

13. Do you have a policy/standard of practice in place for treatment and prevention of SSTIs?
A. Yes
B. No
C. Do not know

If you answered "no" or "do not know", please skip question number 14 and proceed to question number 15 .

14. If you answered "yes" to question number 13, please specify which of the following elements are included in your policy or standard of practice for treatment and prevention of SSTIs. Please check all that apply:

A. Clean \& cover any open wounds

B. Do not allow participation if wound cannot be adequately covered

C. Culture athletes on a regular basis for carriage

D. Culture staff on a regular basis for carriage

E. Treat anyone with positive carriage

F. Use of disposable towels

G. Daily cleansing of all equipment

H. Daily cleansing of all athletic surfaces

I. Reminder email messages

J. Reminder letters

K. Annual or regular athlete/staff education sessions on risks and prevention

L. All wounds must be evaluated by trainer/doctor

M. Policy prohibiting sharing of personal items such as soap and razors

N. Culture all soft skin and tissue infections

O. Posters and signs on high traffic areas/ shower and restroom areas

P. Brochures

Q. Encourage frequent hand washing

R. Other, please specify 
15. Is your practice aware of the Centers for Disease Control and Preventions recommendations for the prevention of MRSA?
A. Yes
B. No
C. Do not know

16. Is your practice aware of the National Athletic Trainers' Association recommendations for the prevention of MRSA?
A. Yes
B. No
C. Do not know

17. Has your setting experienced any laboratory confirmed cases of MRSA?
A. Yes
B. No
C. Do not know

18. Has your practice attempted to quantify any increase in operating costs due to the implementation of prevention and treatment due to the emergence of SSTIs?
A. Yes
B. No
C. Do not know

If you answered "no" or "do not know", please skip question number 19 and proceed to question number 20 .

19. If you answered yes to question number 18 , what financial indications do you evaluate to determine costs associated with SSTIs? Please check all that apply:
A. Additional staff
B. Additional/new/refurbished equipment
C. Structural changes
D. Increased attention to environmental disinfection

20. In my setting, there are adequate financial and human resources to implement the recommendations to prevent SSTIs.
A. Yes
B. No
C. Do not know 
21. Of cases of SSTIs diagnosed in your setting in the last 5 years, in which of the following sports were the cases identified? Please check all that apply:
A. Men's football
B. Gymnastics
C. Volleyball
D. Soccer
E. Tennis
F. Lacrosse
G. Basketball
H. Track \& Field
I. Cross Country
J. Softball
K. Baseball
L. Hockey
M. Rowing/Crew
N. Swimming \& Diving
O. Do not know
P. Others, please specify

22. Of identified cases of SSTIs within the last five years, please approximate your best estimate of the percentage that occurred among male athletes:
A. 0 to $20 \%$
B. 20 to $40 \%$
C. 40 to $60 \%$
D. 60 to $80 \%$
E. 80 to $100 \%$

23. Of identified cases of SSTI within the last five years in your setting, please identify the top five sports in which they have occurred the most. Please rank them with number one as the sport experiencing the most SSTIs and number five the least.

1.

2.

3.

4.

5 . 
24. Approximate your best estimate of how many cases of SSTIs within the last five years required hospitalization?
A. Number of cases
B. Do not know

25. Has there been any incidence in your setting when SSTI was severe enough to impact team performance?
A. Yes
B. No
C. Do not know

26. Has your setting implemented changes in the way that SSTIs are prevented and treated since the emergence of MRSA?
A. Yes
B. No
C. Do not know

If you answered "no" or "do not know", please skip question number 27 and proceed to question number 28 .

27. If you answered yes to question number 26 , what kinds of changes have been implemented? Please check all that apply:
A. Clean \& cover any open wounds
B. Do not allow participation if wound cannot be adequately covered
C. Culture athletes on a regular basis for carriage
D. Culture staff on a regular basis for carriage
E. Treat anyone with positive carriage
F. Use of disposable towels
G. Daily cleansing of all equipment
H. Daily cleansing of all athletic surfaces
I. Reminder email messages
J. Reminder letters
K. Annual or regular athlete/staff education sessions on risks and prevention
L. All wounds must be evaluated by trainer/doctor
M. Policy prohibiting sharing of personal items such as soap and razors 
N. Culture all soft skin and tissue infections

O. Posters and signs on high traffic areas/ shower and restroom areas

P. Brochures

Q. Encourage frequent hand wash

R. Others, please specify

28. What would you identify as the most effective interventions for prevention of SSTIs? Please choose up to five, and rank in order with the most effective intervention numbered 1.

A. Clean \& cover any open wounds

B. Do not allow participation if wound cannot be adequately covered

C. Culture athletes on a regular basis for carriage

D. Culture staff on a regular basis for carriage

E. Treat anyone with positive carriage

F. Use of disposable towels

G. Daily cleansing of all equipment

H. Daily cleansing of all athletic surfaces

I. Reminder email messages

J. Reminder letters

K. Annual or regular athlete/staff education sessions on risks and prevention

L. All wounds must be evaluated by trainer/doctor

M. Policy prohibiting sharing of personal items such as soap and razors

N. Culture all soft skin and tissue infections

O. Posters and signs on high traffic areas/ shower and restroom areas

P. Brochures

Q. Encourage frequent hand washing

R. Other-

29. Have you noticed a difference in incidence of SSTI in your setting this year when compared to last year:

A. Yes, there has been an increase in the incidence of SSTIs this year compared to last year.

B. Yes, there has been a decrease in the incidence of SSTIs this year compared to last year.

C. The incidence of SSTIs has remained the same

D. Do not know 
30. Please share any experiences you have experienced with MRSA infection in the textbox provided. 


\title{
CURRICULUM VITAE
}

\author{
NAME: $\quad$ Alice Kimble \\ ADDRESS: $\quad 17600$ N HWY 259 \\ Stephensport, KY 40170 \\ DOB: $\quad$ Louisville, Kentucky - January 1, 1964 \\ EDUCATION \\ \& TRAINING: $\quad$ B.S., Nursing \\ University of Louisville \\ 1986-1990 \\ M.S., Exercise Physiology \\ 1994-1996 \\ AWARDS: $\quad$ Cura Personalis, Bellarmine University \\ 2010
}

